Universidad de Lima

Facultad de Comunicación

Carrera de Comunicación

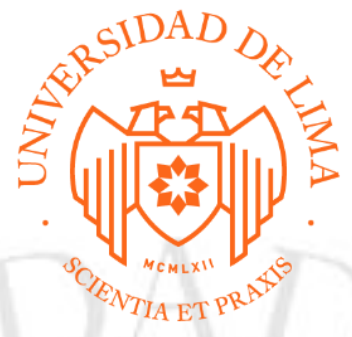

\title{
PROYECTO: CONDOMINIO VILLA DEL
}

\section{ATLETA}

Trabajo de Suficiencia Profesional para optar el Título Profesional de Licenciado en

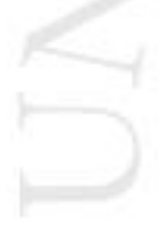

Comunicación

\section{Adriana Toro Lira Poggi}

Código 20091923

$$
\text { Lima - Perú }
$$

Setiembre de 2019 


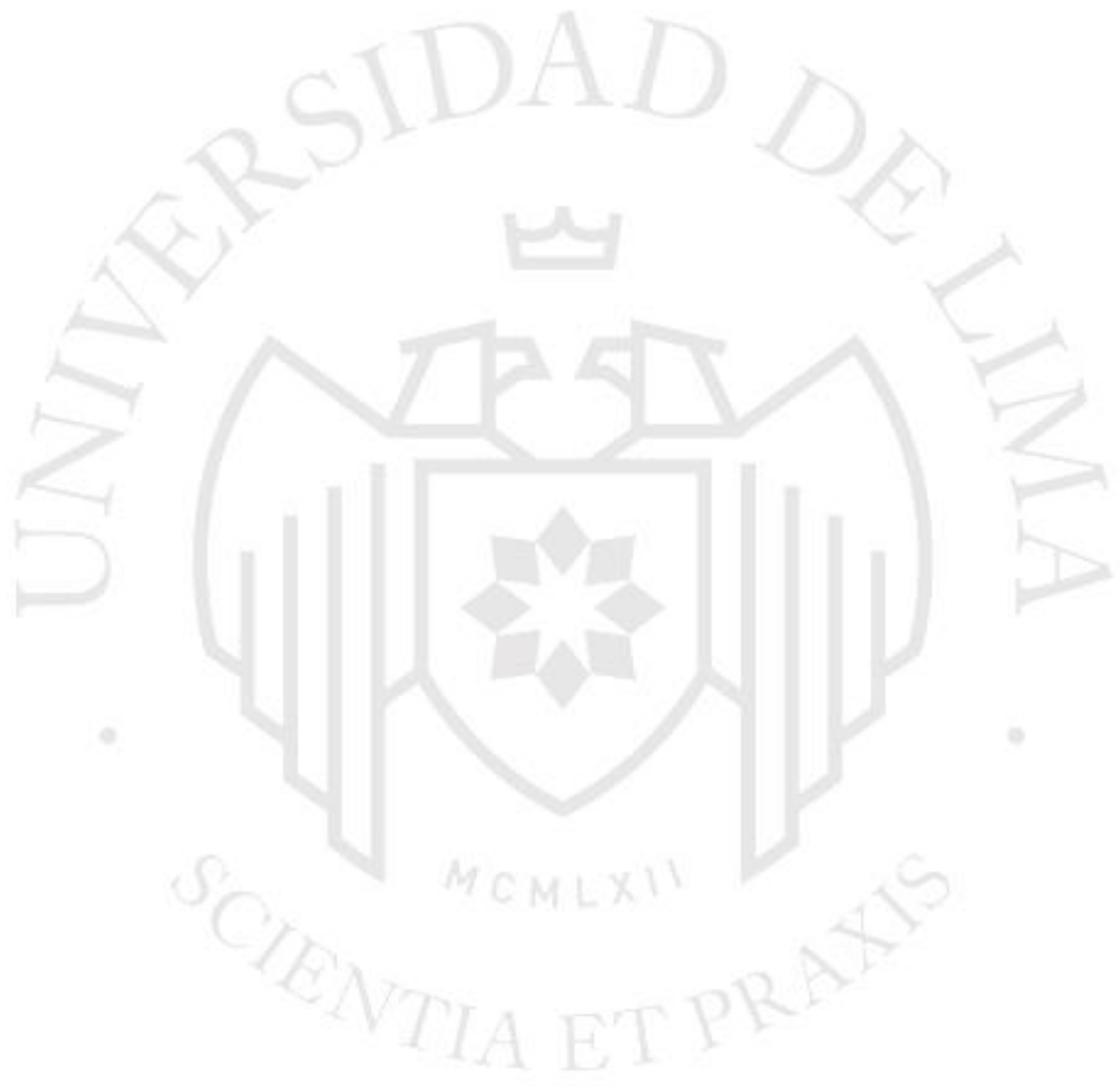




\section{CONDOMINIO "VILLA ATLETA"}




\section{ÍNDICE}

$\begin{array}{lr}\text { RESUMEN } & 8\end{array}$

INTRODUCCIÓN 9

1. CONTEXTO DEL PROYECTO 10

1.1 Descripción del Proyecto 10

1.2 Análisis Externo 12

1.2.1 Político 12

1.2.2 Económico

$\begin{array}{ll}1.2 .3 \text { Social } & 13\end{array}$

1.2.4 El deporte y Lima 2019

1.3 Análisis Interno 17

$\begin{array}{ll}\text { 1.3.1 Mercado } & 17\end{array}$

1.3.2 Análisis de la competencia $\quad 17$

$\begin{array}{ll}1.4 \text { Instituciones asociadas } & 20\end{array}$

\begin{tabular}{l|l}
1.5 Análisis situacional del proyecto & 21
\end{tabular}

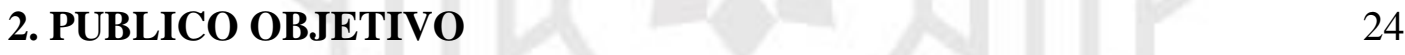

2.1 Perfil demográfico y familiar 26

2.2 Perfil económico y financiero 26

2.3 Comportamiento frente a la adquisición de vivienda 27

2.4 Consumo de medios 29

2.5 Hallazgos claves $\quad 33$

3. OBJETIVOS

3.1 Objetivos de Marketing $\quad 35$

$\begin{array}{ll}3.2 \text { Objetivos de Comunicación } & 35\end{array}$

4. VISIÓN DEL PROYECTO 36

4.1 Insights 36 
4.2 Valor diferencial - promesa

$\begin{array}{ll}4.3 \text { Reason why } & 37\end{array}$

$\begin{array}{ll}\text { 4.4 Posicionamiento deseado } & 37\end{array}$

5. PROPUESTA CREATIVA 38

5.1 Idea Estratégica 38

5.2 Concepto Creativo 38

5.3 Identidad Corporativa $\quad 39$

Nombre 40

Personalidad de la marca 41

$\begin{array}{lll}5.4 \text { Logo } & 41\end{array}$

Identidad Cromática - Paleta de colores 43

Tipografía 45

Aplicación de la Identidad $\quad 45$

6. PLAN DE COMUNICACIONES 49

6.1 Desarrollo de campaña $\quad 49$

6.2 Tono de comunicación $\quad 50$

6.3 ATL

6.3.1 Televisión $\quad 51$

6.3.2 Radio 54

6.3.3 $\mathrm{OOH} \quad 55$

\begin{tabular}{ll|l|l|l|l|} 
6.3.4 Prensa escrita & 57
\end{tabular}

6.4 Medios Digitales $\quad 59$

6.4.1 Redes Sociales $\quad 59$

$\begin{array}{ll}\text { Facebook } & 59\end{array}$

Instagram $\quad 60$

6.4.2 Página Web 61

6.4.3 Inversión en Plataformas inmobiliarias 62

6.4.4 Google Adds 63

6.5 BTL 64

6.6 Eventos 66

$\begin{array}{lll}6.7 & \text { Sponsor a deportistas } & 67\end{array}$ 
6.8 Relaciones Públicas

6.9 Presupuesto

7. CONCLUSIONES 71

8. RECOMENDACIONES

REFERENCIAS

ANEXOS

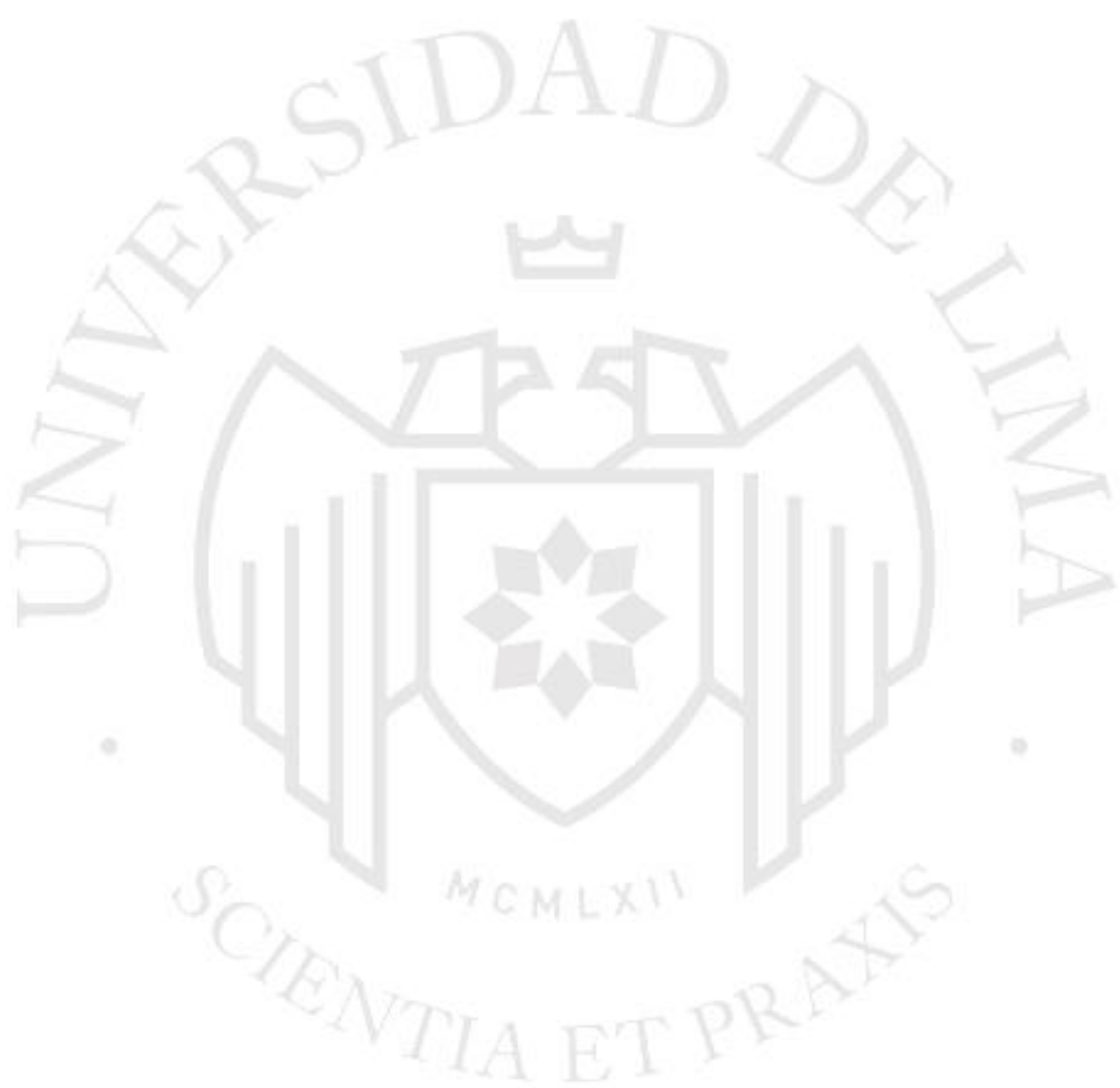


Todas las piezas de comunicación se encuentran en el siguiente enlace:

https://www.dropbox.com/sh/0bqy3ok7xis1qsu/AACJFzYj03orG $\underline{\text { bHluVNxFIUDa?dl }=0}$ 


\section{RESUMEN}

Se plantea el lanzamiento al mercado inmobiliario del condominio "Villa del Atleta", ubicado en Villa El Salvador,

Lima, Perú. Para ello, se dará a conocer sus principales características y se destacarán los atributos de éste complejo habitacional, así como las facilidades de financiamiento para futuros compradores.

La investigación realizada permite evidenciar hallazgos tanto del público objetivo y del rubro inmobiliario, que permiten realizar una propuesta comunicacional y mix de medios que apunte al éxito comercial de éste proyecto. 


\section{INTRODUCCIÓN}

Como gran aporte al óptimo desarrollo de los Juegos Panamericanos, Lima 2019 y el estado peruano construyen la Villa Panamericana para albergar a más de 7 mil deportistas de 41 países distintos, lo que converge una gran obra que mezcla tecnología, infraestructura, sostenibilidad, urbanismo, sentido de comunidad y un legado urbano que perdura en el tiempo.

Este complejo habitacional finaliza su función de residencia para estos deportistas y pasa a transformarse en un condominio de departamentos/hogares para más de mil familias que estén interesadas en una vivienda propia.

De acuerdo a ello y a los requerimientos que se solicitan para el desarrollo y ejecución de un próximo plan comercial para esta obra urbana, este trabajo propone una campaña de lanzamiento para el proyecto inmueble "Villa del Atleta". El mismo, se encuentra compuesto por la identidad corporativa planteada y el desarrollo de una campaña de comunicación integral y mix de medios.

De acuerdo a ello, se desarrolla y realiza un análisis exhaustivo del contexto en el que se encuentra éste proyecto, así como la investigación del público objetivo planteado (NSE C y D) donde se contempla un estudio de resultados demográficos, sociales, de hábitos de consumo, entre otros, sumado de entrevistas a profundidad/focus group de una muestra fidedigna del P.O y la investigación de las tendencias de marketing y publicidad, así como los productos comunicacionales más adecuados para el objetivo principal del proyecto, 


\section{CONTEXTO DEL PROYECTO}

\subsection{Descripción del Proyecto}

La "Villa del Atleta" como se menciona anteriormente, es un condominio multifamiliar de 44 hectáreas situado en el distrito de Villa el Salvador, zona sur de Lima Metropolitana. Este complejo está conformado por 7 torres y en cada una de ellas, entre 19 y 20 departamentos.

Cada piso, está conformado por 8 departamentos. Dando un total de 1096 departamentos individuales, de los cuales un tercio son de fácil acceso y diseñados para personas con discapacidades. Dentro del condominio se tendrán espacios de esparcimiento para las familias y sus miembros, compuesta por edificaciones de uso común y canchas multideportivas. Además, es importante mencionar que todo el condominio se encuentra cercado y delimitado para brindar privacidad y seguridad al mismo tiempo, lo que se compenetra con los grandes espacios de áreas verdes que posee para brindar equilibro entre el urbanismo y la naturaleza que necesitan las familias para desarrollarse.

Por otro lado, es importante destacar que la construcción y los sistemas que se utilizan para el correcto funcionamiento del condominio, es ecoamigable: contribuyen con el medio ambiente con diversos mecanismos para ahorrar consumo de servicios y reutilizar recursos. Esta gran acción ha permitido que el proyecto cumpla con la Certificación Bono verde, que se detallará líneas abajo.

\section{Financiamiento:}

Para la venta de éste proyecto, se facilita la adquisición de un inmueble al comprador final con el financiamiento a través del Nuevo Crédito Mivivienda.

Éste crédito hipotecario es un aporte del Estado Peruano que permite a cualquier persona natural mayor de edad que no sea propietario o copropietario de alguna vivienda a nivel nacional y que no tenga ningún crédito pendiente con el Fondo Mi Vivienda, que pueda comprar cualquier vivienda, ya sea un departamento, casa, terreno.

Posee bonos que benefician al cliente potencial: 
Bono buen pagador: El Bono del Buen Pagador es un subsidio directo no reembolsable que se otorga a los beneficiarios del Nuevo Crédito Mivivienda a través de las Instituciones Financieras Intermediarias (IFI). Este bono es un aporte que realiza el fondo a la cuota inicial para la adquisición de una vivienda de interés social.

Bono verde: El Bono Mivivienda Verde otorga un financiamiento entre 3\% y $4 \%$ del valor de la vivienda que cumpla con criterios de sostenibilidad en su construcción y reducir el impacto negativo ambiental. Estos criterios se distinguen por sistema de iluminación (LED), calentador de agua, griferías y sanitarios con sistema de bajo consumo, y medidores de agua independizados.

El bono verde da dos beneficios:

$4 \%$ de bono y beneficio final a los finalistas que consiste en una tasa de interés más accesible.

Dentro de ello, se identifican los mecanismos sostenibles que utiliza Villa Atleta que contribuyen con el medio ambiente y el logro de la obtención del certificado de Vivienda Verde:

- Reutilización de aguas grises para el riego de las áreas verdes sin necesidad de usar el de la red pública.

- Luminarias LED

- Griferías con controladores de flujos, por lo que el gasto en luz será el menor posible.

Como parte de las alternativas de financiamiento que presenta el proyecto, se encuentra la participación del Fondo Mi Vivienda con el Nuevo Credito MiVivienda, desde el cual los compradores interesados, pueden aplicar desde las siguientes entidades financieras que ofrece crédito y financiamiento al cliente:

\section{Bancos:}

BCP. Interbank, Continental, Scotiabank, Pichincha, Banco del Comercio, Banbif, Banco GNB. 


\section{Cajas Municipales:}

CMAC Sullana, CMAC Ica, CMAC Tacna, CMAC Maynas, CMAC Huancayo, CMAC

Cusco, CRAC Raíz ,Edpyme Mi Casita Hipotecaria, Financiera TFC,Financiera Efectiva

\subsection{Análisis Externo}

\subsubsection{Político}

Desde la creación del Fondo Mivivienda ${ }^{1}$ en el año 1998, el Estado ha venido implementando diversas acciones políticas con el objetivo de promover el acceso de la población de recursos medios y bajos a la propiedad de una vivienda a través de su adquisición, mejoramiento o construcción.

De esta manera, en la actualidad existen diversos programas adscritos al Fondo Mivivienda como el Nuevo Crédito Mivivienda, Techo Propio, y esquemas de subsidios como el Bono Mivivienda Verde ${ }^{2}$ y el Bono del Buen Pagador que promueven el acceso al financiamiento, mejoran las condiciones financieras para la adquisición de viviendas y finalmente permiten dinamizar el mercado inmobiliario.

Niño costero 2017 no querían juegos panamericanos.

\subsubsection{Económico}

Durante el 2018, el Perú creció 4\% anual explicado, principalmente, por el mayor crecimiento de la inversión privada y pública. Dentro de la inversión pública, destaca la ejecución de los Juegos Panamericanos y Parapanamericanos que implicó una inversión de alrededor S/ 4 mil doscientos millones e impulsó diversos sectores como construcción,

\footnotetext{
${ }^{1}$ El Fondo Mivivienda es empresa estatal de derecho privado, comprendido bajo el ámbito del Fondo Nacional de Financiamiento de la Actividad Empresarial del Estado - FONAFE y adscrito al Ministerio de Vivienda, Construcción y Saneamiento cuyo objetivo principal es el financiamiento de la adquisición, mejoramiento y construcción de viviendas de los sectores $\mathrm{C}$ y D.
} 
comercio (a través de las ventas minoristas) y servicios (alojamiento y restaurantes, transportes y telecomunicaciones).

Con respecto al mercado de inmobiliario, de acuerdo con BBVA Research y Scotiabank Research, en el 2018 se vendieron 15,238 viviendas nuevas en Lima (13\% más con respecto al 2017) y se espera que durante el 2019 se vendan entre 16,500 y 17,000 unidades impulsado por la mayor capacidad adquisitiva de la población $(+4.3 \%$ de empleo formal y $+4.7 \%$ de ingreso promedio en el 2018), el acceso al crédito hipotecario ( $+10 \%$ de crecimiento esperado para el 2019), costo de financiamiento atractivo (tendencia a la baja de tasas de interés) y la permanencia de programas estatales que incentivan la adquisición de viviendas como el Fondo Mivivienda.

Por su parte, el Fondo Mivivienda colocó 9,144 créditos durante el 2018 y, según el Marco Macroeconómico Multianual 2020-2023, se espera que durante el 2019 se coloquen 11,000 créditos (la mayor colocación de créditos desde el 2013), de los cuales 4,500 corresponden al Bono Mivivienda Verde. Según la Asociación de Empresas Inmobiliarias del Perú (ASEI), el 25\% de la venta de viviendas se realiza a través del Fondo Mivivienda.

\subsubsection{Social}

De acuerdo con el último censo realizado por el INEI en el año 2017, la población peruana ascendió a 31 millones habitantes, presentando un crecimiento de 11\% desde el 2007. Según el reporte de abril 2019 "Perú: Población 2019" elaborado por la Compañía Peruana de Estudios de Mercado y Opinión Pública, la población alcanzaría 32.5 millones de habitantes de los cuales el 79\% corresponde a población urbana.

Por su parte, Lima Metropolitana representa el 33\% del total de la población con 10.6 millones de habitantes. Dentro de ella, la zona Lima Sur (conformada por los distritos Chorrillos, Lurín, Pachacamac, San Juan de Miraflores, Villa el Salvador y Villa María del Triunfo) representa el 17\% de la población de Lima Metropolitana. 
En cuando a la estructura poblacional de Lima Metropolitana, destacan los siguientes aspectos:

- $\quad$ La población ascendería a 10,580.9 miles de habitantes y estaría compuesta por 2,720.8 hogares en el 2019.

- $\quad$ En la distribución de los niveles socioeconómicos sigue prevaleciendo el NSE C con el $42 \%$ del total, seguido por el NSE A/B con el $28 \%$, D con el $24 \%$ y E con el 6\%. Por su parte, en la zona Lima Sur, el NSE C y D toman mayor relevancia y representan cerca del $80 \%$ de la población (53\% NSE C y $27 \%$ NSE D).

- $\quad$ El rango de edad en el cual se concentra la mayor parte de la población es el rango entre 25 y 39 años (26\%), seguido del rango de edad entre 40 y 55 años $(20 \%)$.

- $\quad$ La distribución de la población por sexo está equilibrada, 50\% hombres, 50\% mujeres.

La población con alguna discapacidad ascendió a 1.6 millones en el año 2017 a nivel nacional según el reporte "Perú: Caracterización de las Condiciones de Vida de la Población con Discapacidad, 2017" preparado por el INEI. Dentro de las principales características de dicha población se encuentra:

- $\quad$ El $46 \%$ de la población tiene de 65 a más años de edad.

- $\quad$ El $83 \%$ de la población con discapacidad padece una enfermedad o malestar crónico.

- $\quad$ El $87 \%$ de la población vive en casas independientes y el $69 \%$ tiene una vivienda "propia totalmente pagada".

- $\quad$ El $45 \%$ de la población forma parte de la población económicamente activa.

- Con respecto al crecimiento demográfico observado a lo largo de los años (aproximadamente $1 \%$ de crecimiento por año), este ha venido acompañado, entre otras cosas, con un incremento en la demanda de viviendas urbanas. Según BBVA Research, actualmente la demanda de viviendas en el mercado limeño excede la oferta; la cual se viene adaptando gradualmente a las características de la demanda (por ejemplo, departamentos de menor tamaño, menos dormitorios). Para los próximos años, esperan que la demanda de 
nuevos departamentos se soporte en la clase media (sectores socioeconómicos B y C).

Gráfico 1: Lima Metropolitana 2019: Población según nivel socioeconómico

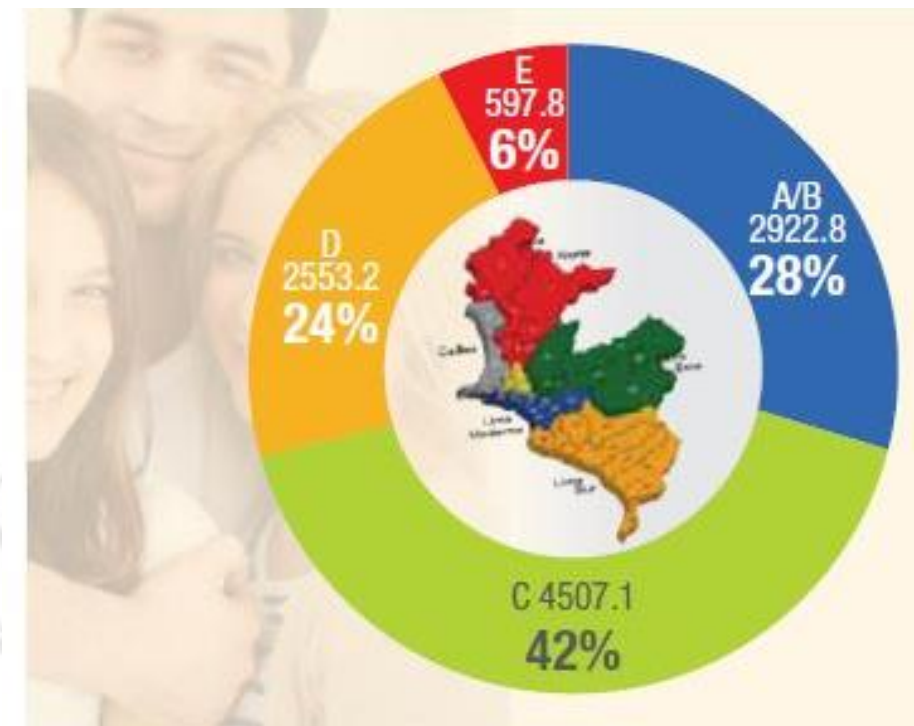

FUENTE: APEIM - Estructura socloeconomica 2018

ELABORACION DEPARTAMENTO DE ESTADISTICA - C.P.I

\subsubsection{El deporte y Lima 2019}

En el marco de la investigación contextual para el desarrollo del proyecto, se posiciona el análisis de los Juegos Panamericanos y Parapanamericanos Lima $2019^{3}$ como un elemento fundamental para comprender el valor y la importancia del proyecto inmobiliario que se desarrollará más adelante en este trabajo.

Como es de nuestro conocimiento, en el presente año se desarrolló uno de los eventos deportivos más grandes a nivel mundial en nuestra capital: Lima 2019. Lo que gratamente a dado que hablar no solo a nivel continental, sino llegando a la opinión publica de grandes países y potencias mundiales.

Los trabajos se iniciaron con el apoyo y el expertiz de Reino Unido (primer gran gasto realizado por el convenio suscrito éste país valorizado en 210 millones de soles aproximadamente)

\footnotetext{
${ }^{3}$ En adelante se mencionará como "Lima2019"
} 
Aunque inicialmente el desarrollo y preparación de estos juegos en nuestro país no fue del agrado de cierta parte de los líderes de opinión de nuestra bancada política (congresistas y Castañeda) debido a la fuerte repercusión negativa que tuvo nuestro país debido al fenómeno del niño del 2017 y los rezagos que deja en infraestructura, vivienda, economía e incluso de perdidas mortales.

Pese a dicho panorama alarmista y de rechazo, se decidió seguir adelante con la planificación y la evidencia de los primeros avances para lo que sería el inicio de un hito deportivo de gran importancia para el Perú.

Frente a ello, es notable el importante legado que tanto el desarrollo Lima2019, como la participación de deportistas peruanos que dejaron en alto el nombre de nuestro país y a su vez, la actitud de la población frente a la visita de más de 10000 personas de diversas culturas y lugares del mundo, que se ha dejado para futuras generaciones que tenemos claro, que van a seguir ampliando la visión del deporte como una herramienta de desarrollo personal, social y cultural.

Los que conocemos el deporte desde adentro, podemos confirmar cómo éste transforma sociedades y crea oportunidades de vida a quienes lo practican, la industria del deporte ha crecido significativamente en los últimos años, y es así que ciudades enteras como Barcelona se han transformado en ciudades deportivas, saludables y seguras, gracias a la organización de juegos. Está claro que la gente que practica deporte siente mayor bienestar, trabaja a gusto y produce más (Sierralta, 2018) 


\subsection{Análisis Interno}

\subsubsection{Mercado}

\section{Mercado inmobiliario}

Dentro del análisis del mismo mercado inmobiliario, según análisis realizados por entidades financieras y asociaciones inmobiliarias, se proyecta un crecimiento en éste sector comercial.

Según la investigación de BBVA Research en el año 2018, se estimó que las ventas seguirían creciendo este año y que alcanzarán entre 16,5 mil y 17 mil unidades en el año. Fundamentando este resultado por la capacidad adquisitiva de la población y el aumento del empleo formal. Con ello, las tasas de interés se mantendrán en niveles atractivos al mercado y también, bonos adicionales (como el Bono Verde) también continuarán creciendo para apoyar el financiamiento de departamentos con las características que cumplen dichos lineamientos del bono.

En base a ello y al despertar de nuevos potenciales clientes por mejoras económicas, el desarrollo de mecanismos alienados a las nuevas tecnologías permite que el usuario se logre informar de modo interactivo con información de gran relevancia para la toma de decisión que, probablemente, sea una de las más importantes para un potencial cliente inmobiliario.

\subsubsection{Análisis de la competencia}

\section{Directa}

Para este análisis, se realizó una observación participante y la estrategia de "Mistery shopper" en la Feria "Nexo Inmobiliaria", además de una entrevista a profundidad realizada al Director de Marketing de Paz Centenario.

\footnotetext{
${ }^{4}$ Concepto conocido para desarrollar el papel de "cliente oculto" que investiga a la competencia.
} 
Para concretizar el análisis, se consideraron variables directas para identificar a los competidores del proyecto, como la venta de departamentos en zonas cercanas al proyecto (en este caso Lima Sur), la venta de proyectos residenciales con características similares apuntando a un público objetivo similar al del proyecto ${ }^{5}$ y de carácter más importante, la venta de departamentos con precios similares obtenidos por el precio por $\mathrm{m} 2$.

De acuerdo a ello, se lograron identificar determinados proyectos de condominios o de complejos con carácter residencial que pueden ser evaluados como competencia hablando sobre las líneas de posicionamiento de los proyectos inmobiliarios en la mente de nuestro público objetivo. Con ello, se incluyen características similares:

- Financiamiento a través del Bono Mivivienda

- Situados en el rubro de vivienda social

- Complejos multifamiliares de 600 departamentos a más

- Ubicados en los conos de Lima Metropolitana

- Orientado al público con niveles socioeconómicos C y D

De acuerdo a la información que brinda el reporte de la Asociación de Desarrolladores Inmobiliarios del Perú (ADIPerú) la venta de departamentos en la zona sur de Lima Metropolitana se encuentra en un rango de 2,600 soles por m2. Como podemos ver en el siguiente gráfico, en precios similares a éste se encuentra el precio por $\mathrm{m} 2$ del distrito de Puente Piedra y San Martin de Porres con precios más elevados.

\footnotetext{
${ }^{5}$ Se desarrollará el análisis del Público Objetivo en capítulos posteriores del trabajo.
} 


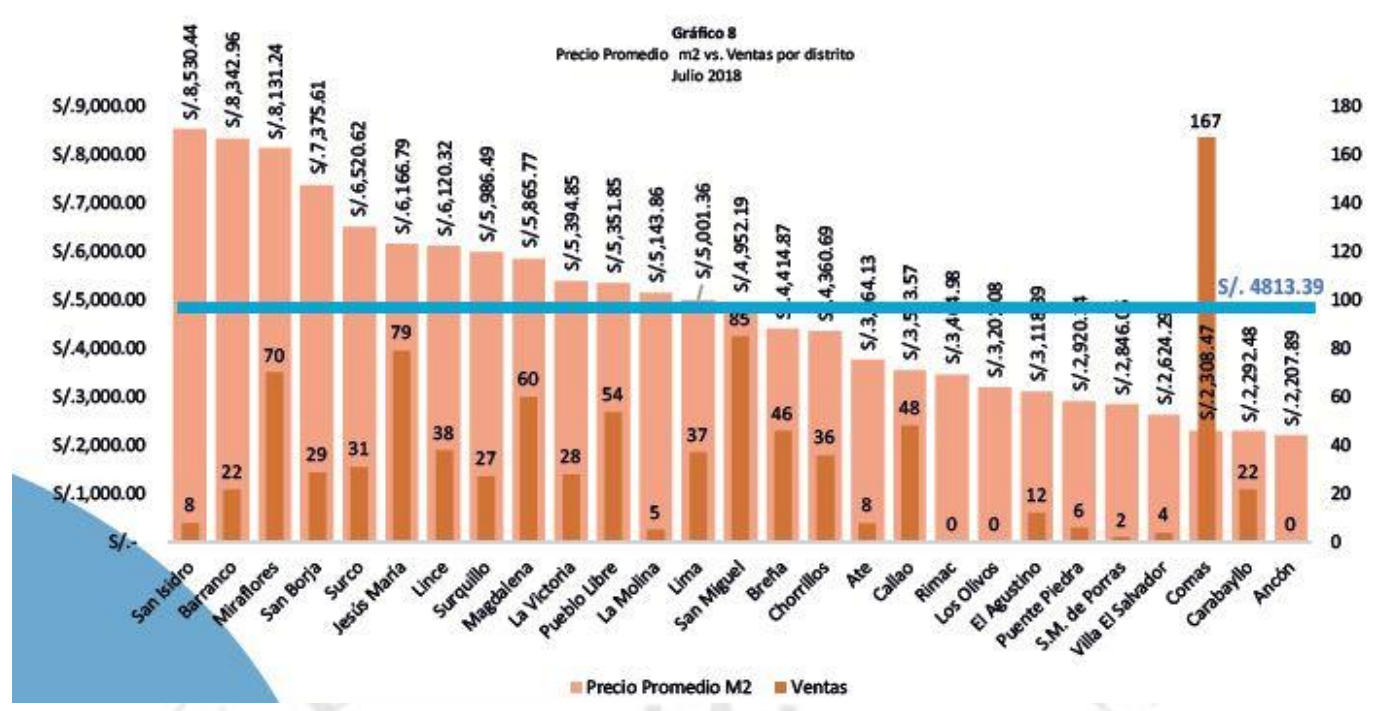

Fuente: ADIPERÚ - 2018

Por otro lado ubicados en menor rango de precio, se encuentran Comas y Carabayllo con diferencias respectivamente.

De acuerdo a la similitud de precios por metro cuadrado, se identifican determinados proyectos propuestos y ofertados de manera online a través de las páginas de las empresas inmobiliarias.

Es importante mencionar que, a diferencia del proyecto a desarrollar en este trabajo, los que a continuación se mencionarán a continuación, no se encuentran $100 \%$ finalizados:

- Los Parques del Callao - Viva Graña y Montero - Callao

- Alborada Club - Viva Graña y Montero - Comas

- Villa Jacarandá - Viva Graña y Montero - Comas

- Proyecto Girasoles - Viva Graña y Montero - Comas

- Ciudad Verde - Paz Centenario - Puente Piedra

- Altaluz Condominio Eco Amigable - Besco - Callao 


\section{Indirecta}

Dentro de lo que se considerará como competencia indirecta, ubicamos al alquiler de inmuebles como una opción alternativa para el potencial cliente que también haya pensado en la posibilidad de ser dueño de una vivienda propia. La aguja del reloj se mueve entre una posibilidad $\mathrm{u}$ otra principalmente por temas económicos iniciales en el proceso de adquisición (ya sea alquiler o venta) ya que existe una gran diferencia entre una cuota inicial y adelantos de garantía que suelen pedir la mayoría de propietarios que alquilan sus inmuebles. Es por ello, que se concluye que dentro de los bullets de comunicación más importantes dentro del plan de marketing, se debe destacar el financiamiento de pago, sus características y las facilidades prontas a través de entidades financieras.

Por otro lado, se considera también la venta de lotes o terrenos urbanizados y respaldados por empresas inmobiliarias y/o entidades financieras para encasillar a éste tipo de competencia junto al proyecto a desarrollar, como oferta formal en el sector inmobiliario. Como competencia indirecta también se encuentra la empresa Los Portales y Besco.

\subsection{Instituciones asociadas}

Como instituciones asociadas identificamos a las entidades financieras autorizadas para el Nuevo Credito Mivivienda a la fecha. Dentro de las cuales se podrá acceder al financiamiento para el proyecto inmobiliario a desarrollar.

Según los resultados de colocaciones de créditos Mivivienda a nivel nacional a agosto de 2019 publicados por el Fondo Mivivienda, 6 Instituciones Financieras explican cerca del $80 \%$ de las colocaciones, liderado por el Banco de Crédito de Perú (31\%) y seguido por Financiera TFC (13\%), Interbank (12\%), Banco Pichincha (9\%), Edpyme MiCasita $(8 \%)$ y BANBIF $(8 \%)$. 
1.5 Análisis situacional del proyecto

Accesibilidad y territorio

El complejo habitacional se sitúa en un distrito de carácter emergente, una zona árida que aún es encabezada por problemas de acumulación de residuos e inseguridad ciudadana (se evidencia en los siguientes gráficos hallados para la investigación)

Gráfico 3: Puntos críticos de residuos sólidos en Lima Metropolitana, 2017

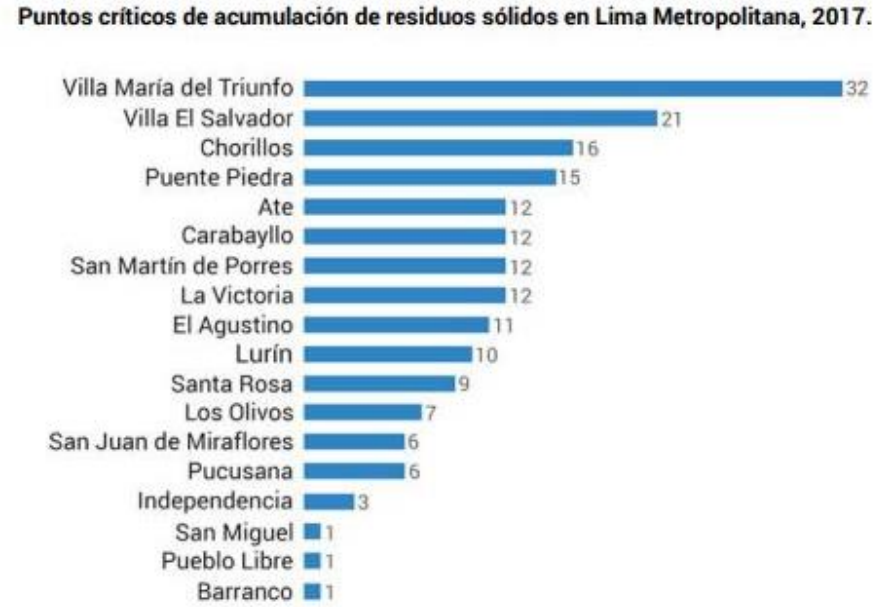

Gráfico 4: Victimización por tipo de delito en Lima Metropolitana y Callao, 2017

Victimización por tipo de delito

En base a la Encuesta Especial sobre Victimización, la mayor cantidad de delitos ocurridos a personas mayores de 15 años en el 2017, tanto en Lima como en Callao, son los robos comunes, que alcanzaron el $14.3 \%$ en Lima y $9.1 \%$ en Callao. A estos le siguen los hurtos y la tentativa de robo.

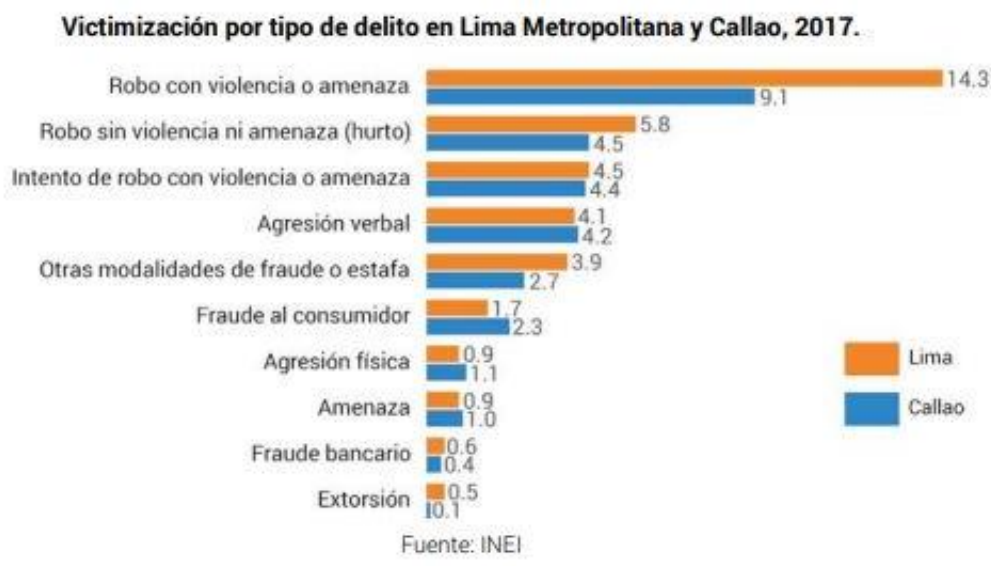


Como se puede apreciar en el último grafico expuesto, los robos y/o intenciones de robo son una actividad de violencia y agresión frecuente según la opinión pública en el año 2017. Donde además, la zona Sur de Lima Metropolitana es destacada como la zona más afectada.

Esto en efecto, es una característica negativa que no permite posicional al distrito del condominio como "un lugar seguro para vivir". Sin embargo, centrándonos en el producto del condominio como tal, al ser una residencia multifamiliar administrada, el sistema de vigilancia realizará su labor de manera constante, lo que se vuelve un bullet de comunicación de gran importancia para destacas como característica del producto.

En cuanto a la accesibilidad del Condominio, identificamos en primer plano la accesibilidad territorial: Panamericana Sur se encuentra muy cerca de la zona urbana del proyecto, así como las conexiones del Metro de Lima ubicados en a pocas cuadras del condominio. La ubicación destaca la pronta identificación del punto de interés entre la intersección de avenidas principales: Avenida el Sol que inicia en la auxiliar de la panamericana sur y culmina en y Av. Mariano Pastor de Sevilla más conocida como Avenida " $C$ " y el conocimiento de la dirección residencial debido al uso previo que se le dio al Condominio Villa Atleta.

Por otro lado, el acceso a la zona del condominio a través de medios de transporte público también es beneficioso para los vecinos, estudiantes, trabajadores y todo quien se movilice por este distrito, tienen las rutas del Metro de Lima a pocas cuadras y paraderos de buses en la esquina del complejo.

Ésta, es otra característica que notablemente interesará al público objetivo, debido a que la mayoría de la población Limeña (más de 9 millones) se moviliza en transporte público. Punto importante también para analizar las ubicaciones estratégicas de medios tradicionales de publicidad, los cuales se desarrollarán en capítulos posteriores. 


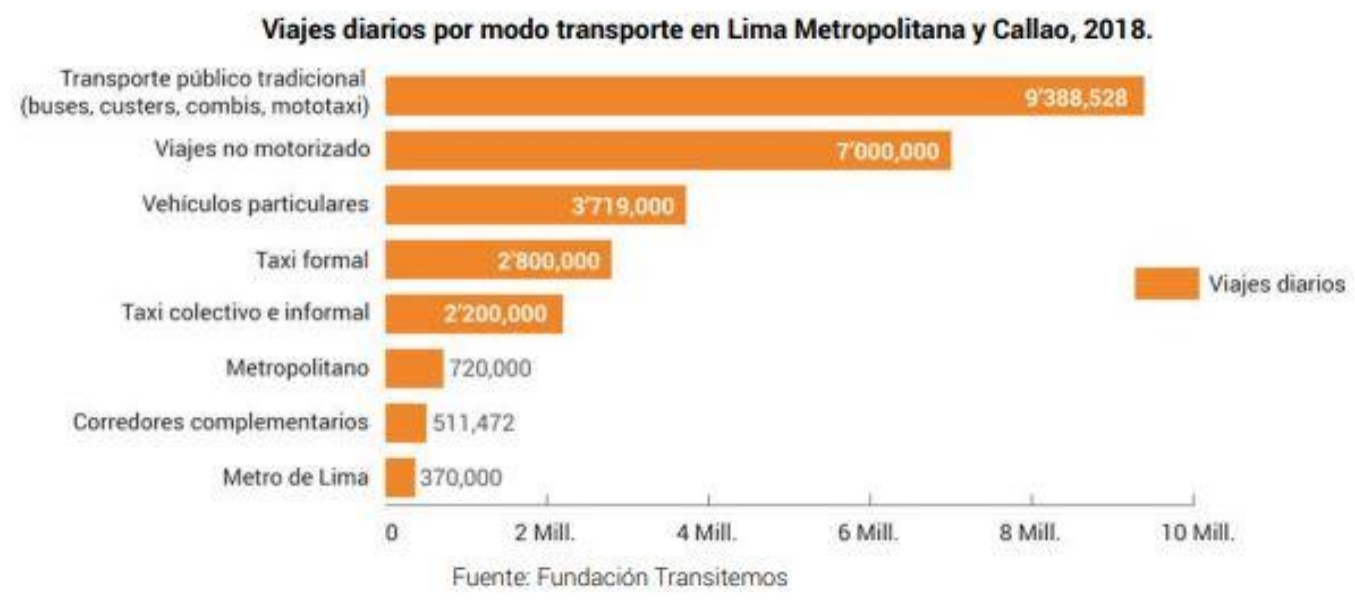

Por otro lado y un punto importante a desarrollar, es el tema de la accesibilidad en la infraestructura del condominio. Como se sabe, alrededor de $1 / 3$ del total de departamentos que se ofrecen, están orientados y destinados para personas con alguna discapacidad física o visual. Lo que vuelve al condominio un gran complejo accesible y a la vez inclusivo para un porcentaje de la población que tal vez es minoría, pero que aún existe un gran déficit de atenciones y servicios para éste público, lo que indirectamente también afecta a sus familias nucleares.

Según la Norma a.120 Accesibilidad para personas con discapacidad y de las personas adultas mayores se establecen reglas y parámetros para temas de construcción y vivienda en beneficio a la inclusión de ésta población. Como por ejemplo, señalización, diseño de rampas, anchos de veredas, puertas y entradas, entre otros.

Lamentablemente no todos los proyectos de construcción consideran el diseño y las necesidades básicas de acceso y libertad de movimiento para la población con discapacidad física y/o visual. Es una necesidad grande que se integra a la realidad de nuestra sociedad, y que en el caso puntual del proyecto Villa Atleta, ofrece un público objetivo puntual pero que a su vez, no solo desea sino necesita una de las principales características que la infraestructura alineada a estándares y parámetros internacionales ha hecho que Villa Atleta Reduzca las barreras de acceso de las personas con discapacidad a bienes y servicios. 


\section{PUBLICO OBJETIVO}

El público objetivo definido para la adquisición de los departamentos del condominio Villa Atleta está conformado por jóvenes y adultos desde los 25 años de edad en adelante, de los Niveles Socioeconómicos C y D.

De acuerdo al análisis e investigación que se realiza a partir de ésta segmentación, se identifica que el target abarca parejas jóvenes sin hijos, familias completas, parejas mayores cuyos hijos ya no viven con ellos, familias con miembros que tengan alguna discapacidad física o visual, jóvenes y adultos que se encuentren en una próspera situación económica y desean invertir en inmuebles. Éste último punto se destaca para iniciar la delimitación más específica del P.O: la intención de compra.

Tomando como punto de partida éste eje, se realiza un análisis exhaustivo de dicho público para identificar y comprender su demografía, comportamiento, intereses, personalidades, situación económica, ubicación territorial, inclusive el conocimiento e impresión que tienen frente al proyecto residencial ya existente el cual busca motivar a la compra de los inmuebles.

Para ello, se presenta a continuación un análisis regido por los niveles socioeconómicos, edades, y a su vez, una identificación geográfica que es clave para delimitar a nuestro foco y donde se centrará el plan de comunicaciones y mix de medios.

En base a esto, se avanzará de rasgos más generales a un análisis más profundo que permitirá comprender las acciones de marketing que se plantean para lograr los objetivos del proyecto. 
En primer lugar, para comprender la magnitud de la población en el siguiente grafico se aprecian los porcentajes de hogares por nivel socioeconómico, destacando el NSE C por tener el mayor porcentaje, seguido del NSE D, lo que evidencia que la mayoría de la población limeña se concentra dentro de nuestro P.O

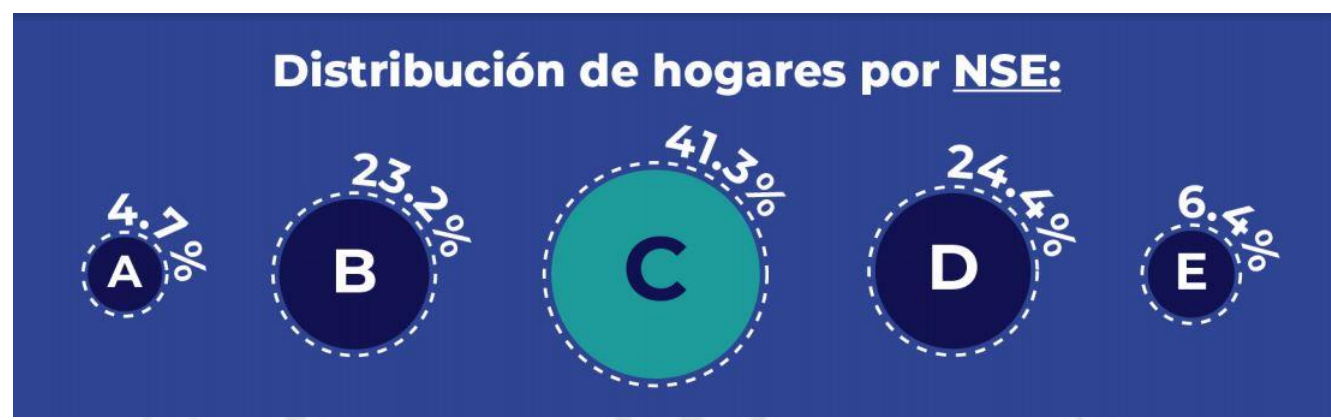

Fuente: Ipsos, 2018.

Dentro de la distribución general de hogares por NSE, podemos comprender también, la distribución geográfica de estos niveles, según las divisiones zonales de Lima Metropolitana.

Gráfico 6: Lima Metropolitana 2019: Estructura socioeconómica de la población por zonas geográficas

\begin{tabular}{|c|c|c|c|c|c|c|c|}
\hline \multirow[b]{2}{*}{ Zonas } & \multirow[b]{2}{*}{ Distritos } & \multicolumn{2}{|c|}{ Población } & \multicolumn{4}{|c|}{ Estructura socioeconómica (\% horizontal) } \\
\hline & & Miles & $\begin{array}{c}\% \text { sobre } \\
\text { total }\end{array}$ & $A B$ & c & D & E \\
\hline LIMA NORTE & $\begin{array}{l}\text { Carabayllo, Comas, Independencia, Los Olivos, Puente } \\
\text { Piedra, San Martin de Porres }\end{array}$ & $2,627.6$ & 24.8 & 22.9 & 44.1 & 27.6 & 5.4 \\
\hline LIMA CENTRO & Breña, La Victoria, Lima, Rimac, San Luis & 828.4 & 7.8 & 33.1 & 43.3 & 20.2 & 3.5 \\
\hline LIMA MODERNA & $\begin{array}{l}\text { Barranco, Jesús María, La Molina, Lince, Magdalena } \\
\text { del Mar, Miraflores, Pueblo Libre, San Borja, San } \\
\text { Isidro, San Miguel, Santiago de Surco, Surquillo }\end{array}$ & $1,416.0$ & 13.4 & 76.8 & 17.4 & 4.5 & 1.3 \\
\hline LIMA ESTE & $\begin{array}{l}\text { Ate, Chaclacayo, Cieneguilla, El Agustino, Lurigancho, } \\
\text { San Juan de Lurigancho, Santa Anita }\end{array}$ & $2,616.4$ & 24.7 & 17.7 & 45.7 & 29.6 & 7.0 \\
\hline LIMA SUR & $\begin{array}{l}\text { Chorrillos, Lurin, Pachacamac, San Juan de Miraflores, } \\
\text { Villa el Salvador, Villa María del Triunfo }\end{array}$ & $1,839.8$ & 17.4 & 13.3 & 53.4 & 27.4 & 5.9 \\
\hline CALLAO & $\begin{array}{l}\text { Bellavista, Callao, Carmen de la Legua Reynoso, La } \\
\text { Perla, La Punta, Mi Perú, Ventanilla }\end{array}$ & $1,100.4$ & 10.4 & 21.7 & 45.9 & 23.6 & 8.8 \\
\hline BALNEARIOS & $\begin{array}{l}\text { Ancón, Pucusana, Punta Hermosa, Punta Negra, San } \\
\text { Bartolo, Santa María del Mar, Santa Rosa }\end{array}$ & 152.4 & 1.4 & 9.7 & 39.9 & 37.7 & 12.7 \\
\hline \multicolumn{2}{|c|}{ TOTAL LIMA METROPOLITANA } & $10,580.9$ & 100.0 & 27.7 & 42.6 & 24.1 & 5.6 \\
\hline
\end{tabular}

FUENTE: APEIM - Estructura socioeconomica 2018

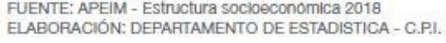

En ella, podemos notar que la mayor concentración de la población C se ubica en Lima Sur, mientras que la población D se encuentra en Balnearios, seguido de Lima Este y Lima Sur respectivamente. 


\subsection{Perfil demográfico y familiar}

Dentro del público objetivo delimitado por NSE inicialmente, podemos identificar que la mayoría de la población de Lima se ubica justamente entre los niveles socioeconómicos C y D (42\% y 24\%), información obtenida de Ipsos, 2019.

Desde este punto, se puede concretar que es una gran masa de población la que inicialmente se segmenta para el objetivo principal del proyecto; lo cual, alineado a los objetivos de comunicación y el mix de medios, demanda focalizar aún más la segmentación para ser más efectivo con lo que se quiere comunicar y dentro de la estructura, vender.

\subsection{Perfil económico y financiero}

De acuerdo a la información obtenida desde el informe de Ipsos 2017, el ingreso mensual del nivel socioeconómico $\mathrm{C}$ es de aproximadamente 1,238 soles, mientras que el ingreso del nivel D es de 807 soles. Concluyendo con éstos datos, es importante mencionar que se evidencia una gran brecha salarial entre los niveles socieconómicos que encabezan la jerarquía.

Por otro lado, y según la Investigación realizada por "Lima Cómo Vamos" en el año 2018, la mayoría del NSE C considera que su situación económica mejoraría para este año 2019 (58.2\%). De forma contraria, sucede con el NSE D, agrupado en ésta oportunidad con el público siendo una minoría pero de todas formas un porcentaje considerable. 


\begin{tabular}{|c|c|c|c|c|c|c|c|c|}
\hline & \multicolumn{4}{|c|}{ Lima } & \multicolumn{4}{|c|}{ Callao } \\
\hline & 2018 & $\mathrm{~A} / \mathrm{B}$ & C & D/E & 2018 & $\mathrm{~A} / \mathrm{B}$ & C & $\mathrm{D} / \mathrm{E}$ \\
\hline Mejorará mucho/Mejorará algo & $54.9 \%$ & $60.8 \%$ & $53.5 \%$ & $46.5 \%$ & $57.0 \%$ & $60.0 \%$ & $58.2 \%$ & $48.8 \%$ \\
\hline Permanecerá igual & $34.7 \%$ & $33.5 \%$ & $33.9 \%$ & $38.1 \%$ & $34.8 \%$ & $34.8 \%$ & $33.3 \%$ & $37.5 \%$ \\
\hline $\begin{array}{l}\text { Empeorará algo/Empeorará } \\
\text { mucho }\end{array}$ & $5.7 \%$ & $2.8 \%$ & $7.2 \%$ & $8.6 \%$ & $3.8 \%$ & $1.9 \%$ & $3.6 \%$ & $7.5 \%$ \\
\hline
\end{tabular}

Base: Total de entrevistados

Respecto al ahorro, el 63\% del NSE C destaca ésta práctica económica; sin embargo, sólo el $27 \%$ se encuentra bancarizado. (Ipsos, 2017)

Esto permite concluir que al existir una gran diferencia entre los porcentajes anteriormente mencionados, la población perteneciente al nivel $\mathrm{C}$, no tiene aún vínculos con entidades financieras, por lo que aún no inician su historial crediticio.

En el caso del NSE D, es un porcentaje menor el que decide ahorrar y lastimosamente, un 35\% tiene alguna deuda por pagar. Respecto al tema de bancarización, al igual que la población perteneciente al nivel C, es un porcentaje menor el que se encuentra vinculado a algún banco, caja o financiera.

Esto, podría ser uno te los tendones de Aquiles para lograr asegurar la venta de un departamento: la aplicación a los créditos y facilidades de pago para el público objetivo.

Podemos concluir que la mayoría de nuestro público objetivo, no establece vínculos fuertes o directos con el sistema bancario.

\subsection{Comportamiento frente a la adquisición de vivienda propia}

Como se ve en el siguiente cuadro, identificamos una estadística de gran relevancia para centrar el foco del P.O establecido para la venta del condominio ubicado en Villa el Salvador. 
Según los resultados arrojados al estudio realizado por Lima Como Vamos 2018; dentro de Lima Metropolitana, la mayoría de la población C y D se mantendría en el mismo distrito en el que actualmente reside si tuviese la oportunidad de mudarse.

Esto, añadido a los fuertes insights hallados en el Focus Group realizado a 7 vecinos de Villa El Salvador ${ }^{6}$, evidencia el gran apego de las familias hacia el distrito donde viven hoy por hoy. Junto a ello, los vínculos familiares y amicales según los barrios y vecindarios, fortalecen la fuerte postura de no cambiar de distrito. Una característica de gran valor para poder confirmar que el foco del P.O debe situarse por la geografía.

Gráfico 7: Intención de mudanza a otro distrito de residencia, Lima Metropolitana y Callao 2018

\begin{tabular}{|c|c|c|c|c|c|c|c|c|}
\hline & \multicolumn{4}{|c|}{ Lima } & \multicolumn{4}{|c|}{ Callao } \\
\hline & 2018 & $\mathrm{~A} / \mathrm{B}$ & C & $\mathrm{D} / \mathrm{E}$ & 2018 & A/B & C & $\mathrm{D} / \mathrm{E}$ \\
\hline $\begin{array}{l}\text { Me quedaria en el } \\
\text { mismo distrito. }\end{array}$ & $65.2 \%$ & $66.1 \%$ & $62.1 \%$ & $68.0 \%$ & $56.3 \%$ & $61.3 \%$ & $53.9 \%$ & $51.3 \%$ \\
\hline $\begin{array}{l}\text { Me mudaría a un distrito } \\
\text { de Lima o Callao. }\end{array}$ & $29.5 \%$ & $30.9 \%$ & $32.0 \%$ & $23.4 \%$ & $38.3 \%$ & $35.5 \%$ & $38.8 \%$ & $42.5 \%$ \\
\hline $\begin{array}{l}\text { Me mudaria a un distrito } \\
\text { fuera de Lima o Callao } \\
\text { (provincia o extranjero). }\end{array}$ & $5.3 \%$ & $3.0 \%$ & $5.9 \%$ & $8.6 \%$ & $5.5 \%$ & $3.2 \%$ & $7.3 \%$ & $6.3 \%$ \\
\hline Base: Total de entrevistados & & & & & & IACO & VAMOS & OP-PU \\
\hline
\end{tabular}

En conclusión a esto, el público objetivo delimitado con una intención de compra de inmueble, va a comenzar su búsqueda por las zonas aledañas y cercanas a donde ya reside.

Respecto a lo que se ha ido mencionando en líneas y capítulos anteriores, las facilidades de pago y financiamiento para los créditos subsidiados por el Estado, están en oferta para los clientes potenciales y según datos estadísticos obtenidos por el Fondo Mivivienda "Estudio de Demanda de Viviendas a Nivel de las Principales Ciudades - Hogares no Propietarios" de Lima Sur, el nivel de conocimiento del Sistema de Crédito Hipotecario

\footnotetext{
${ }^{6}$ En anexos se detalla información de los participantes
} 
en la población de los sectores socioeconómicos C y D es de alrededor $15 \%{ }^{7}$ y $13 \%{ }^{8}$, respectivamente; mientras que el conocimiento sobre el Fondo Mivivienda es de $49 \%$ y $43 \%$ y el producto de mayor recordación es el Nuevo Crédito Mivivienda ( $88 \%$ y 87\%). Información que evidencia que la información y una fácil lectura de ella, es una tarea que debe ser complementada y reforzada por el complejo residencial que desea vender sus inmuebles; en este caso, una labor que en definitiva Villa Atleta deberá realizar.

Con respecto al conocimiento sobre las Instituciones Financieras que otorgan créditos hipotecarios, el $63 \%$ y $71 \%$ de los sectores socioeconómicos C y D afirman que sí tienen conocimiento. Dentro de las Instituciones Financieras con mayor recordación en el público objetivo se encuentran los bancos $(91 \%, 94 \%$ de los sectores socioeconómicos C y $\mathrm{D}$, respectivamente), financieras $(21 \%, 22 \%)$ y cajas municipales $(23 \%, 26 \%)$.

2.4 Consumo de medios y tecnología

\section{Consumo de tecnología}

En el siguiente gráfico podemos identificar que en el presente año, el mayor porcentaje de internautas peruanos se encuentra en el NSE C, seguido del NSE D. Ambos, formando parte del público objetivo y presentando crecimiento respecto al año anterior.

\section{¿Cómo es el internauta peruano?}
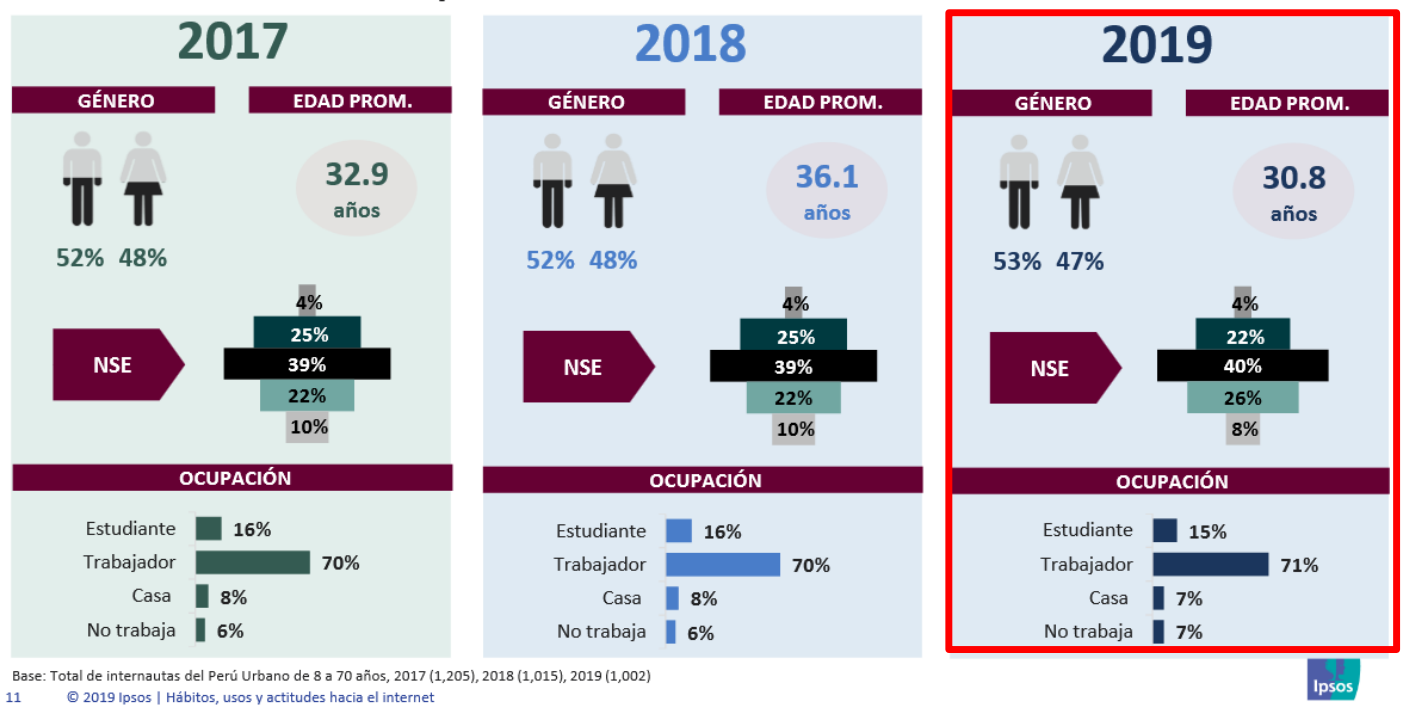

Fuente: Ipsos, 2019.

\footnotetext{
${ }^{7}$ Afirma que reconoce mucho o bastante

${ }^{8}$ Afirma que reconoce mucho o bastante
} 
Por otro lado, respecto a la tenencia de dispositivos tecnológicos en el hogar según nivel socioeconómico de la población, notamos que los NSE pertenecientes a nuestro P.O, poseen en su mayoría un TV o Smart TV (91\% y 89\%); encontrando ya ciertas diferencias en otros dispositivos como Smartphone, PC o Internet móvil o en hogar, donde dentro del NSE C sigue siendo la mayoría de la población, quien posee lo anteriormente mencionado; el NSE D baja en porcentajes de tenencia pero aun siendo considerables.

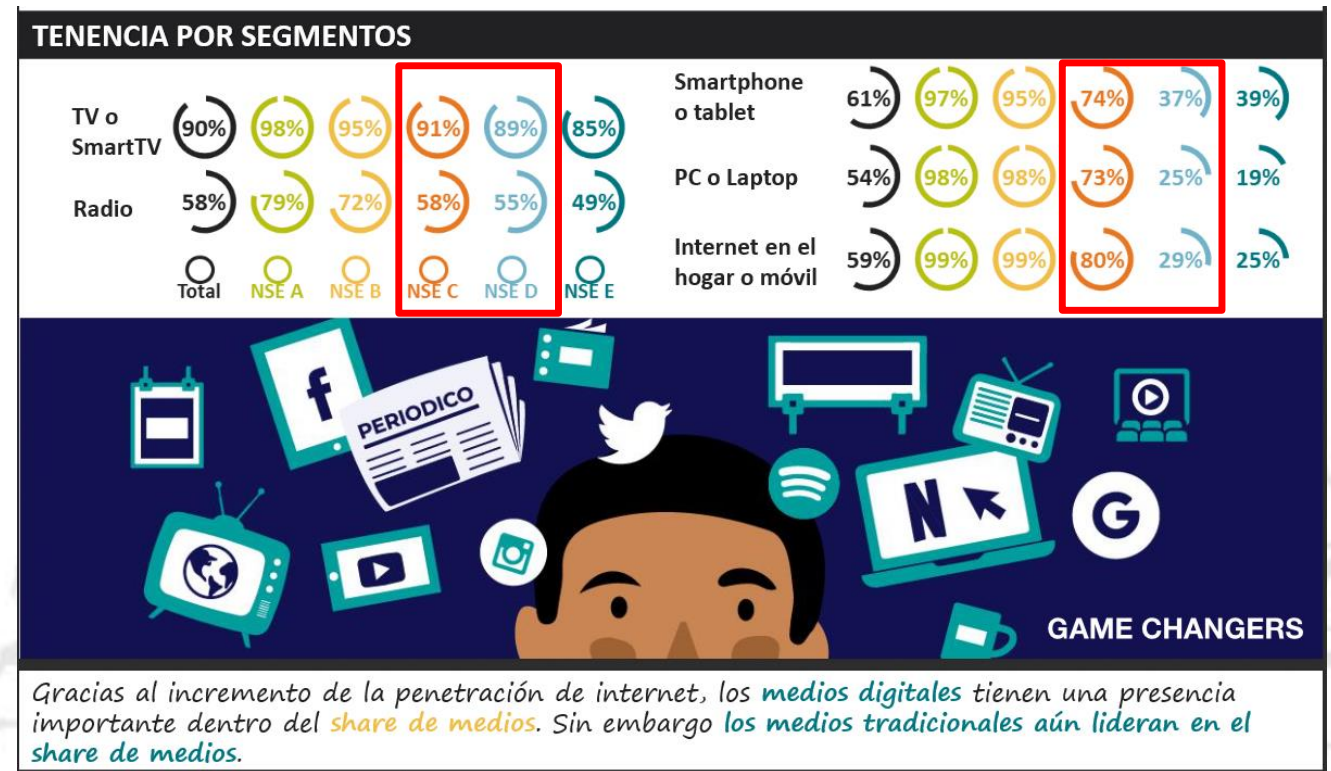

Fuente: Ipsos, 2019.

\section{Consumo de radio}

Respecto al consumo de radio de nuestro público objetivo, el siguiente gráfico demuestra que también los NSE C y D son quienes más consumen éste medio tradicional, destacando el consumo con una frecuencia de "Varias veces al día" liderada por el NSE $\mathrm{C}(36 \%)$.

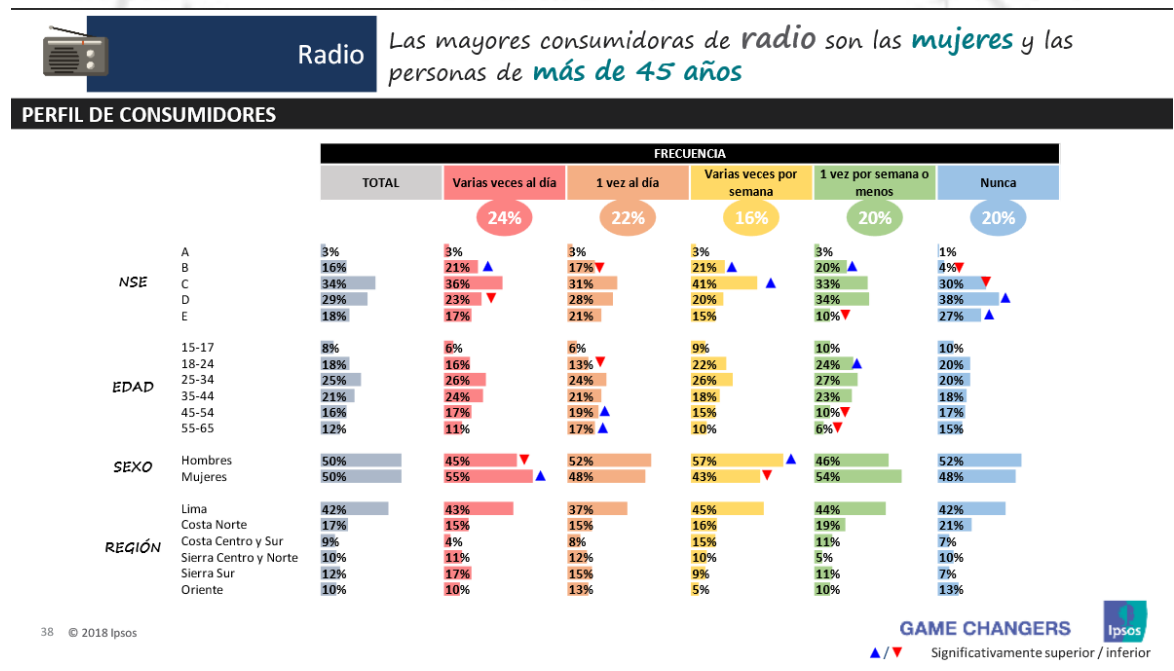

Fuente: Ipsos, 2019. 


\section{Consumo de TV}

La televisión es el medio tradicional más consumido por el público objetivo y con mayor frecuencia a nivel semanal se encuentra la TV de señal abierta. Para los NSE C y D el cable nacional e internacional son de bajo consumo e inclusive antes que estos dos rubros, se encuentra la radio siendo consumida hasta casi 3 horas más por semana.

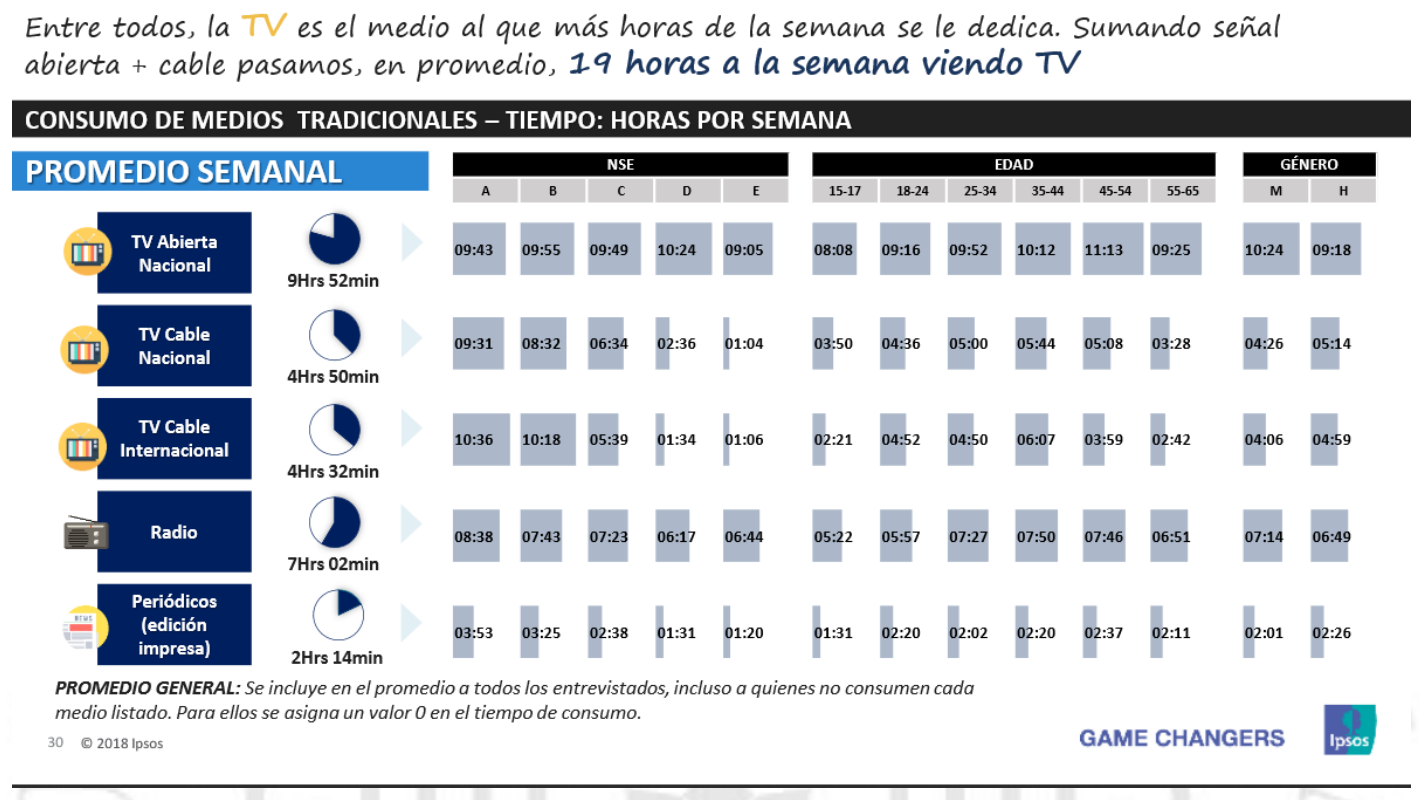

Fuente: Ipsos, 2019

\section{Consumo de diarios}

Otro medio tradicional también muy consumido (en su mayoría destacándose el NSE C con $42 \%$ ) por nuestro público objetivo son los diarios y la prensa escrita. Líneas más adelantes se analizará que diarios son los más leídos por el target.

PERFIL SOCIODEMOGRÁFICO

El lector de diarios es un adulto joven de 37 años en promedio.
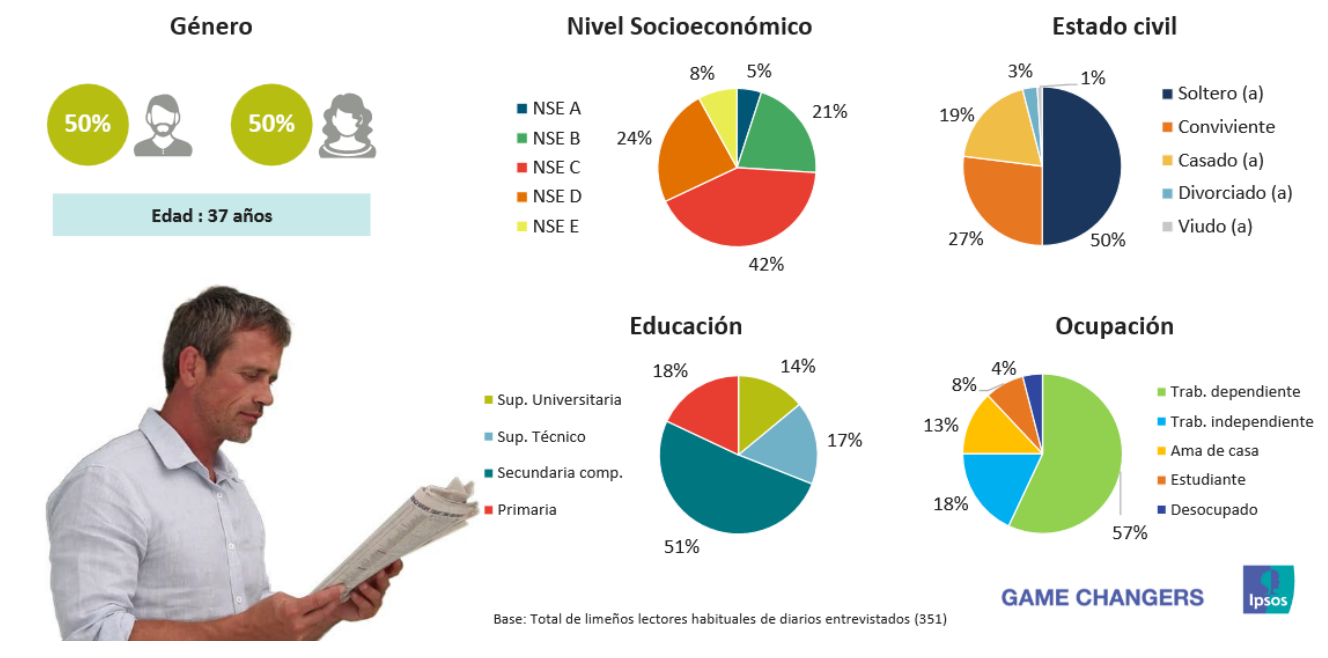

Fuente: Ipsos, 2019. 


\section{Consumo Redes Sociales}

Respecto a las RRSS, destaca Facebook con un alto porcentaje y similar entre todos los NSE. Whatsapp y Messenger se ubican en los siguientes puestos siendo redes sociales principalmente de conversación, y en cuarto lugar se encuentra Instagram. Dentro del análisis puntual de los NSE pertenecientes al P.O, el orden jerárquico se encuentra de la misma forma.

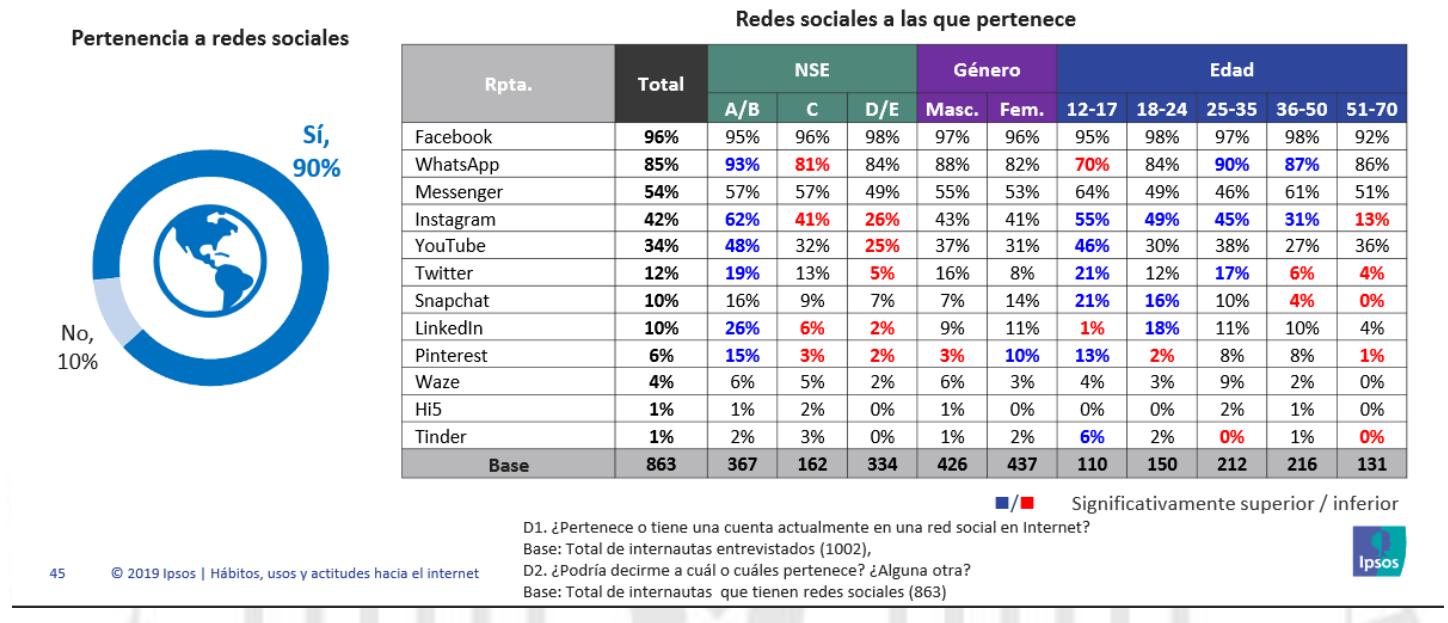

Fuente: Ipsos, 2019.

En el siguiente grafico podemos observar que generacionalmente, Instagram se encuentra mejor rankeado en rangos de edad de menor a mayor, aterrizando también ésta información al análisis de nuestro público objetivo, entre las edades de 25 a 34 años un $50 \%$ de la población consume ésta red social y no quedándose con un mal porcentaje, el rango de edades de 35 a 44 años se ubica con un $31 \%$.

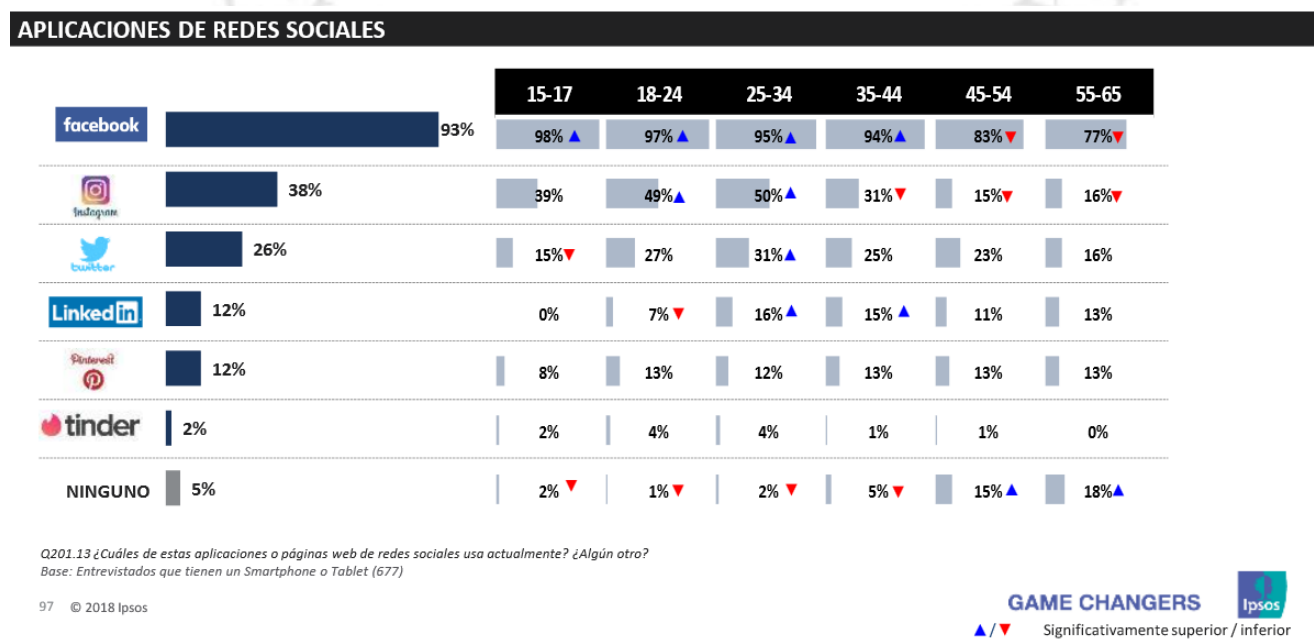

Fuente: Ipsos, 2019. 


\subsection{Hallazgos claves}

Sumado a los informes de fuentes especializadas en investigación de la población y su comportamiento, así como investigación de mercado, consumo y opinión de los niveles socioeconómicos y perfiles demográficos; gracias a las entrevistas a especialistas y la realización de un Focus Group, se logran hallar las siguientes características, posturas y comportamientos enfocados $100 \%$ al producto y su adquisición, que permiten conocer más a detalle al público objetivo:

- $\quad$ El P.O se mueve por un tema de precio

- Se centra en aprovechar las promociones - precios de oportunidad

- Tienen mucha desconfianza en este tipo de negocios. Parientes, amigos o vecinos cercanos a ellos han tenido experiencias negativas (por ejemplo, han fallado en plazo de entrega de proyectos, en la calidad de los materiales de construcción, entre otros)

- El comportamiento de desplazamiento de vecindarios en éste público es gradual: Inicialmente evalúan mudarse a zonas cercanas. Realizar una mudanza de la familia complete de polo a polo geográfico suele ser de carácter poso usual.

- Es importante identificar que el público objetivo consta principalmente de aquellos que tienen la intención de compra de una vivienda propia o ha pensado recientemente en ello.

- "No quieren moverse de su distrito pero quieren vivir mejor en el distrito que ya residen" (Bruno Jordán) ${ }^{9}$

- $\quad$ El público es cada vez más exigente, a diferencia de hace 5, 6 años. Es un público que le gusta estar informado, que valora mucho el plan y estrategia de postventa que tiene la empresa.

- Como se menciona anteriormente, hay público cautivo y de representación minoritaria, pero que presenta una gran necesidad que Condominio Villa Atleta puede satisfacer: la accesibilidad y la inclusión social y territorial.

- Les preocupa el sistema de los cobros, "siempre las cuotas son altas". Fuera del alcance del bolsillo.

\footnotetext{
${ }^{9}$ Director de Marketing de Paz Centenario.
} 
- $\quad$ Buscan flexibilidad en el cobro y en las cuotas.

Otro hallazgo clave adicional que es importante mencionar, es el nivel de satisfacción que tiene el P.O respecto a ciertos aspectos que se encuentran totalmente ligados a características y propuestas que son parte del proyecto Condominio Villa atleta.

\begin{tabular}{|c|c|c|c|c|c|c|c|c|c|}
\hline \multicolumn{10}{|c|}{$\begin{array}{c}\text { ¿Cómo califica su nivel de satisfacción con los siguientes aspectos que influyen en la calidad de vida? } \\
\text { Lima Metropolitana y Callao, } 2018 .\end{array}$} \\
\hline & & Lima & $\mathrm{A} / \mathrm{B}$ & C & $\mathrm{D} / \mathrm{E}$ & Callao & $\mathrm{A} / \mathrm{B}$ & C & $\mathrm{D} / \mathrm{E}$ \\
\hline \multirow{2}{*}{$\begin{array}{l}\text { El cuidado de las } \\
\text { playas y del mar }\end{array}$} & Insatisfecho & $58.2 \%$ & $55.1 \%$ & $59.9 \%$ & $61.5 \%$ & $47.3 \%$ & $48.4 \%$ & $48.5 \%$ & $42.5 \%$ \\
\hline & Satisfecho & $7.2 \%$ & $8.1 \%$ & $6.3 \%$ & $6.8 \%$ & $9.0 \%$ & $5.2 \%$ & $10.9 \%$ & $12.5 \%$ \\
\hline \multirow{2}{*}{$\begin{array}{l}\text { El sistema de } \\
\text { recojo de basura }\end{array}$} & Insatisfecho & $46.7 \%$ & $42.9 \%$ & $48.2 \%$ & $51.0 \%$ & $33.3 \%$ & $25.8 \%$ & $34.5 \%$ & $45.0 \%$ \\
\hline & Satisfecho & $20.6 \%$ & $24.8 \%$ & $18.3 \%$ & $16.8 \%$ & $35.8 \%$ & $40.0 \%$ & $32.7 \%$ & $33.8 \%$ \\
\hline \multirow{2}{*}{$\begin{array}{r}\text { El control de los } \\
\text { niveles de ruido en } \\
\text { la calle }\end{array}$} & Insatisfecho & $60.2 \%$ & $58.1 \%$ & $61.9 \%$ & $61.2 \%$ & $58.8 \%$ & $61.9 \%$ & $60.0 \%$ & $50.0 \%$ \\
\hline & Satisfecho & $8.1 \%$ & $9.1 \%$ & $6.5 \%$ & $8.4 \%$ & $9.3 \%$ & $7.1 \%$ & $9.1 \%$ & $13.8 \%$ \\
\hline \multirow{2}{*}{$\begin{array}{r}\text { Las áreas verdes y } \\
\text { la cantidad } \\
\text { de árboles }\end{array}$} & Insatisfecho & $50.3 \%$ & $43.2 \%$ & $58.0 \%$ & $51.2 \%$ & $34.5 \%$ & $29.0 \%$ & $38.8 \%$ & $36.3 \%$ \\
\hline & Satisfecho & $16.2 \%$ & $20.5 \%$ & $10.8 \%$ & $16.6 \%$ & $33.5 \%$ & $41.9 \%$ & $27.3 \%$ & $30.0 \%$ \\
\hline \multirow{2}{*}{ La calidad del aire } & Insatisfecho & $56.7 \%$ & $53.9 \%$ & $59.1 \%$ & $57.8 \%$ & $52.0 \%$ & $51.0 \%$ & $50.9 \%$ & $56.3 \%$ \\
\hline & Satisfecho & $9.6 \%$ & $12.6 \%$ & $6.5 \%$ & $9.1 \%$ & $12.0 \%$ & $9.7 \%$ & $12.7 \%$ & $15.0 \%$ \\
\hline \multirow{2}{*}{$\begin{array}{l}\text { El cuidado de } \\
\text { los ríos }\end{array}$} & Insatisfecho & $64.9 \%$ & $61.0 \%$ & $67.4 \%$ & $68.0 \%$ & $49.5 \%$ & $51.0 \%$ & $48.5 \%$ & $48.8 \%$ \\
\hline & Satisfecho & $6.4 \%$ & $8.4 \%$ & $4.4 \%$ & $5.9 \%$ & $6.0 \%$ & $5.8 \%$ & $4.8 \%$ & $8.8 \%$ \\
\hline \multirow{2}{*}{$\begin{array}{l}\text { Elacceso y la } \\
\text { calidad del } \\
\text { agua potable }\end{array}$} & Insatisfecho & $42.3 \%$ & $38.1 \%$ & $44.1 \%$ & $47.2 \%$ & $31.0 \%$ & $29.7 \%$ & $28.5 \%$ & $38.8 \%$ \\
\hline & Satisfecho & $21.9 \%$ & $25.2 \%$ & $20.5 \%$ & $18.4 \%$ & $33.3 \%$ & $35.5 \%$ & $33.3 \%$ & $28.8 \%$ \\
\hline
\end{tabular}

Como se muestra en el gráfico anterior, los niveles socieconómicos $\mathrm{C}$ y $\mathrm{D}$ arrojan porcentajes muy considerables de insatisfacción respecto a temas de limpieza, cuidado del medio ambiente, áreas verdes y segregación de residuos, inclusive el manejo y distribución de servicios básicos, entre otros. Con esto, se identifica una necesidad por parte de la población de mejorar los servicios de vivienda, municipales y hasta vecinales. 


\section{OBJETIVOS}

\subsection{Objetivos de Marketing}

- Generación de 4mil leads durante los primeros 3 meses de la campaña.

- Generar awareness en 10000 personas que cumplan características del P.O respecto al Condominio Villa Atleta durante los 2 primeros meses de la campaña.

- Concretar la visita a los departamentos modelos de Villa Atleta del $40 \%$ de los leads obtenidos durante los 6 meses de la campaña.

- Lograr el $100 \%$ de las ventas de departamentos durante el primer semestre del 2020.

\subsection{Objetivos de Comunicación}

- Dar a conocer el condominio Villa Atleta a la población y sus características ecosostenibles y accesibles a discapacitados.

- Generar motivación al target respecto a la adquisición de uno de los departamentos.

- Comunicar al target sobre las facilidades de financiamiento a través del programa Mivivienda y el bono Verde.

- Eliminar la desinformación por parte del P.O sobre la venta de los departamentos y accesibilidad a cualquier persona natural.

- Dar valor a los complejos de viviendas multifamiliares con características que benefician la calidad de vida de las personas como la inclusión, la contribución al medio ambiente y los espacios deportivos comunes que posee Villa Atleta. 


\section{VISIÓN DEL PROYECTO}

De acuerdo a la información recopilada hasta éste punto del trabajo y su desarrollo, se logran enlistar una serie de enunciados que el público objetivo ya profundizado tiene como motor en su actitud frente a nuestro producto, nuestra historia y nuestra oferta al día de hoy.

Los siguientes insights son los pertenecientes a la visión que se tiene del proyecto Condominio Villa Atleta, los cuales ayudarán a seguir identificando una serie de elementos que contribuyen a los cimientos del proyecto y con ello, el futuro desarrollo de las piezas de comunicación.

\subsection{Insights}

\section{Orientados al sentimiento:}

"Lugar donde podrías vivir con el legado de los Juego Panamericanos y Parapanamericanos Lima 2019”

"Orgullo de sentirte peruano y triunfador en un espacio histórico"

\section{Orientados a rasgos del P.O}

"Pertenecer a una comunidad de vecinos unidos y organizados"

"Un espacio residencial y familiar donde se vivirá gratamente"

\section{Orientados a lo que busca el P.O en una vivienda}

"Comunidad, comodidad y seguridad"

"Fácil acceso, fácil pago de servicios"

"Un condominio que te permita ahorrar y optimizar tus gastos" 


\subsection{Valor diferencial - promesa}

Villa Atleta es un legado urbano y deportivo de gran valor nacional. Es un hito en la historia de nuestro país a nivel deportivo e internacional. Se transforma en un complejo habitacional que permitirá que peruanos adquieran viviendas accesibles.

\subsection{Reason why}

Un condominio ecoamigable y accesible: viviendas verdes y departamentos diseñados para personas con alguna discapacidad física o visual.

\subsection{Posicionamiento deseado}

El primer condominio accesible de Lima y además, comprometido con el medio ambiente. Un complejo multifamiliar diseñado para crear oportunidades para las poblaciones emergentes de las zonas periféricas de la ciudad. 


\section{PROPUESTA CREATIVA}

\subsection{Idea estratégica}

De acuerdo a los insights obtenidos según la investigación y el soporte del focus group realizado, el principal interés se encuentra en las características de pago, opciones de financiamiento y flexibilidad que puede llegar a ofrecerse para el cliente. Independientemente de destacar los espacios comunes, áreas deportivas y sistemas que benefician al medio ambiente, es importante resaltar que el motor principal de la estrategia va a centrarse en destacar que el Condominio Villa Atleta brinda las facilidades necesarias para lograr tener una vivienda propia.

El condominio Villa Atleta se encuentra a tu alcance y al de todos. Permite confiar y así, ganar. Es un condominio realmente accesible.

Partiendo de la premisa puntual: alcance y la accesibilidad, se orientará a resaltar los otros atributos diferenciadores del Condominio Villa Atleta, direccionándolos ya de manera más estratégica según el medio de comunicación y el contexto.

"El primer condominio inclusivo de Lima" "Contribuye con el planeta" "Áreas deportivas y espacios comune"

\subsection{Concepto Creativo}

\section{Condominio Villa Atleta, un condominio al alcance de todos}

El concepto creativo para la campaña busca que el consumidor destaque al Condominio Villa Atleta por ser accesible para todos y siempre ofrezca las mejores opciones de pago y flexibilidad para el financiamiento. 
Se mostrará este mensaje madre tanto en medios offline como online de tal manera que el mensaje pueda ser visualizado y comprendido de distintas formas siempre buscando que el Condominio Villa Atleta sea reconocido por sus características amigables y no sea un sueño utópico de adquirir una vivienda por el P.O.

\section{2 Identidad Corporativa}

Dentro de los elementos que componen la identidad corporativa de una empresa o proyecto, se puede identificar la importancia de destacar la filosofía del mismo.

En el caso del condominio "Villa Atleta" definimos la misión, visión y valores de la siguiente manera:

\section{$\underline{\text { Visión }}$}

Ser una reconocida residencia a nivel nacional debido al legado histórico y urbano del que forma parte y a su vez, ser destacada por su innovación y accesibilidad.

\section{Misión}

Permitir que las familias peruanas se encuentren satisfechas con la calidad de infraestructura y con los servicios residenciales de Villa Atleta y a su vez, ser ejemplo de desarrollo, urbanismo y comunidad para el distrito y la ciudad de Lima.

\section{$\underline{\text { Valores }}$}

- Innovación: las tecnologías sostenibles que permiten contribuir con el cuidado del medio ambiente, nuestros estándares internacionales que permiten al condominio ser un completo totalmente accesible.

- Responsabilidad: Villa Atleta es un complejo habitacional que se preocupa tanto por el desarrollo de sus familias como por el desarrollo del distrito de Villa El Salvador.

- Compromiso: el condominio Villa Atleta se encuentra comprometido con mantener los estándares de calidad en sus servicios, respetar las normas y leyes 
que favorecen a los miembros de ésta comunidad y también, aportar como ejemplo de desarrollo a los vecinos del distrito.

\section{Nombre}

El nombre del complejo residencial es "Villa Atleta". Se decide utilizar únicamente éstas dos palabras para vincularlas de manera potente y a su vez, agregarle al sustantivo "Villa" el adjetivo "Atleta" como atributo a éste espacio arquitectónico y complejo residencial que ha marcado un hito en la historia de nuestra sociedad.

Además, de ésta forma, le brindamos un fuerte foco a la palabra "Villa" ya que el vínculo deportivo es tácito debido al antecedente que tiene el complejo y de por sí, la palabra que acompaña: "Atleta”, ya remite rápidamente al atributo ágil y recio además de deportivo y rápido.

\section{Análisis individual de cada palabra:}

\section{"Villa"}

Significado: Población que tiene algunos privilegios con que se distingue de las

aldeas y lugares ${ }^{10}$

Análisis fonético: palabra corta. Inmediata. Sencilla.

Sensación y emoción: pluralidad, abundancia, sentido de comunidad, remite a espacio conjunto, colectividad pero a su vez unidad.

\section{"Atleta"}

Significado: Persona fuerte y musculosa ${ }^{11}$

Persona que posee agilidad o resistencia.

Análisis fonético: Vocales fuertes. Referencia a alguien. Palabra compleja, Sensación y emoción: fuerza, rapidez, agilidad, triunfo, éxito, capaz.

\footnotetext{
${ }^{10}$ Definición según la Real Academia de la Lengua Española.

${ }^{11}$ Definición según la Real Academia de la Lengua Española
} 


\section{Conexión entre palabras}

¿Que genera "Villa del atleta"?

Destaca/ protagoniza al "Atleta".

Si se vincula con la historia de la construcción, con los datos importantes del desarrollo de la edificación, se vincula a los juegos panamericanos, y esto vincula al éxito y orgullo.

Atleta tiene más fuerza para comunicar, lo que significa que Villa. por lo que la parte visual debe reforzar la idea de condominio o edificación y vivienda familiar para contrarrestar el aspecto deportivo/competitivo de Atleta.

\section{Personalidad de la marca}

Villa Atleta es una marca amigable, cercana, justa e inclusiva. Dinámica pero a su vez responsable y seria. Comprometida con las personas y el medio ambiente.

\section{$5.4 \operatorname{Logo}$}

Para la creación de logo y sus elementos, se realizó un moodboard que permita recopilar las sensaciones visuales, de color y de formas, así como el complemento conceptual que se quieren utilizar para la creación de identidad del Condominio Villa Atleta.

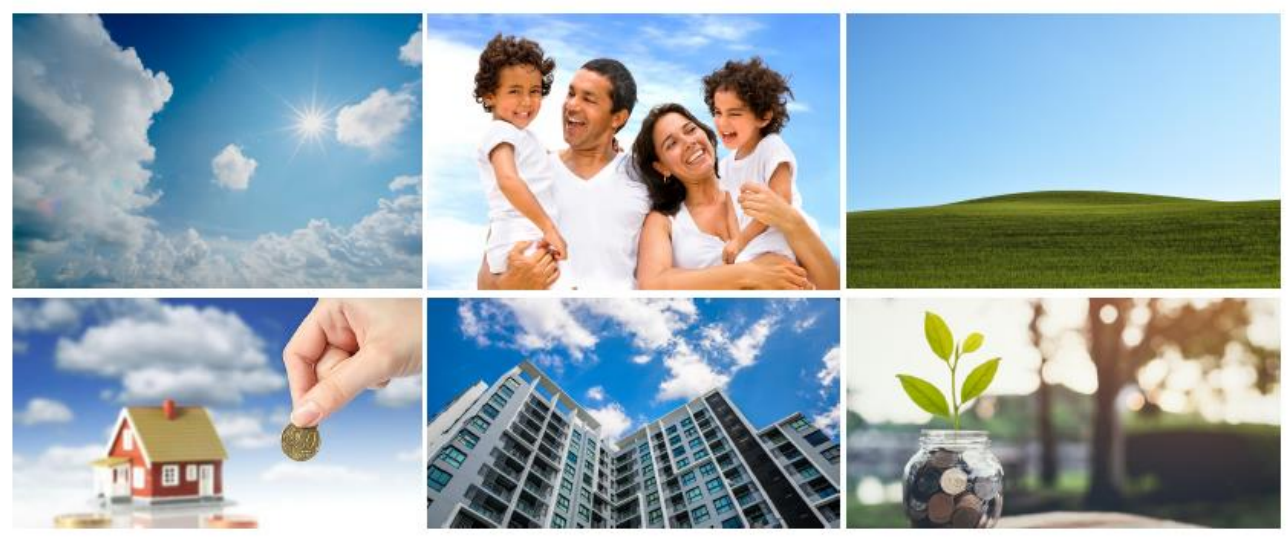




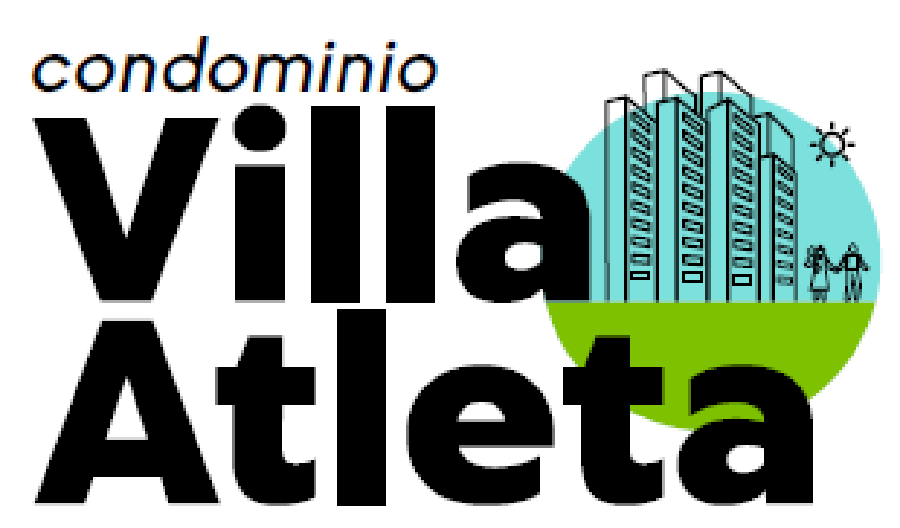

El desarrollo del logo se crea con la principal referencia de una vivienda verde. Un complejo habitacional con conciencia ecológica, lo que principalmente se destaca por la presencia de color y de "área verde" dentro del isologo. Además mantiene un lenguaje universal y cercano a todos, mostrando una postura alcanzable, accesible, aterrizada.

Dentro de los elementos que conforman el isologo, se desea mostrar explícitamente las torres del condominio, algo que lo caracteriza por su imponente infraestructura que muestra solidez, altura, ascendencia, grandeza. Se quiso ser muy literal con la expresión de las 7 torres del condominio, ya que se desea reforzar la idea de un complejo de viviendas y familias numeroso que permite generar una residencia y futura comunidad. Se presenta también una pequeña familia nuclear, ya que se desea sopesar el significado de la fuerte palabra "Atleta" ya presente en el nombre y la tipografía que conforma al logotipo total.

Se desea resaltar el vínculo "cielo y tierra" y la armonía entre ellos. La naturaleza y el urbanismo pero de una manera muy amigable, directa y lineal para el público.

Nuestro público objetivo tiende mucho a recibir información graficada y con una rápida lectura, intentado así dar en el logotipo una lectura rápida a todos los elementos y una comprensión veloz de lo que se desea comunicar. Se tiene también un elemento geométrico importante: el círculo; el cual tiende a proyectar un mensaje de unidad, conjunto, comunidad y sociedad. Se busca proyectar la sensación de algo sólido y un 
grupo unido, que vendría a representar a la comunidad que se formaría en un condominio o residencial.

\section{Elementos complementarios}

En las gráficas posteriormente producidas para las piezas de comunicación, se utilizarán símbolos que mantienen la misma línea grafica del isologo, lo que permitirá crear coherencia entre las imágenes y las formas de encapsular los datos, atributos y características importantes a destacar sobre el condominio. Por ejemplo, se utilizan símbolos como las hojas para evidenciar lo ecológico, elementos como una parrilla para ejemplificar las áreas comunes, símbolos geométricos para expresar las áreas, entre otros.

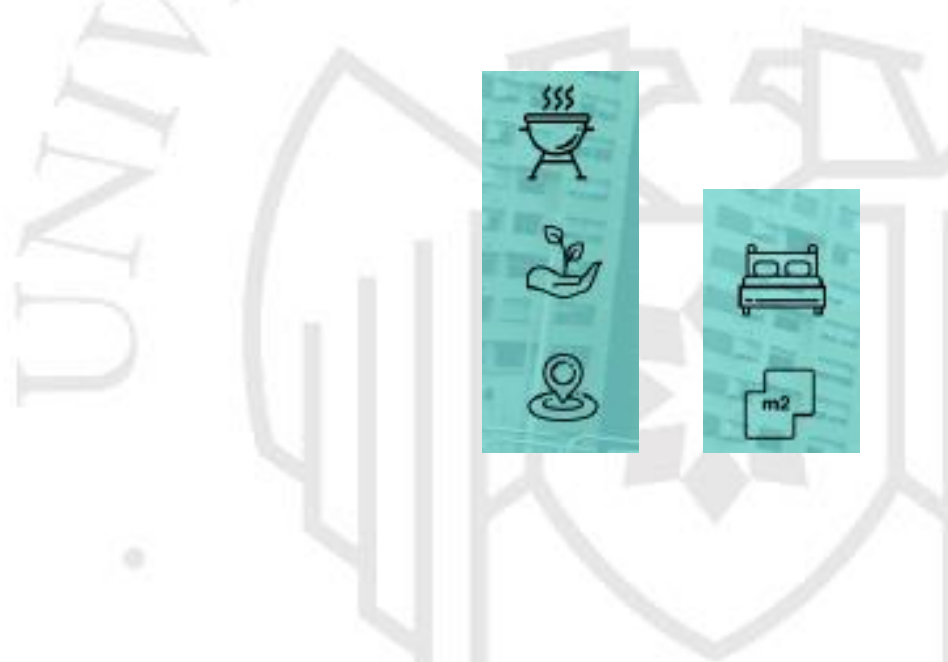

Identidad Cromática - Paleta de colores

En la identidad cromática del proyecto, se utilizan 3 colores principales acompañados del blanco y el negro, que cumplen una función neutral pero que a su vez le da versatilidad a la aplicación del logotipo a diversas plataformas de comunicación y marketing. 


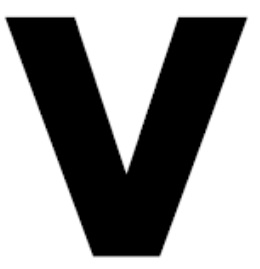

000000

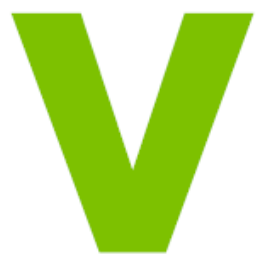

$7 \mathrm{dc} 100$

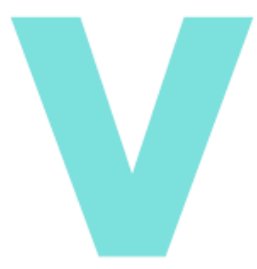

7ce0dc

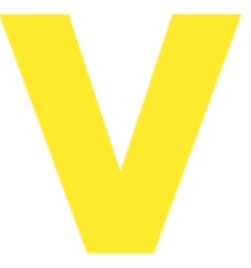

feea2d

El color verde que se utiliza, como se menciona en líneas anteriores, cumple una función de vínculo con la naturaleza y la ecología. Algo que actualmente además representa mucho al distrito donde se encuentra el proyecto. Villa El Salvador tiene entre sus prioridades y ya se encuentra en una fuerte campaña de "verderizacion" del distrito. Se proyecta una gran "arborización" del territorio ya que actualmente es una zona árida que poco a poco está teniendo una nueva cara.

Por otro lado, también se desea vincular al verde con el certificado de Vivienda Verde que tiene el condominio, un atributo importante de destacar por ser de carácter sostenible y comprometido con el medio ambiente.

El color celeste que también integra la paleta de colores, desde el concepto muy general representa a elementos como el agua, y en evidencia al cielo, también vinculados principalmente a la naturaleza y que a su vez, hace de gran complemento al color verde. Esto, permite generar un gran equilibrio a su vez armonía al servir de soportes para los elementos lineales de color negro y también las combinaciones que se logren realizar para las aplicaciones a distintas plataformas.

Por último, el color amarillo que universalmente representa la alegría, la luz, y finalmente cumple un gran vinculo de 3 ángulos junto al verde y al celeste. Algo que también se identificó es que debido al bagaje político y cultural que tiene la población limeña, podría asociarse a aspectos políticos recientes que tienen una cara negativa de las gestiones municipales anteriores en nuestra ciudad, por lo que se es muy cuidadoso al utilizar éste último elemento cromático para evitar generar un ruido en la comunicación debido a que el proyecto del condominio también pertenece a gestiones publicas previas. 


\section{Tipografía}

Se utiliza la tipografía Captura para las palabras VILLA y ATLETA, nombre asignado al condominio. Ésta tipografía, tiende a generar una sensación de cercanía y familiaridad pero a su vez no pierde el orden y cierta seriedad que comparte por las líneas rectas en sus pendientes y curvas en determinadas letras.

\section{Captura}

Para la palabra CONDOMINIO se utiliza la tipografía Ginora Sans Y en versión cursiva, para darle un porcentaje de movimiento a la palabra y al isologo que se diseña de una manera plana y lineal. De esta manera la lectura de todo el logotipo a manera general, permite identificar rápidamente lo que genera un movimiento distinto al resto de elementos.

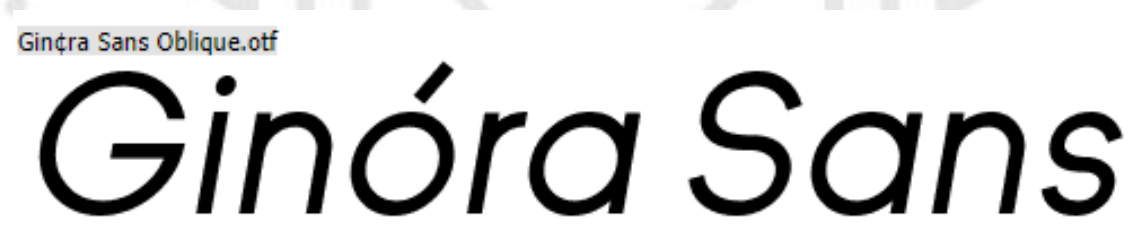

Aplicación de la Identidad

A continuación, se muestra la aplicación de la identidad del proyecto en diferentes plataformas de uso corporativo y acorde a las necesidades de un proyecto inmobiliario como el condominio "Villa Atleta"12. Adicionalmente a ello, se presenta el manual de identidad en el link junto a todas las piezas de comunicación.

\footnotetext{
${ }^{12}$ Las ilustraciones presentadas en las próximas páginas son elaboraciones propias
} 
Uso en brochure

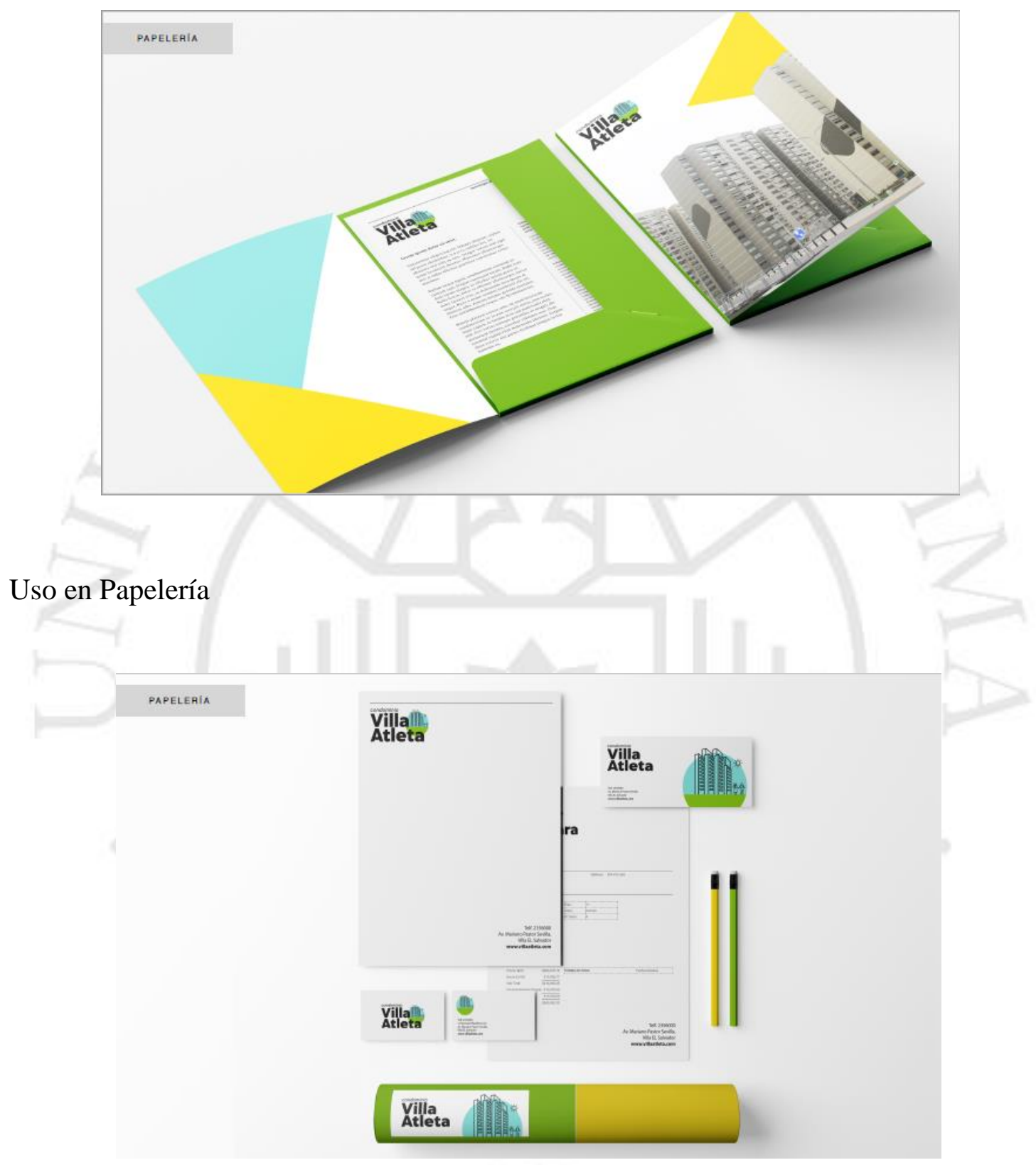


Uso en Piezas graficas (digitales e impresas)
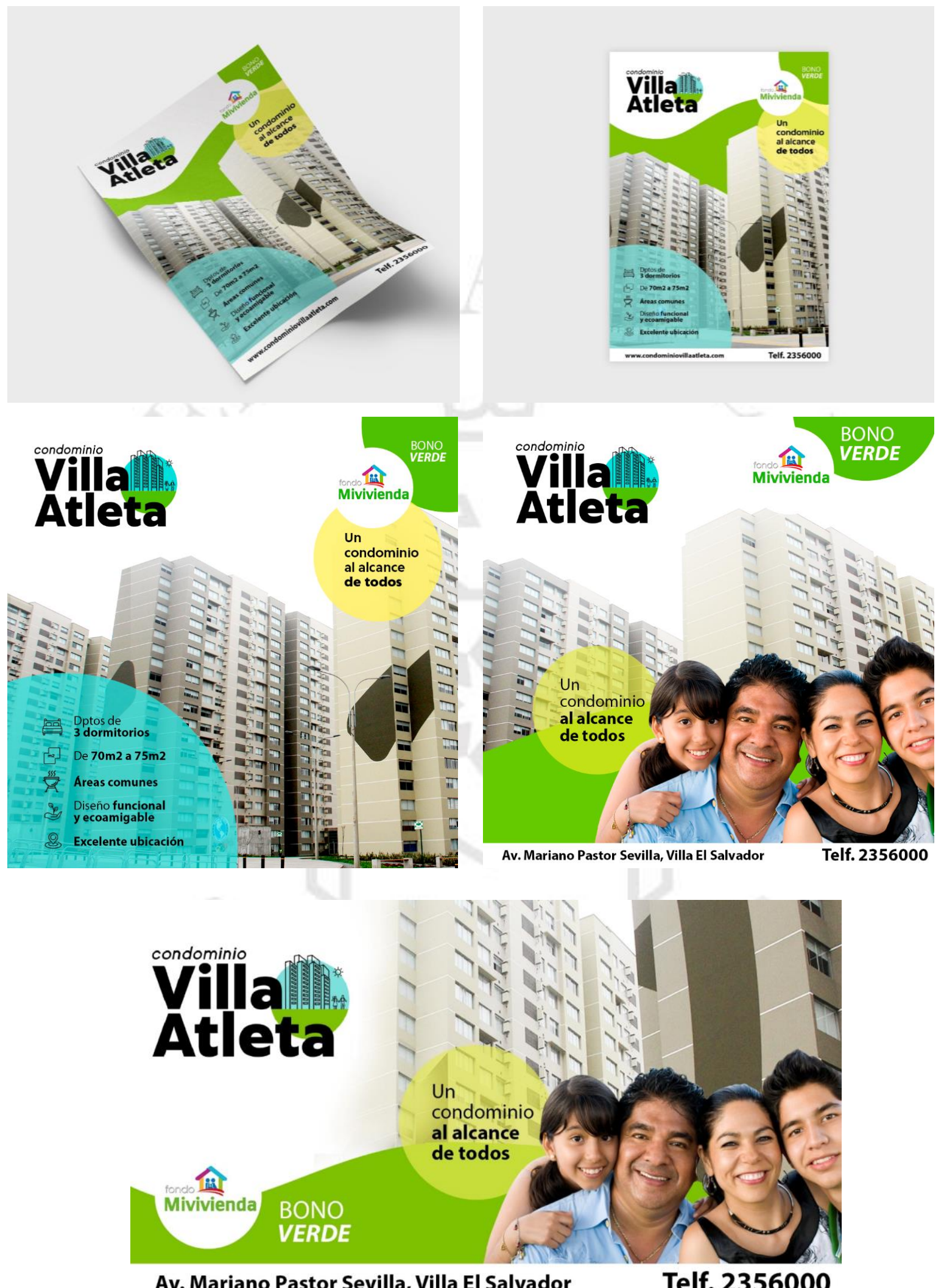
Uso en Web

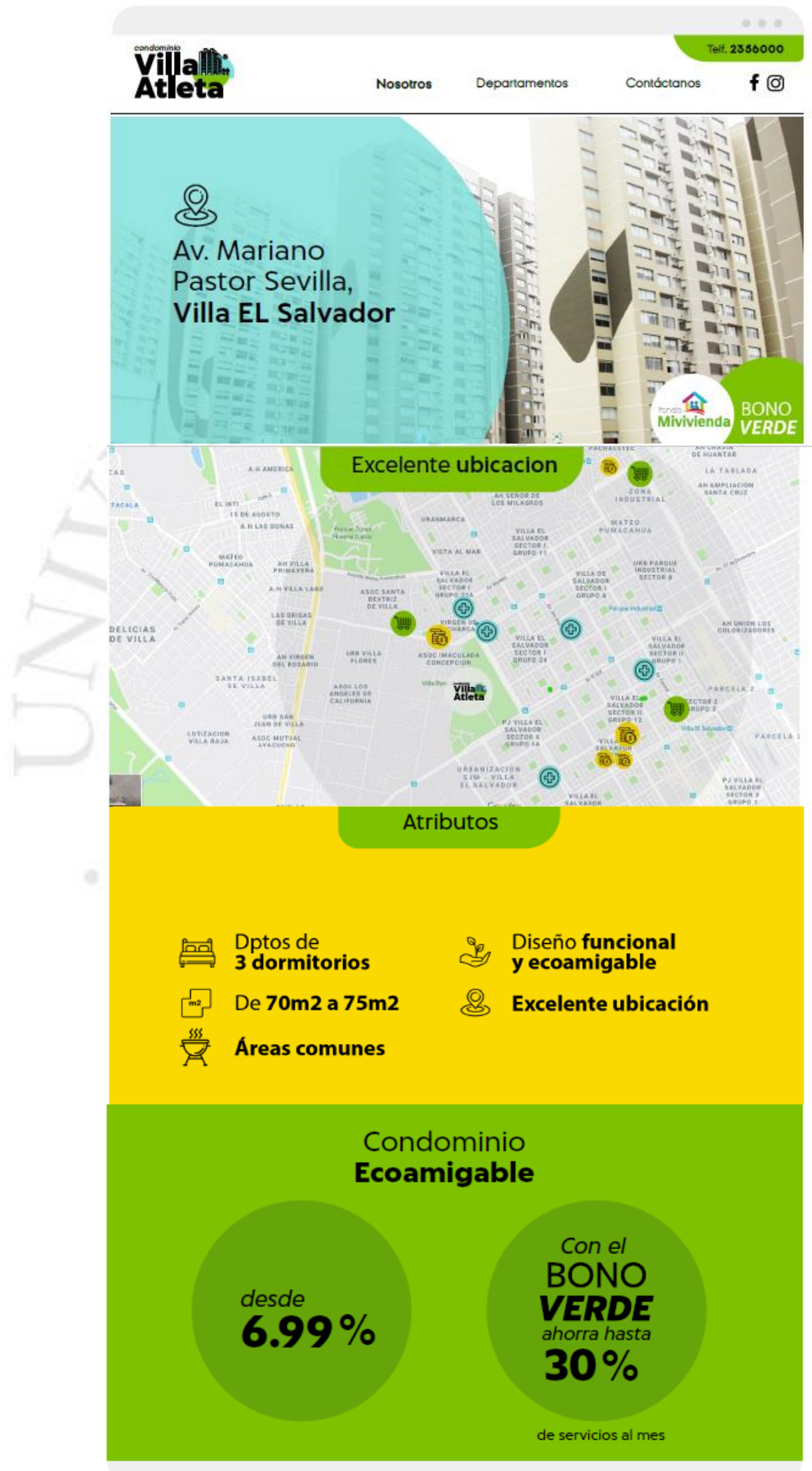




\section{PLAN DE COMUNICACIONES}

\subsection{Desarrollo de campaña}

De acuerdo al análisis realizado, y enfocándolo y orientando al P.O de cuerdo al producto (inmueble) y su intención de compra. Sumado de los insights principales obtenidos del análisis del público objetivo, las herramientas de investigación más directas y a su vez, la experiencias de especialistas tanto en el sector inmobiliario y el marketing, alineado a los objetivos y la cara del proyecto Villa Atleta, se establecerá un plan de comunicaciones acorde al concepto creativo "Un condominio al alcance de todos", resaltando éste mensaje y así utilizando otros recursos adicionales (aspectos visuales, coyunturales, soporte de los eventos, entre otros) que se orientará por los resultados del consumo de medios tradicionales y no tradicionales del P.O, el tono de comunicación, la temporalidad de la campaña, la ubicación y el territorio, así como el fuerte vínculo con el legado deportivo de Lima2019 y la percepción de la población.

Se plantea realizar una estrategia en donde los bullets de comunicación sean liderados por el el concepto de "alcance" y a su vez, destaquen los atributos del proyecto, se mencione y reitere el valor agregado que tienen los departamentos a diferencia de la competencia, se busque brindar información transversal por todos los medios a utilizar en el mix donde se detallen las facilidades de acceso y financiamiento económico para el público, y a su vez, se realce el valor de este complejo como tal, por haber sido un escenario de orgullo y éxito a nivel deportivo nacional.

Según el brief analizado inicialmente, al contar con la finalización de las últimas modificaciones arquitectónicas del condominio para el mes de diciembre del presente año, se considera dentro de la siguiente estrategia, la disposición de "departamentos modelo" dentro de Villa Atleta que se encontrarán abiertos a los clientes potenciales interesados en conocer los inmuebles. Es por ello, que se considera conveniente iniciar 
la campaña de marketing desde el mes de diciembre pero no con la misma inversión (en cuanto a medios) que los meses siguientes que se incluyen en la campaña. ${ }^{13}$

Otro motivo importante por el cual se considera esta época calendario e carácter relevante para el lanzamiento del condominio Villa Atleta al mercado y a la opinión pública, es por la organización y disposición que tiene el público objetivo respecto a su economía tanto personal como familiar.

Al ser el mes (diciembre) donde el trabajador dependiente de una empresa formal recibe la gratificación y bonos adicionales, así como la canasta navideña y ciertos incentivos, compartiendo a su vez, éste mes con los trabajadores independientes no formales, quienes suelen terminar de recibir pagos por parte de clientes, familiares, resuelven deudas o ganan dinero extra de otros trabajos adicionales que no pertenecen a su rubro, se considera un mes importante para comunicar y posicionar al proyecto inmobiliario dentro del mercado y de la mente de sus futuros clientes.

Por ello se establece la campaña de comunicación de Villa Atleta en los siguientes meses:

Gráfico 8: Campaña de comunicación expresada en meses

\begin{tabular}{|c|c|c|c|c|c|c|}
\hline DICIEMBRE & ENERO & FEBRERO & MARZO & ABRIL & MAYO & JUNIO \\
\hline $\begin{array}{l}\text { Lanzamiento } \\
\text { y Awareness }\end{array}$ & $\begin{array}{l}\text { Lanzamiento } \\
\text { y Awareness }\end{array}$ & $\begin{array}{l}\text { Comunicación y } \\
\text { motivación de } \\
\text { compra }\end{array}$ & $\begin{array}{l}\text { Comunicación } \\
\text { y motivación } \\
\text { de compra }\end{array}$ & $\begin{array}{l}\text { Motivación de } \\
\text { compra y } \\
\text { Fuerza de } \\
\text { ventas }\end{array}$ & $\begin{array}{l}\text { Fuerza } \\
\text { Ventas }\end{array}$ & $\begin{array}{l}\text { Fuerza } \\
\text { Ventas, } \\
\text { remate y } \\
\text { liquidación }\end{array}$ \\
\hline
\end{tabular}

\subsection{Tono de comunicación:}

El tono de comunicación de la campaña será el mismo que el del proyecto en sí, se busca la coherencia entre todos los elementos generales: visuales, sensoriales, empíricos. Se

\footnotetext{
${ }^{13}$ Se detallará líneas abajo el flow de medios.
} 
mantiene cercano al cliente y a sus familias, amigable, pero sin perder lo corporativo y la seriedad para que se perciba el compromiso y la veracidad del negocio.

Si nos inclinamos a demasiada coloquialidad, podemos perder la formalidad que el público objetivo busca para confiar en el proyecto. Se deben sentir respaldados y seguros de la decisión que tomen.

\section{$6.3 \mathrm{ATL}$}

\subsubsection{Televisión}

Dentro de la elección de los medios tradicionales, se considera a la televisión, aun liderando en los porcentajes de hábito y consumo de medios en todos los niveles socioeconómicos y todas las edades, como la líder e indispensable para adquirir información y entretenimiento de manera individual y colectiva en familias, amigos, trabajos y diversos escenarios sociales.

A pesar de ser el medio más costoso y al contar con un presupuesto limitado establecido para el proyecto ${ }^{14}$ se decide invertir en un paquete de presencia de marca en el canal 4 , América Televisión en determinados meses de la ejecución de la campaña.

Gráfico 9: Consumo de canales televisivos población Limeña, 2017

América TV es el canal de señal abierta más visto por los televidentes limeños. Panamericana y TV Perú tendrían mayor presencia entre los adultos mayores de 40 años.

\begin{tabular}{|c|c|c|c|c|c|c|c|c|c|c|c|c|c|}
\hline & \multirow{2}{*}{$\begin{array}{l}\text { Total } \\
2017\end{array}$} & \multicolumn{5}{|c|}{ Nivel Socioecendmico } & \multicolumn{2}{|c|}{ Ginero } & \multicolumn{5}{|c|}{ Eded } \\
\hline & & A & B & c & D & E & Masc. & Fem & 12.17 & 18.24 & 25 • 39 & 40.54 & 55.70 \\
\hline Ambrika TV & $67 \pi$ & $58 \%$ & $57 \%$ & $68 \%$ & $72 \%$ & $74 \%$ & $65 \%$ & $69 \%$ & $63 \%$ & 69\% & $66 \%$ & $711 \%$ & $65 \%$ \\
\hline Latina & 366 & $39 \%$ & 55: & $36 \%$ & $31 \mathrm{~s}$ & $32 \%$ & 315 & $44 \%$ & $26 \mathrm{X}$ & 3006 & $37 \times 6$ & 458 & $46 \mathrm{~K}$ \\
\hline ATV & $37 \times$ & $30 \%$ & $37 \times 6$ & 348 & 3006 & $52 \%$ & $36 \%$ & $38 \%$ & $41 \%$ & 336 & $26 \mathrm{~N}$ & $47 \times 6$ & $47 \mathrm{~s}$ \\
\hline Panamericana & $14 \%$ & $11 \mathrm{x}$ & $11 \%$ & $16 \%$ & $13 \%$ & $14 \%$ & $18 \%$ & $11 \%$ & $1 \mathrm{~s}$ & $11 \times$ & 78 & 288 & 248 \\
\hline arve & $\pi \%$ & $1 \mathrm{~N}$ & $4 \%$ & $11 \%$ & $7 x$ & $1 \mathrm{*}$ & $10 \mathrm{x}$ & 58 & $4 \%$ & 5* & 85: & $9 \%$ & gs \\
\hline TV Perú & $3 \times$ & 83 & $8 \mathrm{x}$ & $2 \pi$ & $2 \mathrm{~K}$ & $2 \mathbf{x}$ & $4 \%$ & $3 \mathbf{x}$ & $1 \mathrm{~K}$ & ox & $1 \mathrm{H}$ & s* & (125) \\
\hline NexTV & $2 \pi$ & ox & $4 \%$ & $3 \mathbf{3}$ & $1 \%$ & $1 \%$ & $2 \%$ & $3 \%$ & $1 \%$ & $3 \%$ & OS & $8 \mathrm{x}$ & OA \\
\hline
\end{tabular}

\footnotetext{
${ }^{14}$ Se detallará los porcentajes de inversión en medios dentro del presupuesto planteado.
} 
Podemos observar en el gráfico anterior que el canal seleccionado para la estrategia de medios, es el canal más consumido por los NSE C y D.

\section{MOMENTOS DEL DÍA EN LOS QUE SUELEN VER TELEVISIÓN}

\section{Los adultos mayores suelen ver televisión en las primeras horas de la mañana y en las noches.}

\begin{tabular}{|c|c|c|c|c|c|c|c|c|c|c|c|c|c|}
\hline \multirow{2}{*}{ Horas } & \multirow{2}{*}{$\begin{array}{l}\text { Total } \\
2017 \\
\end{array}$} & \multicolumn{5}{|c|}{ Nivel Socioeconómico } & \multicolumn{2}{|c|}{ Género } & \multicolumn{5}{|c|}{ Edad } \\
\hline & & A & B & c & D & E & Masc. & Fem. & 12 a 17 & 18 a 24 & 25 a 39 & 40 a 54 & 55 a 70 \\
\hline Inicio de la mañana (06 am - $09 \mathrm{am})$ & $28 \%$ & $40 \%$ & $34 \%$ & $27 \%$ & $21 \%$ & $35 \%$ & $24 \%$ & $32 \%$ & $12 \%$ & $16 \%$ & $21 \%$ & $37 \%$ & $61 \%$ \\
\hline Final de la mañana (09 am- $12 \mathrm{pm})$ & $15 \%$ & $7 \%$ & $10 \%$ & $16 \%$ & $20 \%$ & $12 \%$ & $13 \%$ & $17 \%$ & $22 \%$ & $18 \%$ & $20 \%$ & $5 \%$ & $9 \%$ \\
\hline Al mediodía $(12 \mathrm{pm}-03 \mathrm{pm})$ & $24 \%$ & $12 \%$ & $12 \%$ & 然 & - & $27 \%$ & $18 \%$ & $31 \%$ & $23 \%$ & $15 \%$ & $20 \%$ & $34 \%$ & $32 \%$ \\
\hline Al inicio de la tarde $(03 \mathrm{pm}-06 \mathrm{pm})$ & $26 \%$ & $20 \%$ & $25 \%$ & $22 \%$ & $38 \%$ & $22 \%$ & $18 \%$ & $35 \%$ & $41 \%$ & $25 \%$ & $21 \%$ & $26 \%$ & $26 \%$ \\
\hline Al final de la tarde $(06 \mathrm{pm}-08 \mathrm{pm})$ & $27 \%$ & $26 \%$ & $32 \%$ & $30 \%$ & $16 \%$ & $35 \%$ & $24 \%$ & $30 \%$ & $38 \%$ & $22 \%$ & $17 \%$ & $35 \%$ & $31 \%$ \\
\hline Al inicio de la noche $(08 \mathrm{pm}-10 \mathrm{pm})$ & $49 \%$ & $55 \%$ & $55 \%$ & $45 \%$ & $51 \%$ & $45 \%$ & $52 \%$ & $46 \%$ & $26 \%$ & $45 \%$ & $58 \%$ & $46 \%$ & $58 \%$ \\
\hline Al final de la noche $(10 \mathrm{pm}-12 \mathrm{am})$ & $29 \%$ & $40 \%$ & $38 \%$ & $30 \%$ & $21 \%$ & $21 \%$ & $31 \%$ & $27 \%$ & $20 \%$ & $36 \%$ & $27 \%$ & $35 \%$ & $22 \%$ \\
\hline Después de la medianoche ( $12 \mathrm{am}-02 \mathrm{am})$ & $3 \%$ & $5 \%$ & $3 \%$ & $5 \%$ & $1 \%$ & $1 \%$ & $5 \%$ & $2 \%$ & $1 \%$ & $8 \%$ & $2 \%$ & $5 \%$ & $1 \%$ \\
\hline En la madrugada (02 am $-06 \mathrm{am})$ & & & & & $1 \%$ & $3 \%$ & - & $1 \%$ & - & - & $1 \%$ & - & $1 \%$ \\
\hline
\end{tabular}

Analizando el gráfico ubicado líneas arriba, podemos encontrar que el rango horario en el que la TV es más consumida es de $8 \mathrm{pm}$ a $10 \mathrm{pm}$, con un $45 \%$ en el NSE C y $51 \%$ en el NSE D. Horario más conocido como "prime" el cual posee los precios de pauta publicitaria más altos del mercado.

De acuerdo a la información adquirida en medición de alcance ${ }^{15}$ y un balance presupuestal que permita tener presencia en este medio sin dejar de lado la inversión en otras plataformas, se establece invertir en horarios de consumo que también tienen porcentajes considerables: horario de mediodía y final de la noche.

Dentro de ellos y el canal de TV seleccionado por ser el más consumido por el P.O, se seleccionan como programas de interés y el contenido de la pauta, América Noticias Noche (10.30pm) y En Boca de Todos (1pm). ${ }^{16}$

\section{América Noticias Noche}

Programa informativo conducido por Mávila Huertas y René Gastelumendi, periodistas reconocidos por el medio, quienes brindan a los televidentes los acontecimientos nacionales e internacionales actuales.

\footnotetext{
${ }^{15}$ Información adquirida por agencia de medios Publicis y presentada en anexos.

${ }^{16}$ Información adquirida por agencia de medios Publicis
} 


\section{$\underline{\text { En Boca de Todos }}$}

Programa magazine conducido por Maju Mantilla, Tula Rodriguez y Ricardo Rondon, brindan segmentos de espectáculos y concursos.

Inversión:

Canal: América TV

Programa y distribución:

América Noticias Noche (paquete de 1 mención de 20' y 01 Banner) 2 veces en el mes de enero

América Noticias Noche (paquete de 1 mención de 20' y 01 Banner) 3 veces en el mes de febrero

En Boca de Todos (paquete de grabación conductor en condominio 20' y 01 banner) 3 veces en el mes de marzo

Con esto, se tendrá una frecuencia de 9 veces en TV durante enero (a partir de quincena), febrero y marzo, meses seleccionados para comunicar y posicionar al proyecto y reforzar el lanzamiento de la campaña en general que dará inicio en el mes de diciembre con inversión en otras plataformas (como por ejemplo, radio). 


\subsubsection{Radio}

De acuerdo a la información actualizada de audiencia radial y alineada al consumo directo del P.O ${ }^{17}$ se evidencia que la radio con mayor audiencia es Karibeña, seguida de Radio Moda. Por lo que se invertirá en un spot radial con una duración de 20 segundos y una cantidad de 6 menciones diarias rotativamente.

Se plantea realizar las menciones diarias con una frecuencia 5 días aleatorios a la semana por una cantidad de 9 Semanas (la distribución calendario se encuentra en el link de piezas)

Spots compuestos:

Voz (Masculina)

Condominio Villa Atleta:

Contamos con departamentos $100 \%$ accesibles, áreas deportivas, un diseño amigable con el medio ambiente y además, ¡Tendrás las mejores opciones de pago gracias a los bonos Mivivienda! Condominio Villa Atleta: ¡Un condominio al alcance de todos! Visita nuestros departamentos en Av. Mariano Pastor de Sevilla - Villa El Salvador. Voz (Gladys Tejeda)

¡Hola! Soy Gladys Tejeda, medallista de Lima2019 y te invito a que recorramos juntos el condominio Villa Atleta. ¡Un condominio al alcance de todos! Diseño ecoamigable, áreas deportivas y opciones de pago flexibles pensadas para ti. Entérate de todos los detalles llamando al 2356000 o entra a nuestra web www.condominiovillaatleta.com.pe

\section{Efecto de sonido}

Música alegre, animada

Efecto de sonido

Música deportiva

\footnotetext{
${ }^{17}$ Información procesada adjunta en anexos.
} 


\subsection{3 $\mathrm{OOH}$}

Paneles publicitarios:

Se contratará a una agencia de producción de paneles publicitarios para la instalación por 5 o 6 meses ${ }^{18}$ ubicados en zonas estratégicas de Lima Sur. Considerando la afluencia de autos, medios de transporte público, zonas comerciales y transeúntes.

Se detallan los siguientes productos de publicidad exterior a producir y contratar el servicio para la campaña:

- $\quad$ Torre Unipolar iluminada 14.40 X 7.20mt (AV. LOS HEROES CDRA 6 FTE AL 670) x 5 meses

- $\quad$ Panel a doble cara 8.00 x 4.00mt (Av. Pastor Sevilla. 6 cruce Av. El Sol) x 6 meses

- $\quad$ Panel a doble cara iluminado 8.00 x 4.00mt (Av. Pan Sur antigua, a $100 \mathrm{mts}$ de la Av. El Sol) x 5 meses

- TORRE UNIPOLAR 14.40 X 7.20mt (Av. Pachacútec con Av. 26 de noviembre en Villa Maria del Triunfo) x 5 meses

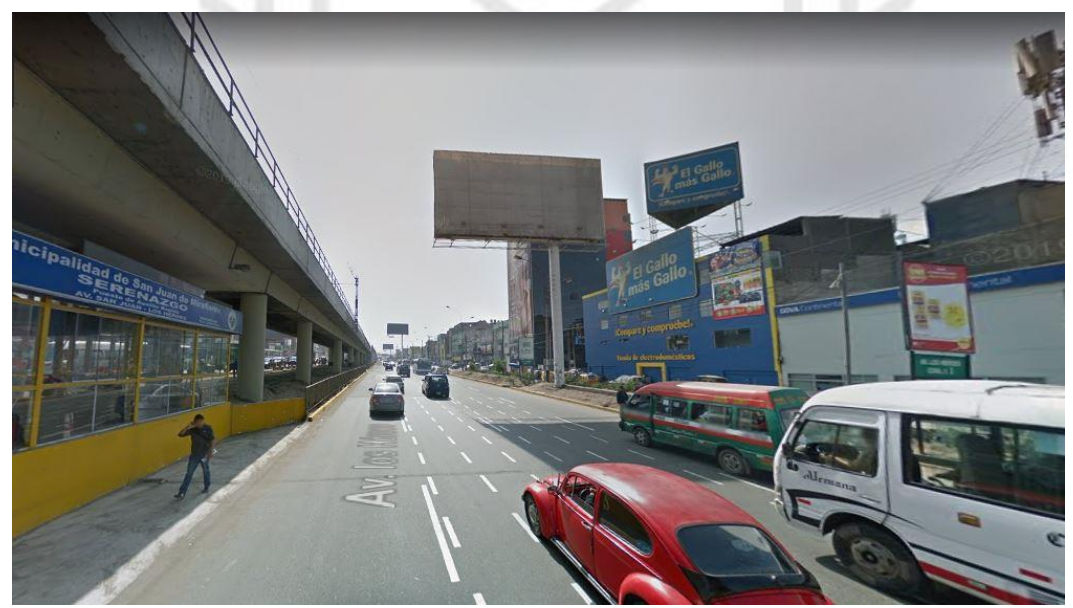

Fuente: Google Maps. Av. Los Heroes cdra 6)

\footnotetext{
${ }^{18}$ Detalle en el cronograma de medios (se encuentra en anexos al final del trabajo)
} 
El contenido de las vallas y paneles tendrá un tono de comunicación emocional (determinadas ubicaciones más grandes) y directo (brindando la distancia desde el punto hacia el Condominio Villa Atleta). De esta forma se hace al espectador un llamado a la acción, refuerzo de posicionamiento del proyecto, y gancho emocional que genere awareness.

Además se distribuirá una batería de señaléticas que destacan precios y áreas comunes del condominio. Éstas, también serán ubicadas en zonas clave como estaciones del Metro de Lima.

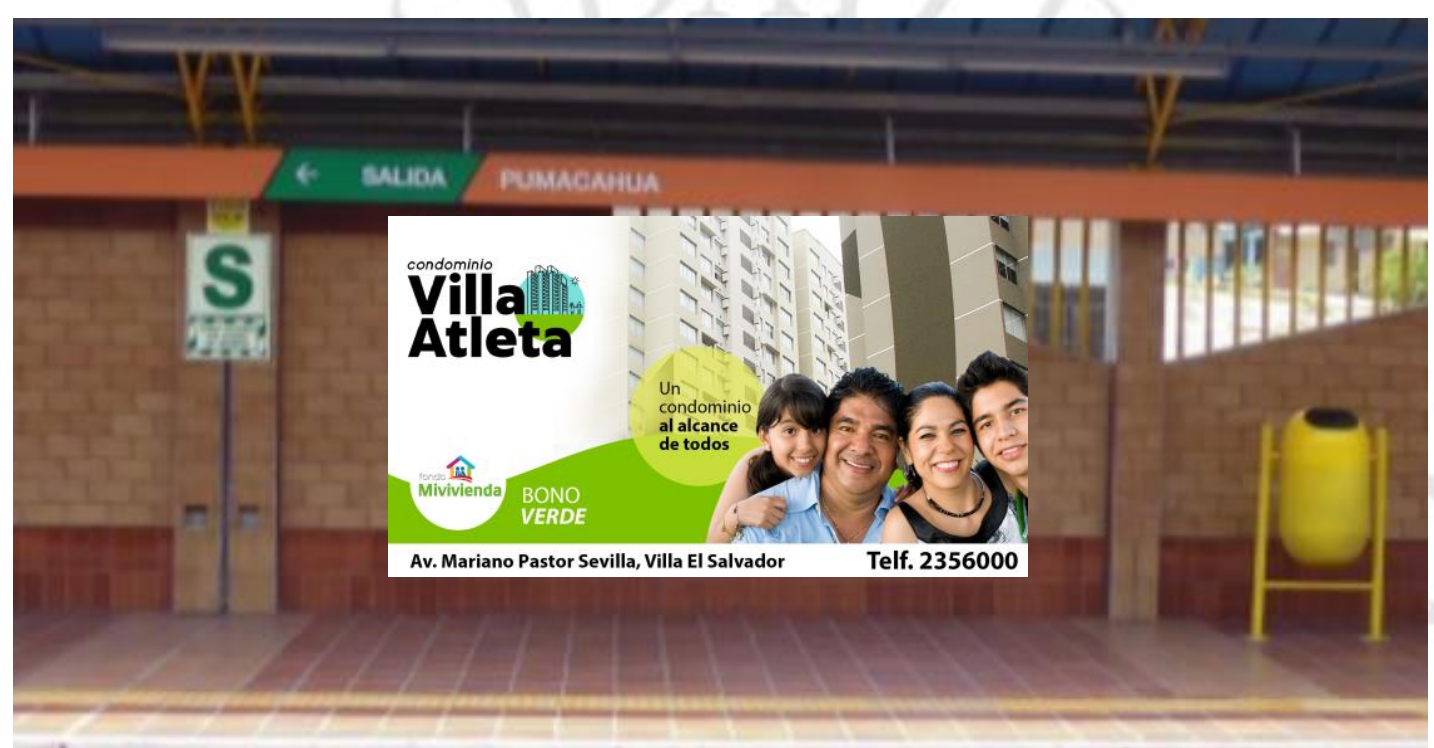

Fuente: Elaboración propia

- $\quad$ Estación Atocongo

- $\quad$ Estación Villa

- $\quad$ Estación Villa El Salvador

Además de mantener el concepto creativo como sostén de las piezas gráficas para $\mathrm{OOH}$, también se plantea utilizar una imagen familiar en donde el público objetivo logre verse reflejado. De esta manera, buscando humanizar y acercar más la propuesta a un posible consumidor. 


\subsubsection{Prensa escrita:}

Para prensa escrita, de acuerdo al consumo de diarios escritos por nuestro público objetivo, se definen las siguientes inversiones con Publireportajes o displays:

DIARIOS QUE ACOSTUMBRA A LEER CON FRECUENCIA

El Comercio y Gestión es el diario más leído en el NSE A, mientras que Trome lidera el mercado en los demás niveles.

\begin{tabular}{|c|c|c|c|c|c|c|c|c|c|c|c|c|c|}
\hline & \multirow{2}{*}{$\begin{array}{l}\text { Total } \\
2017\end{array}$} & \multicolumn{5}{|c|}{ Nivel Socioeconómico } & \multicolumn{2}{|c|}{ Género } & \multicolumn{5}{|c|}{ Edad } \\
\hline & & A & B & c & D & E & Mas. & Fem & 12 a 17 & 18 a 24 & 25 a 39 & 40 a 54 & 55 a 70 \\
\hline Trome & $55 \%$ & $22 \%$ & $62 \%$ & $64 \%$ & $38 \%$ & $60 \%$ & $61 \%$ & $50 \%$ & $64 \%$ & $58 \%$ & $56 \%$ & $42 \%$ & $68 \%$ \\
\hline El Comercio & $31 \%$ & $75 \%$ & $33 \%$ & $32 \%$ & $21 \%$ & $20 \%$ & $31 \%$ & $30 \%$ & $27 \%$ & $31 \%$ & $35 \%$ & $32 \%$ & $20 \%$ \\
\hline Ojo & $24 \%$ & $3 \%$ & $22 \%$ & $29 \%$ & $22 \%$ & $17 \%$ & $20 \%$ & $27 \%$ & $13 \%$ & $14 \%$ & $23 \%$ & $33 \%$ & $27 \%$ \\
\hline Correo & $10 \%$ & $15 \%$ & $18 \%$ & $6 \%$ & $13 \%$ & $3 \%$ & $13 \%$ & $8 \%$ & $7 \%$ & $11 \%$ & $13 \%$ & $5 \%$ & $16 \%$ \\
\hline Depor & $9 \%$ & $4 \%$ & $5 \%$ & $8 \%$ & $12 \%$ & $19 \%$ & $16 \%$ & $2 \%$ & $26 \%$ & $22 \%$ & $6 \%$ & - & $9 \%$ \\
\hline La República & $9 \%$ & $18 \%$ & $14 \%$ & $7 \%$ & $6 \%$ & $3 \%$ & $9 \%$ & $8 \%$ & $2 \%$ & $17 \%$ & $8 \%$ & $4 \%$ & $13 \%$ \\
\hline El Bocón & $8 \%$ & $5 \%$ & $4 \%$ & $13 \%$ & $5 \%$ & $1 \%$ & $15 \%$ & - & $2 \%$ & $16 \%$ & $7 \%$ & $3 \%$ & $12 \%$ \\
\hline Perú.21 & $7 \%$ & $18 \%$ & $12 \%$ & $5 \%$ & $4 \%$ & $1 \%$ & $9 \%$ & $4 \%$ & $9 \%$ & $18 \%$ & $2 \%$ & $4 \%$ & $10 \%$ \\
\hline El Popular & $7 \%$ & $3 \%$ & $1 \%$ & $13 \%$ & - & $10 \%$ & $2 \%$ & $11 \%$ & $18 \%$ & $1 \%$ & $1 \%$ & $13 \%$ & $8 \%$ \\
\hline Gestión & $5 \%$ & $27 \%$ & $6 \%$ & - & $8 \%$ & - & $4 \%$ & $6 \%$ & - & $6 \%$ & $8 \%$ & $1 \%$ & $5 \%$ \\
\hline Líbero & $3 \%$ & $2 \%$ & $5 \%$ & - & $7 \%$ & $3 \%$ & $6 \%$ & - & - & $4 \%$ & $1 \%$ & $7 \%$ & $3 \%$ \\
\hline Extra & $2 \%$ & - & $1 \%$ & $2 \%$ & $5 \%$ & - & $1 \%$ & $3 \%$ & - & - & - & $6 \%$ & $6 \%$ \\
\hline Publimetro & $1 \%$ & $4 \%$ & $2 \%$ & - & - & - & $1 \%$ & - & - & $3 \%$ & - & - & $1 \%$ \\
\hline
\end{tabular}

Como observamos en el grafico anterior, el diario más consumido por los NSE C y D es Trome (64\% y 38\% respectivamente), seguido del diario El Comercio y en tercer lugar el diario Ojo.

\section{Diario El Trome}

Para el caso del diario El Trome, que es el medio más consumido en términos generales por nuestro público objetivo. Se contarán espacios en Publireportaje en TROME LIMA por dos fechas y espacios en Publireportajes en TROME ZONAL "Lima Sur" por 4 fechas para realizas una focalización del P.O de manera geográfica. 


\section{Eldiario del nuevo peruano 4}

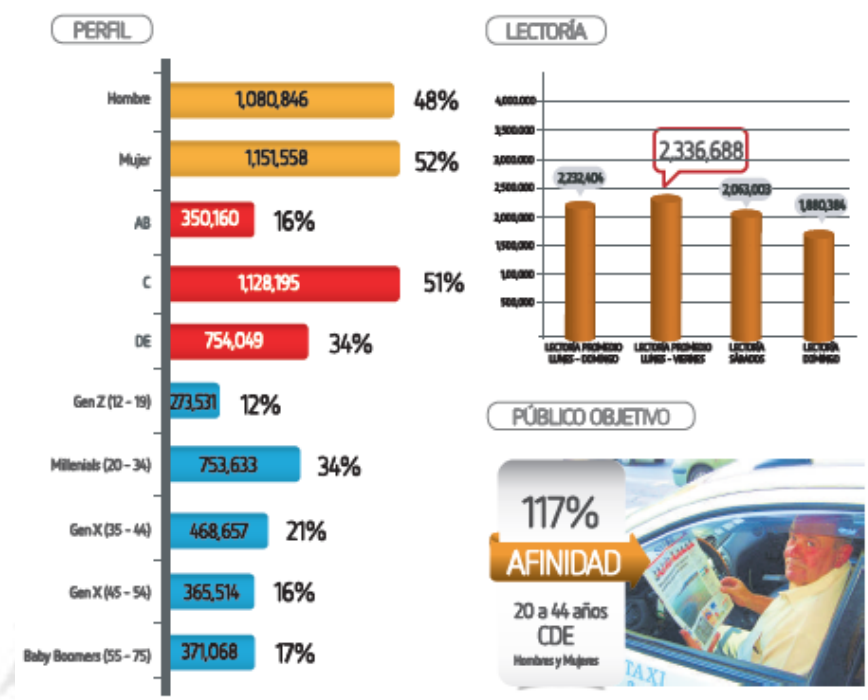

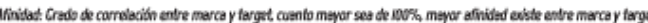

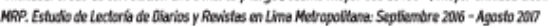

\section{Diario Ojo}

Se comprará un espacio en Publireportaje en el diario a nivel nacional por 8 fechas distribuidas en el cronograma de inversión de medios. La elección de éste diario también se vincula principalmente por la afinidad que tiene el público objetivo (en este caso un acercamiento más puntual a amas de casa C y D) y además un análisis y balance presupuestal que permite tener alcance para la inversión de más de un diario, siendo Ojo el elegido.
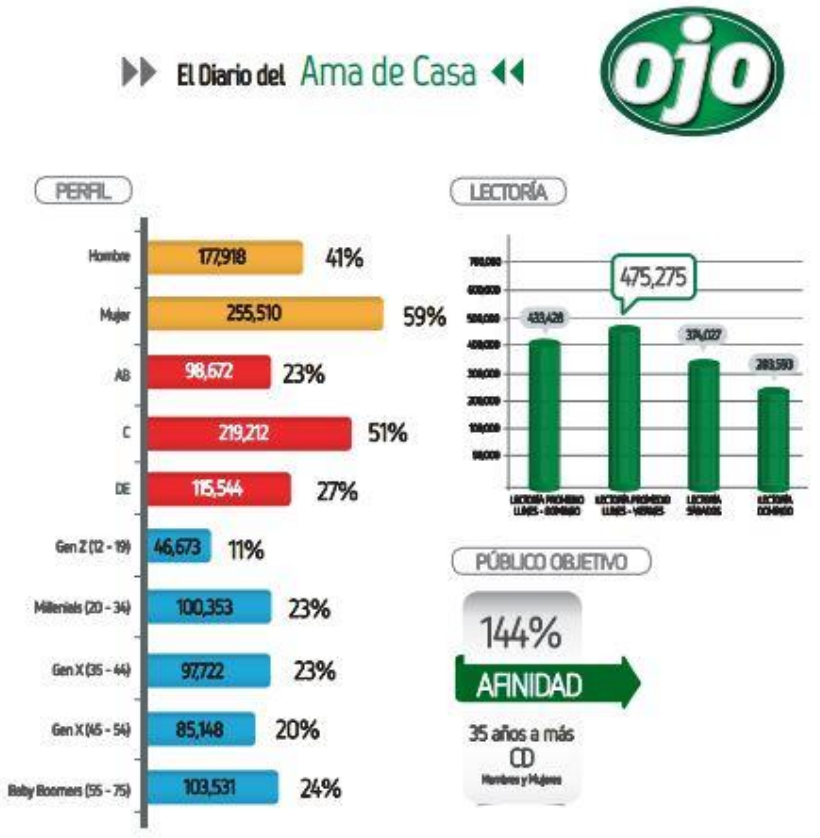

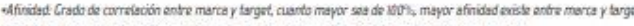




\subsection{Medios Digitales}

\subsubsection{Redes Sociales}

Como se mencionó anteriormente en el análisis del público objetivo respecto a su consumo de medios y tecnología, vemos que el internauta peruano sigue en crecimiento, teniendo a las redes sociales en una gran posición que destaca y que evidencia el gran impacto que tiene frente a sus usuarios y el gran poder que posee con la herramienta de segmentación. Es por ello, que se selecciona la red social más consumida: Facebook y la inversión además de Instagram para situarnos más cercanos con adultos jóvenes y el inicio de rango de edad de nuestro público objetivo.

\section{$\underline{\text { Facebook }}$}

La página de Facebook tendrá como objetivo principal generar comunidad de usuario y la captación de leads, así como información útil para el público interesado en la adquisición de viviendas propias, modos de financiamiento, tips para el hogar, entre otros.

Se publicará como contenido audiovisual, se establecerá un pequeño programa con el apoyo de medallistas que nos harán conocer virtualmente el condominio y sus características, también se publicarán micro videos de 15 a 20 segundos. Se realizarán sorteos con premios, transmisiones en vivo de los eventos con los medallitas y álbumes de fotos.

Página de Facebook: https://www.facebook.com/condominiovillaatleta/ 


\section{Instagram}

Como se menciona anteriormente, es importante tener ésta plataforma para cualquier interacción por un público millenial que tome interés por la adquisición de viviendas, y a su vez, genere influencia en sus familiares si el caso es de un adolescente

Debemos estar presente en todos los medios digitales posibles para las búsquedas que pueda realizar el posible consumidor. Principalmente, el público juvenil.

La presencia del contenido será de carácter visual y estético, con contenido útil y ameno para el usuario, con un tono de comunicación más coloquial que otros medios ya que el público consumidor es más joven. ${ }^{19}$

También se reforzará el contenido con medallistas de Lima 2019 que generen "Instagram stories" ${ }^{20}$ remitiendo y generando interactividad entre sus cuentas y la cuenta oficial de Villa Atleta.

También es importante resaltar que según estudios realizados recientemente, existe un grado de simultaneidad en el uso de dos medios de comunicación. Como vemos en el siguiente cuadro elaborado por Ipsos, el $68 \%$ de los usuarios ven televisión y utilizan su Smartphone al mismo tiempo, lo que evidencia que el consumo del medio tradicional tan determinado en décadas empieza a tener gran competencia no solo por reemplazo del consumo del medio, sino por un recojo de información comercial y estadística con un gran margen de error.

\footnotetext{
${ }^{19}$ Se detalla un bosquejo del perfil de Instagram en el link compartido

${ }^{20}$ Algunos ejemplos de Instagram stories en el link compartido
} 


\section{Uso simultáneo de dispositivos}

\section{(TV y smartphone)}

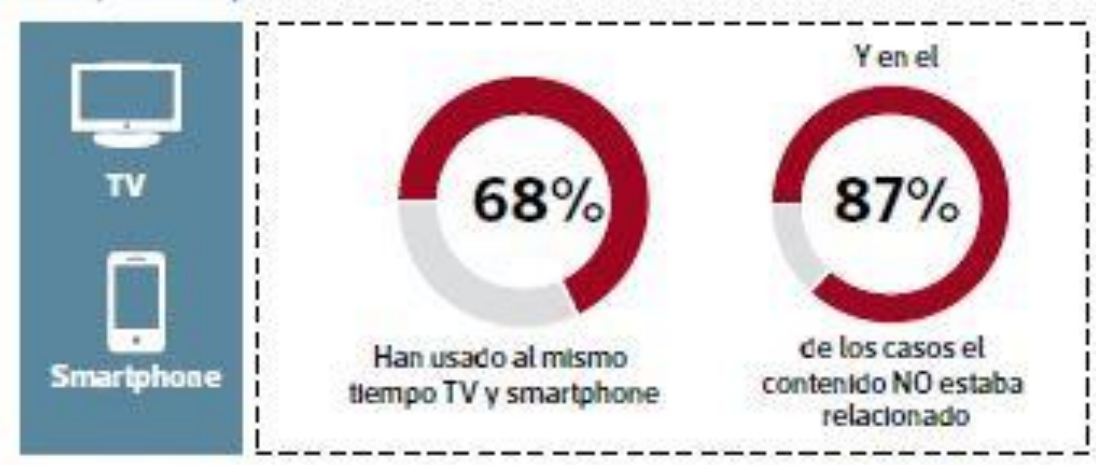

Fuente: Ipsos, 2018.

El público de 25 a 35 años que recién se empieza a interesarse sobre la adquisición de viviendas y no tiene mayor conocimiento sobre los créditos hipotecarios, las facilidades de compra de viviendas en el Perú, entre otros, puede ser un público de rápida captación por esta red. Por otro lado, al ser una red de fácil uso e inmediata, permitirá poder recopilar información como leads al realizar sorteos o dinámicas sencillas características de Instagram.

\subsubsection{Página Web}

Para el proyecto del condominio Villa Atleta, la presencia de una página web es imprescindible Internet, medio que permite medir los resultados de las campañas de publicidad emprendidas de manera inmediata, lo cual garantiza en gran medida llegar a conclusiones acertadas y un retorno de la inversión bastante elevado, o al menos, previsible. Se utilizará una plataforma de lectura amigable y ligera. Con muchos gráficos y fotografías del proyecto. Por otro lado se brindará información de relevancia (teléfono, dirección del complejo, datos de contacto) en diversas pastillas de comunicación dentro de la plataforma digital, para evitar vacíos de lectura o desinformación por parte del público objetivo. 
También se plantea contar con un chatbot que permita absolver las dudas que tengan los clientes interesados y así permita a su vez, la generación de leads constantemente.

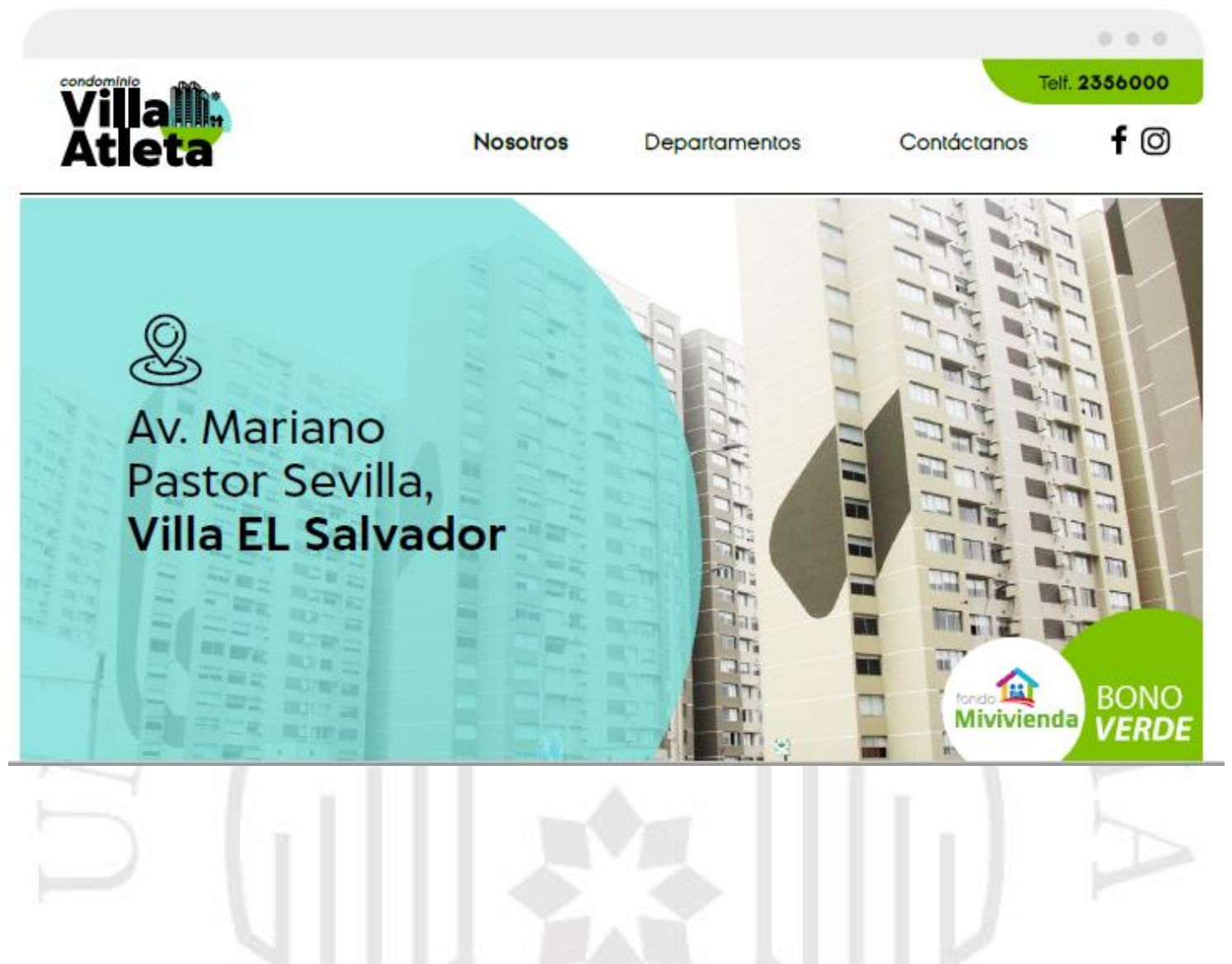

\subsubsection{Inversión en Plataformas inmobiliarias}

Se plantea considerar una inversión en plataformas inmobiliarias que vienen mostrando un uniforme crecimiento. Si bien es cierto se invertirá con mayor fuerza en otros medios digitales, es considerable mantenerse cerca a publicaciones de venta de condominios, departamentos, viviendas, lotes, o incluso propuestas de alquiler (venta indirecta) para no retirarnos de la mente del cliente potencial.

La interactividad, fácil uso, y fácil acceso desde cualquier momento o lugar del usuario internauta permite que pueda revisar la información una y otra vez sin necesidad de moverse de donde está. Además las opciones de filtros también muestran ser una gran herramienta para que el consumidor encuentre rápidamente lo que está buscando. 
"Hoy en día ya muchos proyectos de vivienda multifamiliar son ofertados vía plataformas online y cada vez son más las personas que consideran y buscan este tipo de oferta, porque el canal online brinda la posibilidad de buscar, comparar y acceder, en muchos casos, a un mejor precio. Todo realizado desde la tranquilidad de la oficina o el hogar" (Rafael Portilla, Country Manager de OLX, 2018)

La lectura fácil y la interactividad, así como las imágenes y hasta videos que brindan información completa sobre el inmueble, permite al usuario revisar la información al ritmo que desee y revisarlo reiteradas veces. Para el condominio Villa Atleta, se considerará la inversión en 2 plataformas inmobiliarias: adondevivir.com y Urbania.

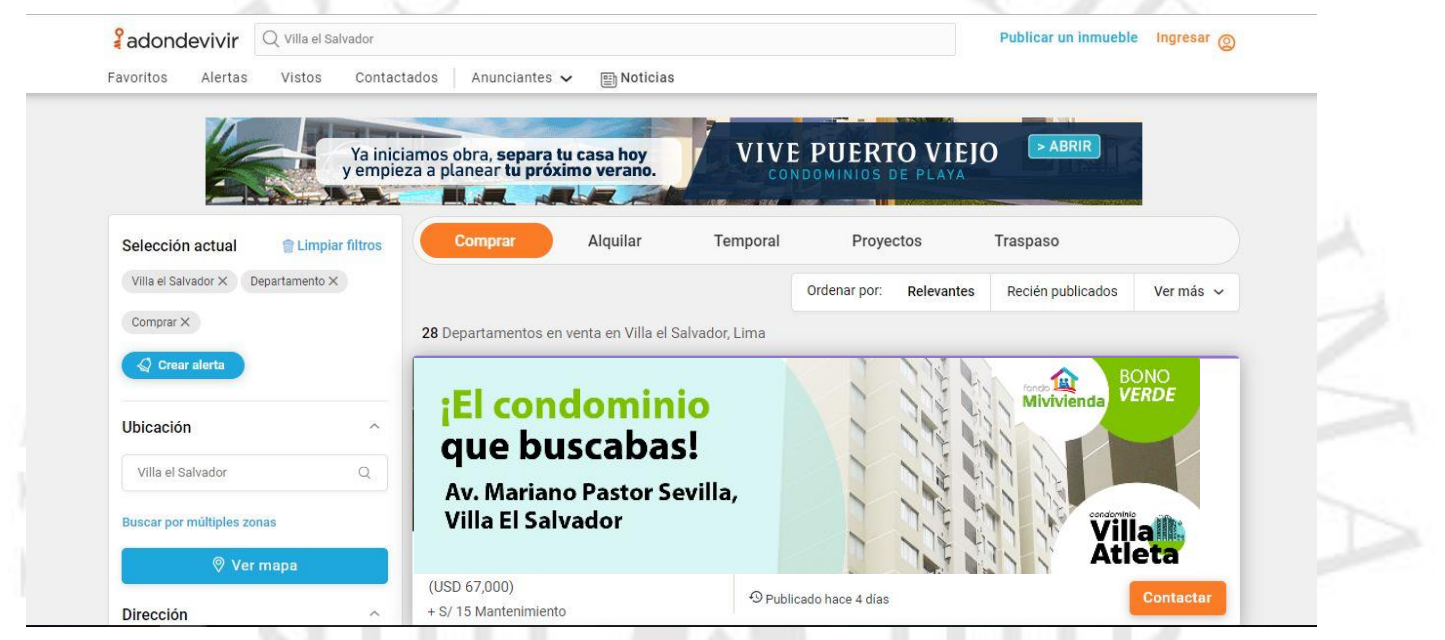

Fuente: Elaboración propia

\subsubsection{Google Adds}

Se realizará una inversión mensual durante los 6 meses de campaña dirigido a un mix entre Google Búsqueda y Google Display (que se irá evaluando durante el desarrollo de la campaña). Estas herramientas permitirán rápidamente figurar para el consumidor con intención de compra, ya que ha realizado la búsqueda inicial en Google de las palabras asociadas a la inversión del proyecto. Es decir, al seleccionar palabras como “Condominio" "Villa" "Panamericanos" "Departamentos" la página web de Condominio Villa Atleta, así como las publicaciones realizadas en plataformas inmobiliarias, figurarán instantáneamente en los primeros resultados de la búsqueda, posicionándonos así, rápidamente como la respuesta que el cliente potencial estaba buscando. 
Por otro lado, en lo referente a Google Display, se realizará una inversión más cautelosa para ir evaluando el comportamiento (medido en impresiones de los usuarios) durante los primeros meses.

A pesar de que ésta opción publicitaría permite la colocación de un display visual, está orientada a la oferta, lo que no garantiza en primera instancia haber llegado a nuestro P.O con intención de compra.

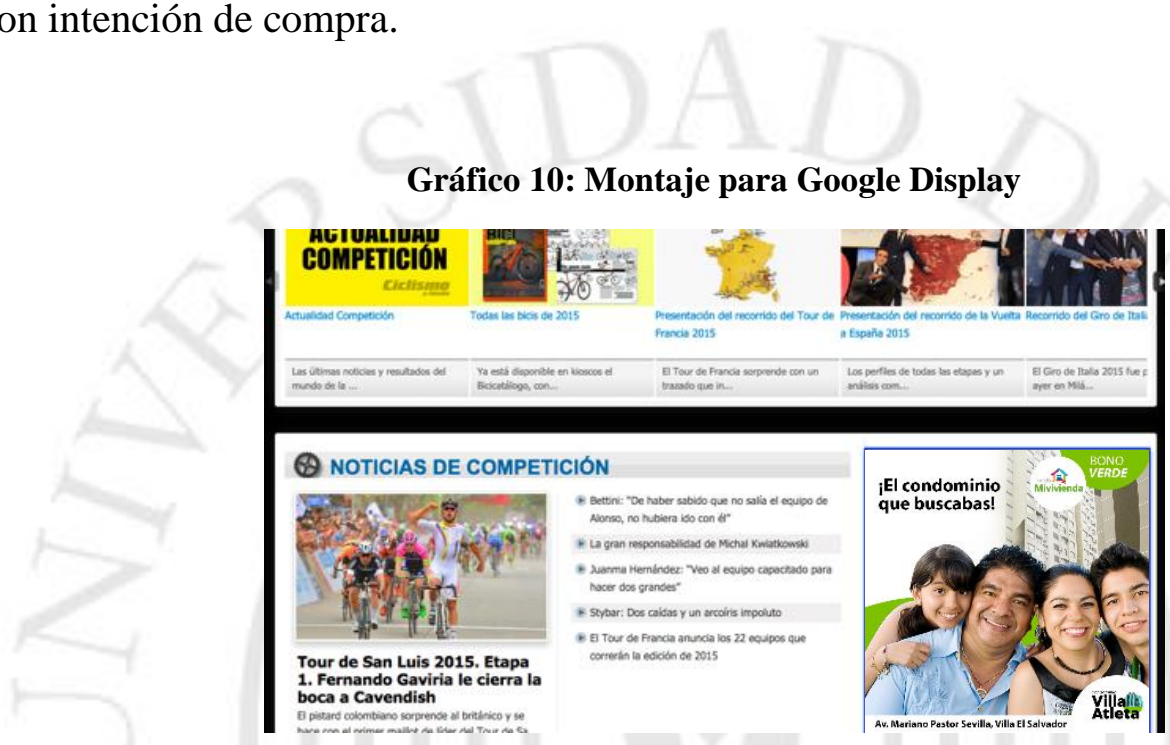

Fuente: Elaboración propia

\subsection{BTL}

Se realizará la instalación de stands o módulos informativos con promotores de venta en ubicaciones estratégicas de gran afluencia de público.

Se determinan los siguientes puntos de interés:

- $\quad$ Mall del Sur

- $\quad$ Parque Zonal Huascar

- $\quad$ Parque Zonal Huayna Capac

- $\quad$ Complejo Deportivo Andres Av. Caceres

- $\quad$ Mercado Unicachi

- $\quad$ Plaza de Armas de Villa Maria del Triunfo y San Juan de Miraflores

- Zona comercial cerca al puente Atocongo

- $\quad$ Real Plaza Villa Maria del Triunfo 


\section{- $\quad$ Parque Industrial}

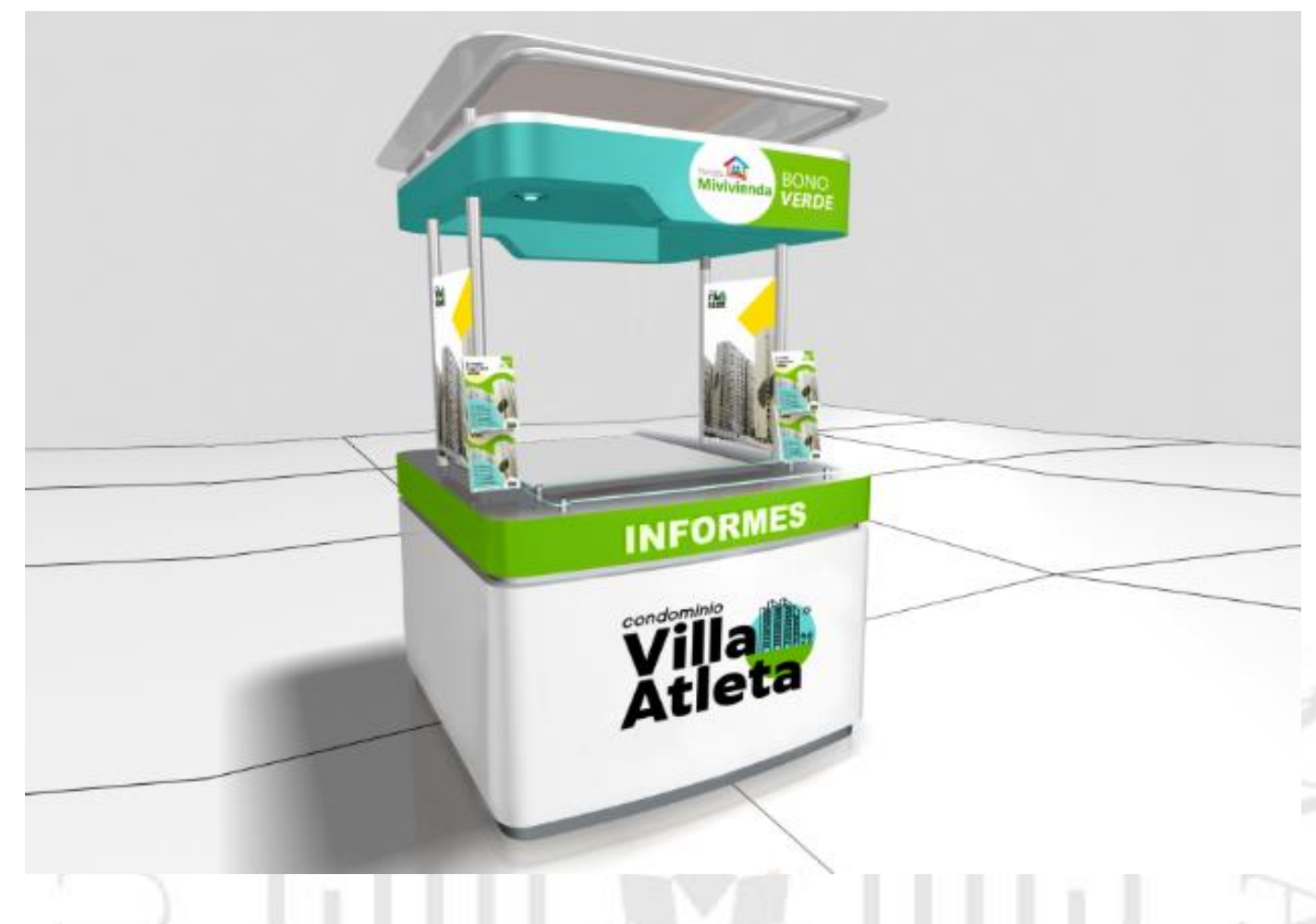

Se contarán con promotores de venta (uno para cada módulo) que brindarán información, generarán leads, contestarán dudas, orientaran entre los días Viernes y Domingos de las semanas incluidas dentro de los meses de la campaña. ${ }^{21}$

Adicionalmente a ello, gracias a los insights obtenidos, de identifica que el P.O interesado a veces no cuenta con los medios y el tiempo para dirigirse a realizas la visita y consultas sobre el bien inmueble (apuntando en particular, a los vecinos de distritos aledaños a Villa El Salvador)

Los fines de semana, el P.O invierte su tiempo en pasear con sus familiares, ir a parques zonales o centros comerciales y estar al aire libre. Por lo que se propone la accesibilidad de llegar al Condominio Villa Atleta de manera gratuita, rápida y fácil.

“Te llevamos a conocer el depa de tus sueños" es la pastilla que se utilizará para generar intriga a quienes visualizan la custer por zonas periféricas al condominio y además, desde

${ }^{21}$ Se brinda detalle en el Flow de medios en el link de piezas. 
la experiencia inicial permite posicional a la mente del consumidor con la fuerte presencia de la identidad del proyecto.

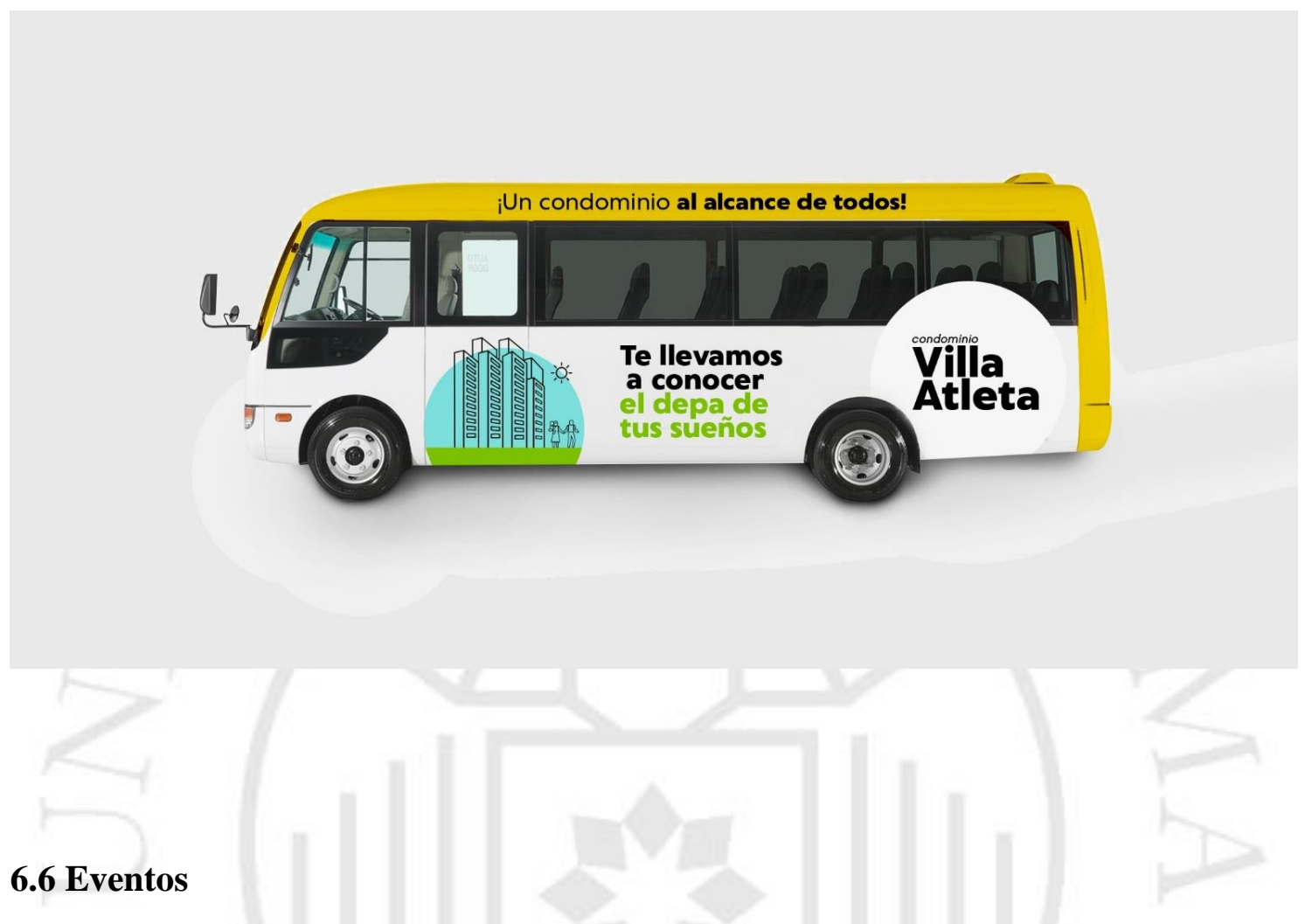

Otro insight importante que se destaca del estudio y análisis realizado, es el gran interés empírico del P.O.

Muestran total interés por actividades, eventos y experiencias tanto vinculadas a temas que les permitan ampliar sus conocimientos sobre tópicos de interés (en este caso puede orientarse a Lima 2019, a los medallistas peruanos, pero a su vez a temas más serios como las formas de financiamiento, el crédito Mivivienda, entre otros)

Es por ello, que dentro de la estrategia se plantea realizar "Visita Guiadas" por Medallistas peruanos que estén bajo nuestro auspicio o sponsor.

En esta oportunidad y como se menciona líneas arriba, se propone contar con la participación de Gladys Tejeda (deportista peruana medallista de Lima 2019) y Jesus Salvá (paradeportista peruano medallista de Lima 2019 como protagonistas. Sin embargo se plantea invitar a otros deportistas interesados en participar en actividades de este corte 
que los vincula con un público aspiracional y de constante orgullo frente a estos deportistas de su mismo país.

\subsection{Sponsor a deportistas}

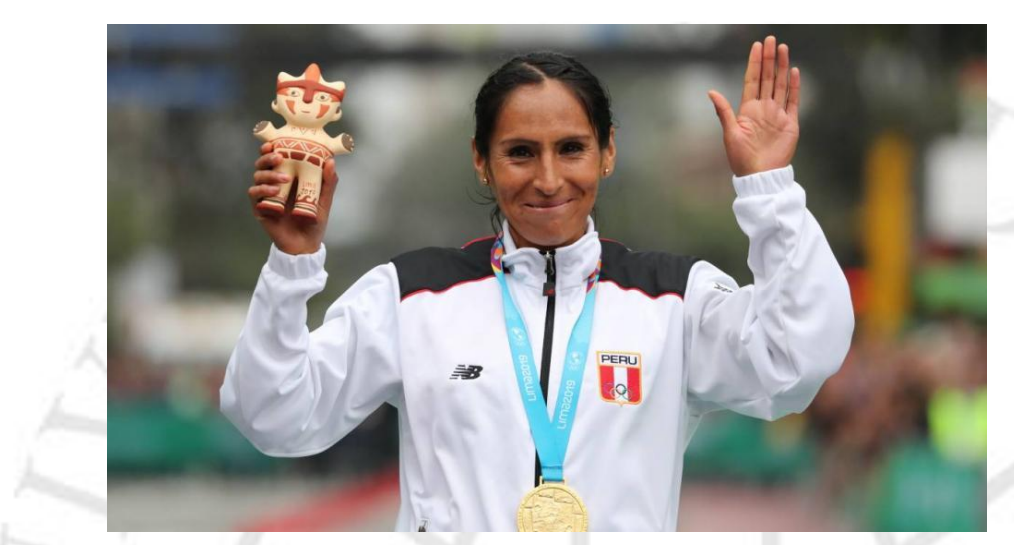

Fuente: GEC

\section{Gladys Tejeda}

Como parte de la estrategia de medios, se auspiciará a la maratonista peruana Gladys Tejeda. Con la coyuntura de los Juegos Lima 2019, el mantenimiento del sentimiento de orgullo y reconocimiento a los deportistas exitosos que consiguieron grandes logros para nuestra sociedad, y además con el interés y afinidad del P.O hacia personas de influencia, sobretodo quienes son destacados y reconocidos por logros llenos de valores y que evidencian un gran avance para el país, Gladys Tejeda será parte de la imagen para acciones puntuales de medios dentro de la estrategia.

"Hay un desplazamiento de la persona común al elegido [deportista] y si este representante consigue logros importantes, entonces la transmisión inmediata es que el logro es de todos. Se interioriza de que ha sido un trabajo en equipo" (Castro, El Comercio, 2019)

Por otro lado, como se comenta en medios digitales, el análisis lleva también a identificar una gran sensación de reivindicación étnica, cultural e inclusive socioeconómica en nuestra sociedad. 
"Hemos visto cómo una persona de origen huanca, un grupo poblacional que ha sido invisible hasta ahora, pasa a ser representante del país. Esto es muy rico para la sociedad porque visibiliza la potencia de la diversidad", dijo Castro para el Comercio.

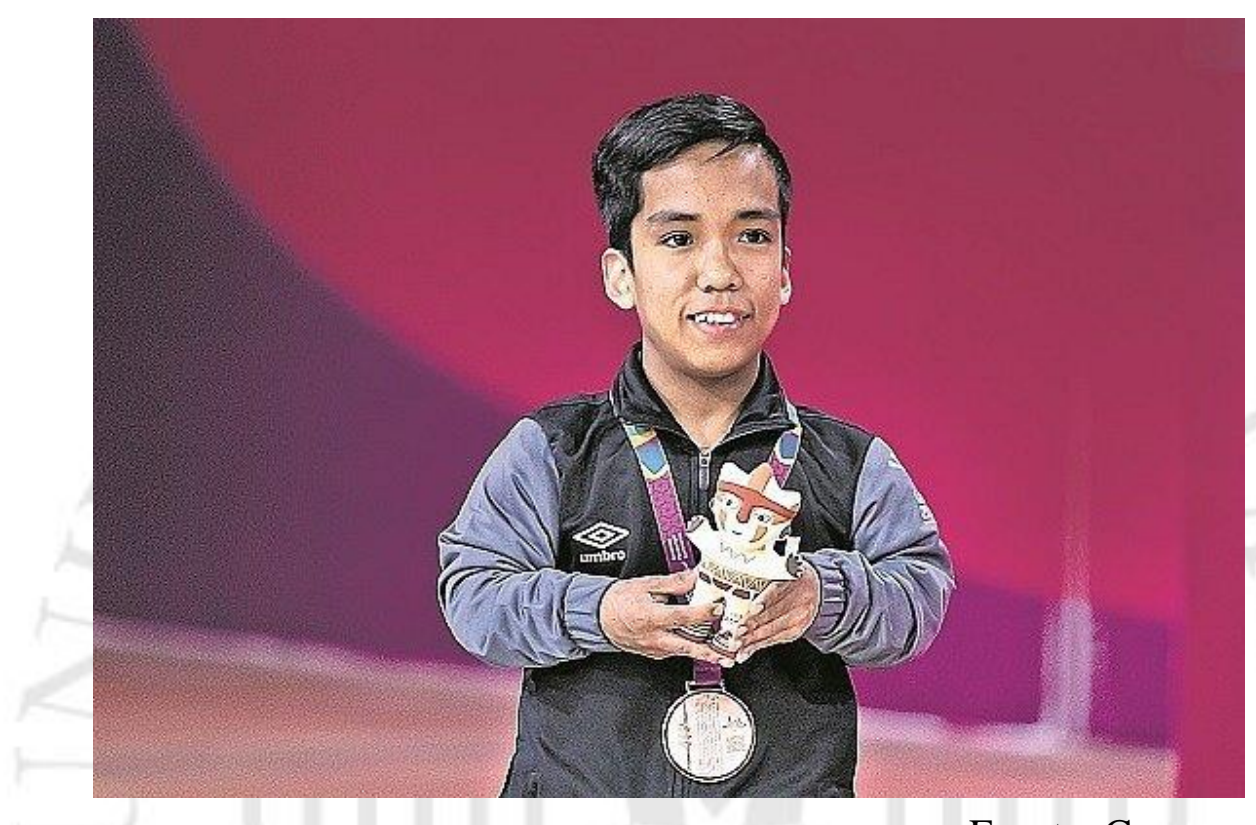

Fuente: Correo

\section{Jesus Salvá}

Otro deportista peruano que también se incorporará a la acción de auspicio, es el paradeportista Jesus Salva.

Medallista en parabadminton de Lima 2019, permite que tanto él como nuevos atletas con discapacidades físicas puedan destacarse, vincularse de una forma más horizontal con la población y esto genere la inclusión que busca el Condominio Villa Atleta como parte de sus valores de marca.

"La participación de nuestros atletas en las diversas competencias internacionales han debido ser financiadas por ellos mismos o con el apoyo de la actividad privada, pues no ha habido ningún apoyo estatal, sin embargo, los resultados obtenido han sido mucho mejores, en términos de triunfos y medallas que los de los deportistas sin discapacidad"

(Huerta, 2006) 


\section{"Recorre la Villa Atleta junto a Gladys Tejeda”}

Se propone realizar un evento en día familiar, con una difusión y convocatoria ya más focalizada (obtenida por leads entre los primeros meses) la que permitirá afianzar y fortalecer el vínculo con los potenciales clientes.

En el evento, los participantes podrán conocer a la medallista peruana, tomarse fotos con ella. Y determinados grupos seleccionados conocerán los departamentos, las áreas comunes

Además, otra acción interesante para este evento, es la instalación de una "miniferia" donde se invitaran a las principales entidades financieras (bancos y cajas rurales y municipales) a que participen y puedas orientar al público interesado sobre las características y requisitos para el financiamiento a través del nuevo crédito Mivivienda. Se propone permitirle al público potencial, realizar simulaciones con las entidades financieras, resolver dudas, establecer contactos claves y además tener una experiencia familiar amena que siempre recordarán.

\subsection{Relaciones Públicas}

Se contratará una agencia de PR para dar soporte a la cobertura de los eventos puntuales con medallistas de Lima 2019 dentro del condominio, esto como parte de la imagen, puntualmente concentrado en eventos para el target y de identificación con el tema de la idea de "depa propio", tomen interés por cubrir dicha información/primicia de manera orgánica. Ésta noticia va a llevar al espectador a interesarse por el proyecto e investigar un poco más acerca de él, lo que sería reforzado con la inversión en otros medios permanentes como las RRSS, señalética y los módulos informativos.

La relación colaborativa entre los medios y el condominio Villa Atleta, permitiría la expansión de información a través de la narración de logros por los medallistas que han 
sido reconocidos y hasta tomados como ejemplos por la población peruana. Definitivamente se apuesta por que sea un gran gancho emocional y de orgullo.

\subsection{Distribución presupuesto}

A continuación se detalla la distribución del presupuesto estimado (s/. 500,000.00) para el mix de medios según un análisis exhaustivo del consumo de los mismo por el público objetivo viéndolo de manera macro, y en algunos casos, focalizado según la zona geográfica. (Lima Sur)

El presupuesto se adjunta e incluye en el link de las piezas y el material empleado para la campaña:

https://www.dropbox.com/sh/0bqy3ok7xis1qsu/AACJFzYj03orGbHluVNxFlUDa?dl=0

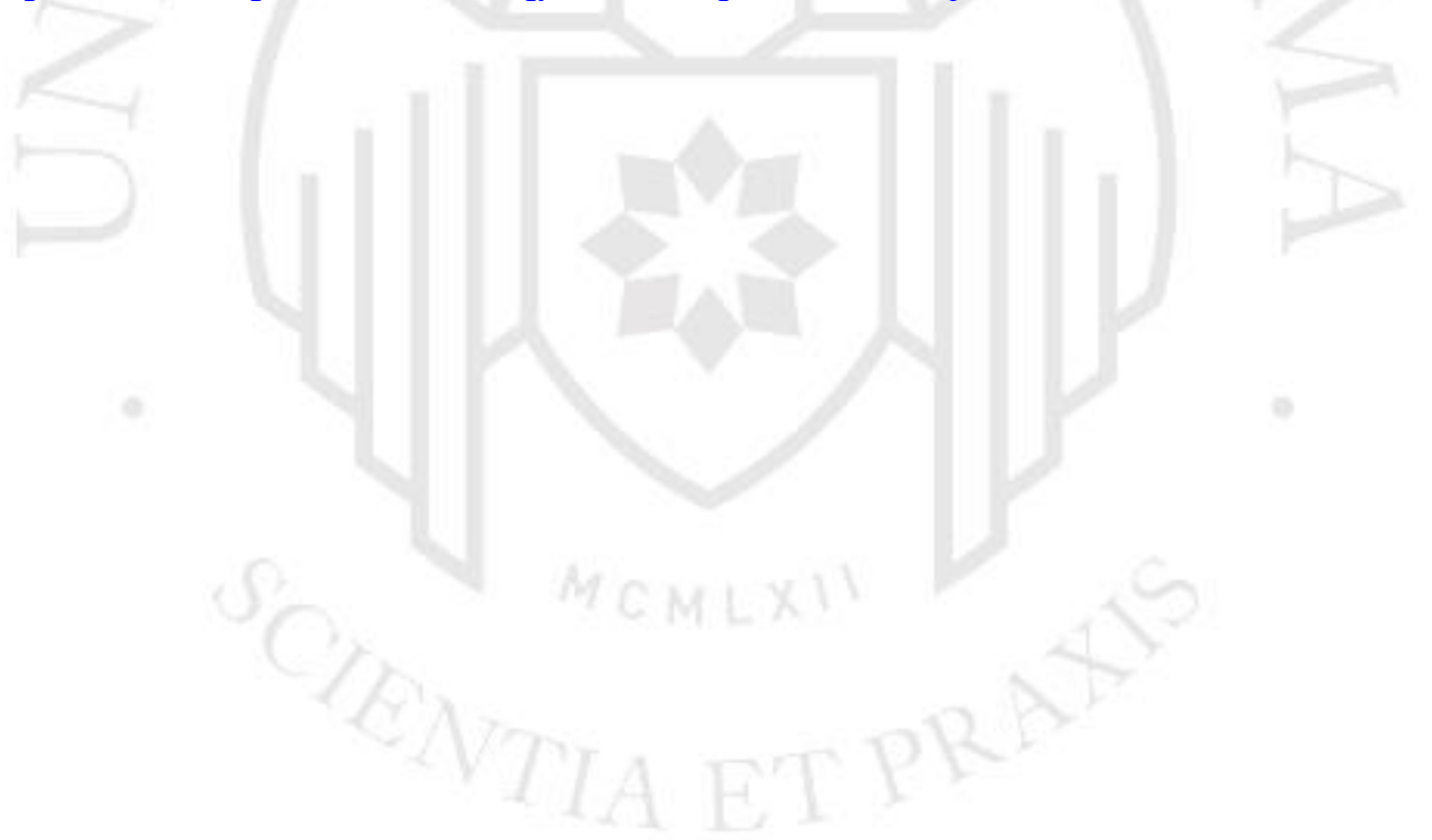




\section{CONCLUSIONES}

- La identificación del foco dentro público objetivo establecido ha sido fundamental para la ubicación y delimitación territorial y de geolocalización de muchos medios y plataformas de marketing que van a ser más efectivas bajo ésta estrategia.

- De acuerdo a las herramientas de investigación utilizadas para el público objetivo hay un gran hallazgo que el proyecto "Villa Atleta" debe de reforzar con el marketing de experiencias y eventos propuestos dentro de la campaña de comunicaciones, y es justamente enfocarse en un proceso de "reivindicación" con la población, sobretodo de Lima Sur, la que ha tenido mucho ruido respecto a la información desde la planificación del proyecto, la rápida gestion y ejecución, y justamente su futuro y destino, que ahora se va a confirmar, que es la venta totalmente abierta a cualquier persona natural que tenga el anhelo de una vivienda propia.

- El fuerte insight del "legado urbano" o "hito histórico" de éste complejo habitacional ubicado en un distrito emergente de nuestra ciudad, es una gran promesa y contenido que el marketing de Villa Atleta debe saber tomar provecho, tanto con la campaña que se propone, pero también y no menos importante, con la comunicación face to face que realizan los promotores de venta y el canal de call center, quienes agendan citas, fidelizan clientes y podrían sembrar futuros promotores del condominio para aumentar las ventas. 


\section{RECOMENDACIONES}

- Es fundamental transmitir confianza, veracidad, transparencia para este público. Esto se puede lograr con la formalidad que requiere el proceso de compra y asesoría sobre el financiamiento que un potencial cliente podría necesitar.

- Las acciones de marketing de carácter empírico (como BTL o visitas guiadas) pueden ser pieza clave para reforzar la venta de los departamentos durante el segundo trimestre si es necesario. Lo que podría requerir una inversión adicional en dichas acciones. (considerando que se utiliza el 100\% del presupuesto establecido desde el inicio de la campaña)

- Si el área financiera autoriza, realizar convenio/alianza estrategia con entidades financieras que soporten la veracidad del condominio, considerando que dichas EF suelen requerir descuentos en los precios de los departamentos.

- El servicio de agendado de visitas a los departamentos modelos, así como el servicio postventa (ambos pertenecientes al área comercial de un proyecto inmobiliario) es de suma importancia y deben ser desarrollados exitosamente para asegurar la fidelización de comunidades de clientes que se pueden volver los principales promotores del complejo residencial. 


\section{REFERENCIAS}

Alarcón, K. S. (8 de Diciembre de 2018). Villa panamericana, un legado lleno de oportunidades. Lima. Obtenido de https://peru21.pe/opinion/villa-panamericanalegado-lleno-oportunidades-445542-noticia/

Andina Agencia Peruana de Noticias. (6 de Septiembre de 2018). Lima 2019: viviendas cercanas a Villa de Atletas se revalorizarán en 60\%. Lima. Obtenido de https://andina.pe/agencia/video-lima-2019-viviendas-cercanas-a-villa-atletas-serevalorizaran-60-45085.aspx

Arellano, R. (2010). Al medio hay sitio. El crecimiento social según los Estilos de Vida. Lima: Planeta.

El Comercio. (26 de Abril de 2017). Limeños y chalacos se preocupan más por el medio ambiente. Lima. Obtenido de https://elcomercio.pe/peru/limenoschalacos-preocupan-medio-ambiente-416974

El Comercio. (9 de Septiembre de 2018). Censos 2017: el 10\% de los peruanos tiene algún tipo de discapacidad. Lima. Obtenido de https://elcomercio.pe/peru/censos-2017-10-peruanos-tipo-discapacidad-noticia555610

García, E. (11 de Julio de 2019). Ahora se desembolsan créditos hipotecarios hasta en un día. Lima. Obtenido de https://gestion.pe/tu-dinero/desembolsan-creditoshipotecarios-dia-272918-noticia/

García, E. (15 de Julio de 2019). Personas que solicitan crédito Mivivienda ganan más de S/ 2,000. Lima. Obtenido de https://gestion.pe/tu-dinero/finanzaspersonales/personas-solicitan-credito-mivivienda-ganan-s-2-000-273153noticia/

García, E. (15 de Julio de 2019). Personas que solicitan crédito Mivivienda ganan más de S/ 2,000. Lima. Obtenido de https://gestion.pe/tu-dinero/finanzaspersonales/personas-solicitan-credito-mivivienda-ganan-s-2-000-273153noticia/

Gestión. (22 de Junio de 2018). ¿Piensa vender su vivienda online? Este es el tiempo que demora. Lima. Obtenido de https://gestion.pe/tu-dinero/inmobiliarias/olxventa-viviendas-online-peru-236630-noticia/

Gestión. (24 de Junio de 2019). Bancos reducen cuota inicial de los créditos para viviendas a 10\%. Lima. Obtenido de https://gestion.pe/economia/bancosreducen-cuota-inicial-creditos-viviendas-10-271096-noticia/

Gestión. (2 de Marzo de 2019). Scotiabank: Este año se venderán alrededor de 17,000 viviendas en Lima. Lima. Obtenido de https://gestion.pe/economia/scotiabankano-venderan-alrededor-17-000-viviendas-lima-260205-noticia/?ref=gesr

Gestión. (16 de Junio de 2019). Tres errores que debe evitar al comprar un departamento. Lima. Obtenido de https://gestion.pe/tu-dinero/inmobiliarias/treserrores-debe-evitar-comprar-departamento-270208-noticia/

Huerta Peralta, J., \& Isola, J. (2006). Discapacidad y accesibilidad. La dimensión desconocida. Lima: Fondo Editorial del Congreso del Perú.

La República. (26 de Mayo de 2019). Familias del segmento C buscan proyectos de vivienda con áreas comunes. Lima. Obtenido de 
https://larepublica.pe/economia/1476517-familias-segmento-c-buscanproyectos-vivienda-areas-comunes/

La República. (23 de Mayo de 2019). MiVivienda: ¿Quiénes pueden acceder al Bono Verde y cuánto pueden ahorrar? Obtenido de https://larepublica.pe/economia/1474267-mivivienda-acceder-bono-verdeahorrar/

Martell, S. (29 de Agosto de 2019). ¿Piensas mudarte? Así son y esto costarían los departamentos de la Villa Panamericana. Lima. Obtenido de https://rpp.pe/economia/economia/parapanamericanos-piensas-mudarte-asi-sony-esto-costarian-los-departamentos-de-la-villa-panamericana-panamericanoslima-2019-noticia-1216677/6

Martell, S. (22 de Agosto de 2019). Bono verde: ¿Qué es y cómo acceder a este subsidio para comprar una vivienda? Lima. Obtenido de https://rpp.pe/economia/economia/bono-verde-conoce-como-obtener-estesubsidio-para-comprar-una-vivienda-sostenible-noticia-1215542

Mejía, M. (2 de Mayo de 2019). MEF: sector inmobiliario mantiene perspectivas favorables para el 2019. Lima. Obtenido de https://andina.pe/agencia/noticiamef-sector-inmobiliario-mantiene-perspectivas-favorables-para-2019750138.aspx

MINISTERIO DE ECONOMÍA Y FINANZAS DEL PERÚ. (23 de Agosto de 2019). Obtenido de https://www.mef.gob.pe/contenidos/pol_econ/marco_macro/MMM_2020_2023. pdf

Municipalidad Distrital de Villa el Salvador. (s.f.). Obtenido de http://www.munives.gob.pe/distrito.php\#DatosGenerales

Preyra, G. (22 de Agosto de 2019). El impacto positivo de Lima 2019: ¿qué legado dejan los Juegos Panamericanos? Lima. Obtenido de https://elcomercio.pe/lima/sucesos/lima-2019-impacto-positivo-legado-dejanjuegos-panamericanos-poblacion-noticia-ecpm-667806

Scott Robinette, C. B. (2001). Marketing Emocional. El método de Hallmark para ganar clientes para toda la vida. Barcelona: Gestión 2000.

Velasquez, S. (16 de Marzo de 2018). Influencers de Perú. Lima. Obtenido de https://larepublica.pe/sociedad/1212775-influencers-de-peru/ 


\section{ANEXOS}

\section{Anexo 1}

Corrida de Radio

(Fuente: Elaboración propia)

\begin{tabular}{|r|l|r|l|r|}
\hline Rnkg & Emisora & \multicolumn{1}{l|}{ Mls. } & \#Horas \\
\hline 0 & AUDIENCIA ACUMULADA & 94.5 & 3404.4 & 25.36 \\
\hline 1 & La Karibeña (FM) & 26.8 & 965.0 & 6.12 \\
\hline 2 & Moda (FM) & 25.8 & 928.7 & 7.18 \\
\hline 3 & R.P.P. (FM/AM) & 25.6 & 921.1 & 7.24 \\
\hline 4 & lueva Q Fm (FM) & 24.2 & 873.6 & 7.54 \\
\hline 5 & Ritmo Romantica (FM) & 21.7 & 780.1 & 5.09 \\
\hline 6 & Panamericana (FM/AM) & 20.6 & 741.7 & 5.36 \\
\hline 7 & La Kalle (FM) & 18.3 & 660.6 & 7.51 \\
\hline 8 & Radiomar (FM) & 17.3 & 622.3 & 6.54 \\
\hline 9 & La Zona (FM) & 16.9 & 608.7 & 5.00 \\
\hline 10 & Onda Cero (FM/AM) & 16.5 & 596.0 & 5.12 \\
\hline
\end{tabular}


Anexo 2

\section{INFORMACIÓN IMPORTANTE - FOCUS GROUP}

Datos y edades de los participantes (para proteger datos, se ocultan apellidos)

\begin{tabular}{ll} 
NOMBRES & EDAD \\
\hline Pablo Ferrer & 46 \\
Haydee Gloria & 48 \\
Jessica & 29 \\
Yuli & 31 \\
Cinthia & 31 \\
Herminia & 48 \\
Luis & 29
\end{tabular}

\section{GUÍA FOCUS GROUP}

(Semi estructurado)

- $\quad$ Principalmente el tema es la vivienda. La casa propia. Seguridad para la familia.

- ¿Es un anhelo que tienen?

- ¿Han pensado o querido comprar una casa o departamento?

- Mostrar primera imagen. ¿Qué opinan o saben?

- ¿Sabían que iba a estar a la venta? ¿Que saben? ¿Que habían escuchado?

- Información de la venta de los departamentos

- Hablar sobre producto

- Hablar sobre el precio y el Fondo Mivivienda

- Condición de facilidades

CONDOMINIO "VILLA DEL ATLTA"
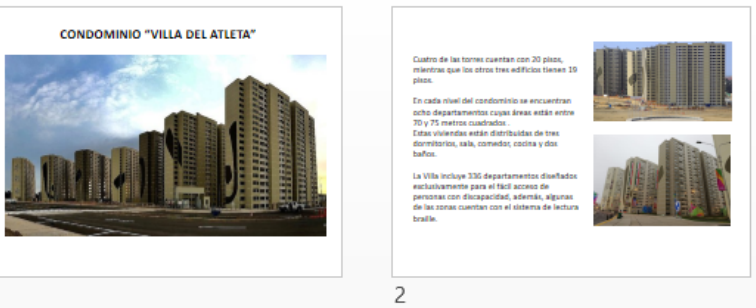

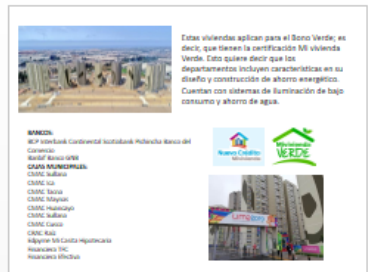

3

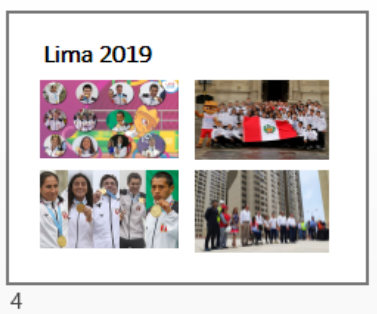


Anexo 3

Ejemplos de cotizaciones realizadas $(\mathrm{OOH})$

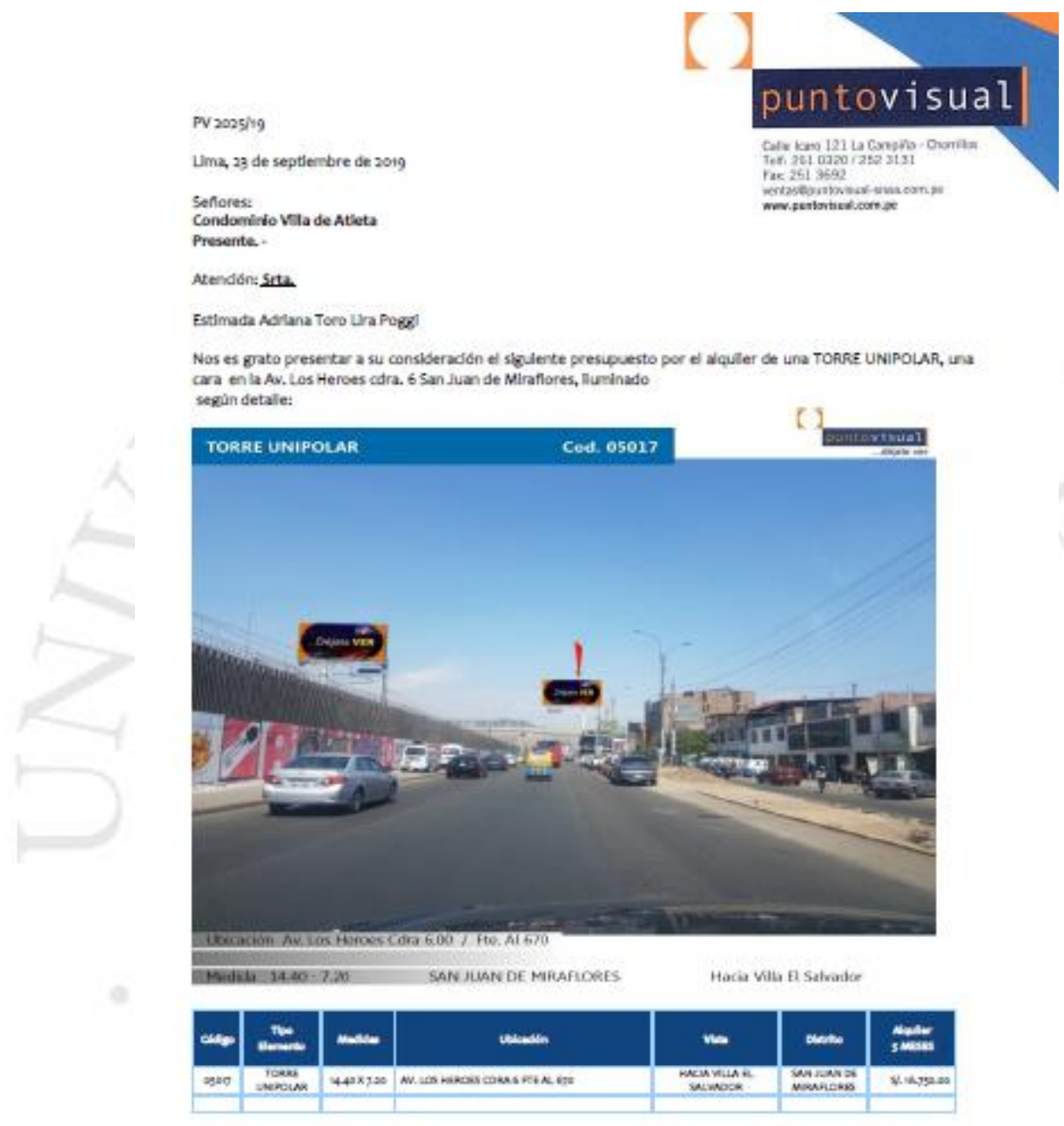

Sin otro partloular y a la espera de tu grata respuesta o coneista adidena, nos despedhor. 
Anexo 4

Guía de preguntas - Entrevista a especialista en marketing inmobiliaio

- Bajo tu experiencia ¿Cómo describirías al NSE C y D de 25 años a más en cuanto a personalidad de compra de un inmueble? ¿Qué características destacarías o consideras más importantes a la hora de aplicar el plan de MKT del producto inmueble para éste público?

- ¿Qué proyectos has trabajado para éste público? ¿Cuál fue tu estrategia principal para alcanzar las ventas deseadas?

- ¿Qué herramientas utilizas para decidir finalmente que mix de mkt realizar para el P.O?

- ¿Qué características destacarías de tu estrategia de marketing para la venta de inmuebles a éste sector?

- ¿Qué caso de éxito podrías compartir?

- ¿Cuál es el tono de comunicación que se debe utilizar con éste público? 


\section{Anexo 5}

Corrida de medición de audiencia según público objetivo

\begin{tabular}{|c|c|c|c|c|c|c|c|c|}
\hline \multicolumn{3}{|c|}{ Ranking } & & & & & & \\
\hline \multicolumn{9}{|c|}{ Datos: Perú } \\
\hline \multicolumn{9}{|c|}{ Filtro de programación: Tanda } \\
\hline \multicolumn{9}{|c|}{ Regiones: Lima } \\
\hline \multicolumn{9}{|c|}{ Región base: Lima +6 ciudades } \\
\hline \multicolumn{9}{|c|}{ Targets: HM 25 A 60 חा(Ind->Nivel:C, } \\
\hline \\
\hline & Grupo & Canal & $\operatorname{lni}-$ & Fil $=$ & Género & Dias - & & ivo - \\
\hline 1 & EEG-TA & América Televisión & $18: 49$ & $\ldots$ & Concurso & LMWJV & 9.1 & 622 \\
\hline 2 & DE VUELTA AL BARRIO-NO & América Televisión & $20: 41$ & $\ldots$ & Comedias & LMWJV & 8.9 & 548.8 \\
\hline 3 & EN LA PIEL DE ALICIA-NO & América Televisión & $21: 32$ & $\ldots$ & Novelas & LMWJV & 8.6 & 534.2 \\
\hline 4 & EL ARTISTA DEL AÑO-S-NO & América Televisión & $20: 59$ & $\ldots$ & Concurso & $\mathrm{s}$ & 5.2 & 540 \\
\hline 5 & LA ROSA DE GUADALUPE-TA1 & América Televisión & $17: 59$ & 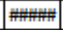 & Novelas & LMWJV & 4.6 & 305 \\
\hline 6 & AMERICA NOTICIAS-NO & América Televisión & $22: 27$ & 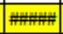 & Noticieros & LMWJV & \begin{tabular}{l|l}
4.4 \\
\end{tabular} & 272.2 \\
\hline 7 & EL REVENTONAZO DE LA CHOLA-S-N & América Televisión & $18: 59$ & $\ldots$ & Musicales & s & 3.8 & 301.7 \\
\hline 8 & PRIMERA EDICION NACIONAL-MA & América Televisión & $07: 00$ & 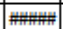 & Noticieros & LMWJV & 3.6 & 374.3 \\
\hline 9 & MI MAMA COCINA MEI.Q TUYA-D-NO & América Televisión & $18: 47$ & $\ldots$ & Otros & $\mathrm{D}$ & 3.5 & 270.1 \\
\hline 10 & RINGO-MA & América Televisión & $10: 59$ & $\ldots$ & Novelas & LMW & 3.3 & 217.9 \\
\hline 11 & LA ROSA DE GUADALUPE-D-TA & América Televisión & $17: 15$ & $\ldots$ & Novelas & $\mathrm{D}$ & \begin{tabular}{l|l}
3.3 \\
\end{tabular} & 257.6 \\
\hline 12 & +ESPECTACULOS-MA & América Televisión & $09: 35$ & $\ldots$ & Magazine & LMWJV & 3.2 & 193.6 \\
\hline 13 & LA ROSA DE GUADALUPE-TA & América Televisión & $17: 00$ & $\ldots$ & Novelas & LMWJV & 3.1 & 235 \\
\hline 14 & AL FONDO HAY SITIO-TA & América Televisión & $15: 08$ & $\ldots$ & Comedias & LMWJV & 2.9 & 220.5 \\
\hline 15 & MUJERES SIN FILTRO-S-NO & América Televisión & $23: 45$ & 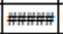 & Magazine & $s$ & \begin{tabular}{l|l}
2.7 \\
\end{tabular} & 166.3 \\
\hline 16 & LA ROSA DE GUADALLUPE-MA & América Televisión & $10: 16$ & $\ldots$ & Novelas & LMWJV & 2.7 & 172.1 \\
\hline 17 & LA BANDA DEL CHINO-NO & América Televisión & $23: 29$ & 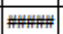 & Periodisticos & LMWJV & 2.7 & 159.2 \\
\hline 18 & EN BOCA DE TODOS-TA & América Televisión & $12: 59$ & 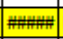 & Magazine & LMWJV & 2.6 & 254.8 \\
\hline 19 & LA ROSA DE GUADALUPE-D-TA1 & América Televisión & $17: 52$ & $\ldots$ & Novelas & $\mathrm{D}$ & 2.6 & 186.3 \\
\hline 20 & BUTACA AMERICA-D-TA EL REGRESO DE LA NANA MAGICA & América Televisión & $15: 16$ & 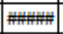 & Peliculas/Cine & $\mathrm{D}$ & 2.6 & 189.5 \\
\hline
\end{tabular}

